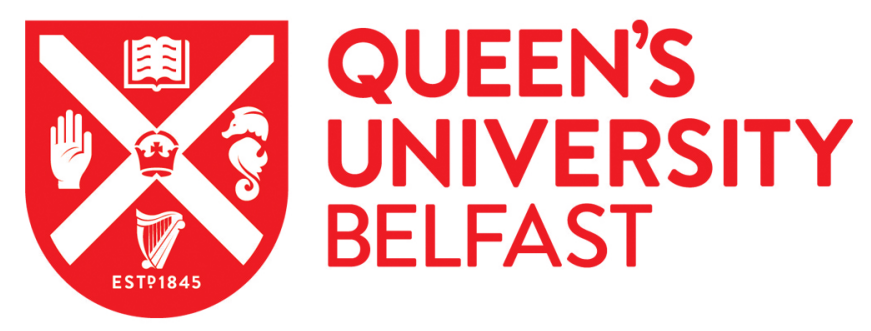

\title{
Ischemic Retinal Vein Occlusion: characterizing the more severe spectrum of retinal vein occlusion
}

Khayat, M., Williams, M., \& Lois, N. (2018). Ischemic Retinal Vein Occlusion: characterizing the more severe spectrum of retinal vein occlusion. Survey of ophthalmology. https://doi.org/10.1016/j.survophthal.2018.04.005

\section{Published in:}

Survey of ophthalmology

\section{Document Version:}

Peer reviewed version

Queen's University Belfast - Research Portal:

Link to publication record in Queen's University Belfast Research Portal

\section{Publisher rights}

Copyright 2018 Elsevier.

This manuscript is distributed under a Creative Commons Attribution-NonCommercial-NoDerivs License

(https://creativecommons.org/licenses/by-nc-nd/4.0/), which permits distribution and reproduction for non-commercial purposes, provided the author and source are cited.

\section{General rights}

Copyright for the publications made accessible via the Queen's University Belfast Research Portal is retained by the author(s) and / or other copyright owners and it is a condition of accessing these publications that users recognise and abide by the legal requirements associated with these rights.

\section{Take down policy}

The Research Portal is Queen's institutional repository that provides access to Queen's research output. Every effort has been made to ensure that content in the Research Portal does not infringe any person's rights, or applicable UK laws. If you discover content in the Research Portal that you believe breaches copyright or violates any law, please contact openaccess@qub.ac.uk. 


\section{Accepted Manuscript}

Ischemic Retinal Vein Occlusion: characterizing the more severe spectrum of retinal vein occlusion

Dr. Meiaad Khayat, MBBS, MSc, Dr. Michael Williams, BMedSci, MD, MRCOphth, MMedEd, Noemi Lois, MD, PhD, FRCS(Ed), FRCOphth, Professor

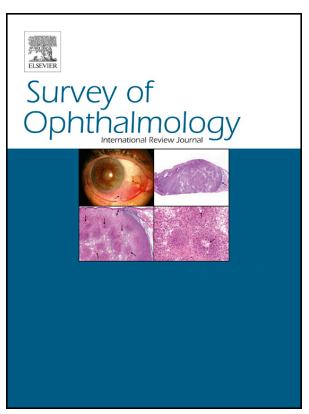

PII: S0039-6257(17)30113-3

DOI: 10.1016/j.survophthal.2018.04.005

Reference: SOP 6793

To appear in: Survey of Ophthalmology

Received Date: 22 April 2017

Revised Date: 14 April 2018

Accepted Date: 20 April 2018

Please cite this article as: Khayat M, Williams M, Lois N, Ischemic Retinal Vein Occlusion: characterizing the more severe spectrum of retinal vein occlusion, Survey of Ophthalmology (2018), doi: 10.1016/ j.survophthal.2018.04.005.

This is a PDF file of an unedited manuscript that has been accepted for publication. As a service to our customers we are providing this early version of the manuscript. The manuscript will undergo copyediting, typesetting, and review of the resulting proof before it is published in its final form. Please note that during the production process errors may be discovered which could affect the content, and all legal disclaimers that apply to the journal pertain. 
Ischemic Retinal Vein Occlusion: characterizing the more severe spectrum of retinal vein occlusion

Dr. Meiaad Khayat, MBBS, MSc

Wellcome-Wolfson Center for Experimental Medicine,

School of Medicine, Dentistry \& Biomedical Sciences

Queen's University Belfast

$\&$

Department of Anatomy,

Collage of Medicine-Rabigh Branch

King Abdulaziz University

Dr. Michael Williams BMedSci, MD, MRCOphth, MMedEd

Center for Medical Education

School of Medicine, Dentistry \& Biomedical Sciences

Queen's University Belfast

Professor Noemi Lois, MD, PhD, FRCS(Ed), FRCOphth

Wellcome-Wolfson Center for Experimental Medicine,

School of Medicine, Dentistry \& Biomedical Sciences

Queen's University Belfast

Address of Correspondence: Professor Noemi Lois, Wellcome-Wolfson Center for Experimental Medicine, School of Medicine, Dentistry \& Biomedical Sciences Queen's University Belfast, 97 Lisburn Road, BT9 5BW, Belfast, United Kingdom. Email: n.lois@qub.ac.uk 
Outline: Ischemic Retinal Vein Occlusion (iRVO)

I. Introduction

II. Definitions
A. Ischemic CRVO
B. Ischemic BRVO

III. Epidemiology
A. Ischemic CRVO
B. Ischemic BRVO

IV. Risk Factors
A. Ischemic CRVO
B. Ischemic BRVO

V. Etiology and Pathogenesis

A. Etiology

B. Pathologic Mechanisms following Retinal Venous Thrombosis and its Clinical Consequences.

1. Macular edema

2. Retinal capillary non-perfusion

3. Retinal and vascular cell damage

4. Collateral vessels and neovascularization

5. Inflammatory, angiogenic and hypoxia induced factors
a. Hypoxia-inducible factor (HIF-1 $\alpha)$
b. Vascular endothelial growth factor (VEGF)
c. Nitric oxide synthase (NOS)
d. Glutamate
e. Other factors

VI. Clinical Findings and Ancillary Studies
A. Visual Acuity (VA)
B. Clinical Findings
C. Findings on Ancillary Studies

1. Functional tests

a. Pupillary Examination

b. Visual fields (VF)

c. Microperimetry

d. Electroretinography (ERG)

e. Oximetry

f. Retinal blood flow

g. Ocular surface temperature (OST)

h. Ophthalmodynamometry

2. Structural tests
a. Fluorescein angiography
b. Spectral domain optical coherence tomography (SD-OCT)
c. Optical coherence tomography angiography (OCT-A) 
d. Fundus autofluorescence (AF)

3. Patients reported outcomes (PRO)

VII. Natural History
A. Ischemic CRVO
B. Ischemic BRVO

VIII. Management and outcomes following treatments

A. Current treatments of ischemic RVO

1. Treatment for macular edema secondary to iRVO
a. Macular laser photocoagulation
b. Anti-VEGF
c. Steroids
d. Pars plana vitrectomy

2. Therapies to treat or prevent proliferative retinopathy secondary to iRVO
a. Sector and pan-retinal photocoagulation
b. Anti-VEGF
c. Steroids
d. Pars plana vitrectomy

B. Other therapies for $\mathrm{iRVO}$

IX. Summary- Proposed characterization of the disease and practical points for clinicians

X. Conclusion

XI. Method of Literature Search 


\section{Abstract}

Retinal vein occlusion (RVO), including central (CRVO), branch (BRVO) and hemicentral and hemispheric RVO, is the second most common vascular cause of visual loss, surpassed only by diabetic retinopathy. The presence and extent of retinal ischemia in RVO is associated with a worse prognosis. On this basis, most previously conducted studies considered $\mathrm{iRVO}$ and non-iRVO as separate entities based on set thresholds of existing retinal ischemia, as determined by fundus fluorescein angiography (FFA). Other diagnostic technologies have been used specifically in the differentiation of iCRVO and non-iCRVO. To date there is not a fully accepted definition for iRVO. Some clinicians and researchers may favor establishing a clear differentiation between these forms of RVO; others may prefer not to consider iRVO as a separate entity. Whatever the case, retinal ischemia in RVO confers a higher risk of visual loss and neovascular complications and, thus, should be determined as accurately as possible in patients with this disease and should be considered in clinical and experimental studies. Most recently conducted clinical trials evaluating new treatments for macular edema secondary to RVO, included none or only few patients with iRVO based on previous definitions (i.e. few patients with sizeable areas of retinal ischemia were recruited in these trials) and, thus, it is unclear whether the results observed in recruited patients could be extrapolated to those with retinal ischemia. There has been scarce research aiming at developing and/or testing treatments for retinal ischemia as well as to prevent new vessel formation result of RVO.

This manuscript aims at providing the reader with a detailed review on the knowledge gathered over the years on $\mathrm{RVO}$, from controversies on its definition and diagnosis to the understanding of its epidemiology, risk factors and pathogenesis, the structural and functional effects of this disease in the eye and its complications, natural history, and outcomes following treatment. In each section, the definition of iRVO used is given so, independently 
of whether $\mathrm{iRVO}$ is considered a separate clinical entity or a more severe end of the spectrum of RVO, the information contained herein will be useful to clinicians, to determine patient's risk, guide therapeutic decisions and counsel patients and for researchers to design future studies. 
Keywords: Retinal vein occlusion (RVO); ischemic retinal vein occlusion (iRVO); ischemic central retinal vein occlusion (iCRVO), ischemic branch retinal vein occlusion (iBRVO); non-perfused retinal vein occlusion; retinal perfusion; retinal ischemia; ischemic retinopathy. 


\section{Introduction}

Retinal Vein Occlusion (RVO) appears to be the second most common vascular cause of visual loss, surpassed only by diabetic retinopathy ${ }^{(74)}$. Obstruction of the retinal venous system is a serious condition which may result in devastating complications including irreversible blindness ${ }^{(119,122,196,253)}$. Classically, RVO has been divided into two main types based on the site at which the occlusion occurs: Central Retinal Vein Occlusion (CRVO) and Branch Retinal Vein Occlusion (BRVO) ${ }^{(2,6)}$.

In CRVO, blockage of the main vein draining the retina, the central retinal vein, occurs ${ }^{(74,114)}$. In this type, the occlusion usually takes place at or behind the laminal cribrosa. CRVO is the most severe form as it affects the entire retina ${ }^{(74,114)}$. BRVO is a blockage of one or more retinal vein branches (tributaries) which typically occurs at arteriovenous crossings ${ }^{(74,114)}$. It can be major, macular or peripheral based on the affected retinal region (74,114) . Two other types of RVO should be considered, hemispheric and hemicentral retinal vein occlusion. In the literature, the terms hemispheric and hemicentral RVO have been used often as synonymous, with no distinction made between these two entities ${ }^{(96,261)}$. However, hemispheric RVO and hemicentral RVO refer to different entities. Hemispheric RVO affects half of the retina with the site of the occlusion occurring at an arteriovenous crossing, like in $\mathrm{BRVO}^{(54-56,109,225)}$. In contrast, hemicentral RVO occurs in patients with a congenital abnormality involving the presence of a dual trunk central retinal vein; in these cases the occlusion takes place at one of these trunks of the central retinal vein and, on this regard, is closer to CRVO ${ }^{(54-56,109,225)}$. Herein, we will refer to hemispheric RVO in the BRVO section, although with a clear statement that data presented refers to hemispheric RVO, when data is available. We will refer to hemicentral RVO in the CRVO section and, similarly, we will clearly state that data presented refers to hemicentral retinal vein occlusion. Data from studies where no distinction between the two was made will be presented under the BRVO 
section, given the fact that hemispheric RVO appears to be more common than hemicentral RVO, but stating also clearly that distinction between the two was not provided.

Each of these RVO types has been further classified into ischemic or non-ischemic sub-types based on the area of retinal capillary non-perfusion present ${ }^{(2,6,74,109,119,196,253)}$. This distinction is clinically relevant as the presence and extension of the area of retinal ischemia appears to have important prognostic and management implications ${ }^{(2,6,109,196)}$. However, as discussed below, there is no consensus on where the threshold of retinal ischemia should be set to define iRVO. Determining the presence and extent of retinal ischemia in RVO is important and agreement exists with regard to the risk it confers to patients with this vascular disorder. Thus, it is essential that retinal ischemia is considered when phenotyping patients with RVO and that patients with retinal ischemia are included in trials testing new therapies for this condition. For example, many of the recently conducted clinical trials on new treatments for macular edema result of RVO did not include or included very scarce numbers of patients with retinal ischemia $^{(29,37,43,99,128,137,153,234,264)}$ (Table-1). As a result, the benefit of these treatments for this group of patients is uncertain (see section VIII. Management, below).

The purpose of the work presented herein is, through a systematic review of published literature, to provide the reader with current knowledge on iRVO, from controversies on its definition and diagnosis to the understanding of its risk factors and pathogenesis, the structural and functional effects of the disease in the eye and its complications, natural history, as well as outcomes following current treatments, their potential side effects and limitations. In each of these sections, the definition of $\mathrm{iRVO}$ is given so data can be interpreted appropriately. 


\section{Definitions}

Many other terms have been used to refer to iRVO including non-perfused, severe, hemorrhagic, or pre-proliferative $\mathrm{RVO}^{(39)}$. The definition of $\mathrm{iRVO}$ is controversial. Different authors have adopted different parameters to differentiate iRVO from non-iRVO, making comparison between studies difficult. For example, some have used a single test to define iCRVO namely, fundus fluorescein angiography (FFA)

$(2,6,18,37,38,45,65,85,128,137,153,177,207,220,226,240,242,248,264,295)$, electroretinography (ERG) $(2,131,155,162,170,190,199,312)$, or visual acuity of $\leq 20 / 200^{(22)}$ whereas others have suggested the use of a combination of tests for this purpose ${ }^{(20,123,197,236)}$. The most commonly used parameter to differentiate ischemic and non-ischemic RVO has been the area of retinal capillary nonperfusion as determined by FFA ${ }^{(6,18,37,38,45,65,95,128,137,153,177,207,220,226,228,240,242,248,264,295)}$. Most studies using FFA, determined the total area of retinal capillary non-perfusion by measuring it and then dividing it by the optic disc area to calculate the area of retinal capillary nonperfusion in disc areas (DA) ${ }^{(2,6)}$.

\section{A. Ischemic CRVO}

Commonly, ischemic central retinal vein occlusion (iCRVO) is defined by the presence of $\geq 10$ DA of retinal capillary non-perfusion based on FFA ${ }^{(6,38,128,137,226,244)}$. However, other thresholds to define iCRVO have been used, such as $\geq 5 \mathrm{DA}^{(153)}$ or $\geq 30 \mathrm{DA}^{(240)}$. As stated above, the risk of neovascular events appears to increase with greater disc areas of nonperfusion. In the Central Vein Occlusion Study (CVOS) the risk of developing iris/ angle neovascularization was found to be $16 \%, 36 \%$ and $52 \%$ for eyes with $10-29,30-74$ and $\geq 75$ DA or capillary non-perfusion ${ }^{(6)}$. For those with $\geq 10$ DA the risk was $28 \%$ and for those $\geq$ 30 DA the risk was $43 \%$, with $96 \%$ of neovascularizations occurring during the first year of follow-up ${ }^{(6)}$. 
The precision of determining the area of retinal capillary non-perfusion may be enhanced by the use of newer and improved technologies, such as wide angle-FFA (WAFFA) which allows a larger area of the retina $\left(>200^{\circ}\right)$ to be imaged; this corresponds to $82 \%$ of the entire fundus area in comparison to standard FFA which is restricted to $30-55^{\circ}$ $(274,290,300)$. Even when each quadrant of the retina is imaged by standard FFA, the area of retina visualized is not as extensive as that observed by WA-FFA.

An earlier study by Magargal and colleagues used the ischemic index to define the ischemic status of the retina in CRVO ${ }^{(183)}$. The ischemic index (ISI) was defined as follows:

$$
\text { Ischemic index (ISI) }=\frac{\text { Area of non }- \text { perfused retina }}{\text { Total area of visible retina }} \times 100
$$

As with the DAs, different ISIs have been used to differentiate between iCRVO and noniCRVO. Magargal and colleagues defined non-iCRVO by an ISI of $\leq 10 \%$, intermediate when ischemic index was $11-50 \%$, and iCRVO when the ISI was $>50 \%{ }^{(183)}$. Giuffre et al. used an ischemic index of $\geq 30 \%$ to define $\mathrm{iCRVO}^{(90)}$. It would be expected that the more the retina visualized the more accurate the estimate of the area of retinal ischemia and, thus, wide angle technologies would be preferred when evaluating patients with RVO.

The relationship between the ISI and the presence of ocular neovascularization of any type [anterior segment (iris or angle) and/or posterior segment (retinal) neovascularization] was investigated using WA-FFA and it was found that an ISI of $\geq 45 \%$ was associated with the presence of concurrent new vessels ${ }^{(300)}$ (see section VI. Clinical Findings and Ancillary Studies). The relationship between ISI and macular edema was also investigated using WAFFA and it was found that an ISI of $>10 \%$ was associated with the presence of this complication $^{(274)}$ (see section VI. Clinical Findings and Ancillary Studies). It is possible to have a relatively low ISI but significant ischemia involving the macula ${ }^{(274)}$. 
None of the definitions discussed above take into consideration the location of the area of retinal ischemia (i.e. macula, midperipheral or peripheral retina). The center of the macula (fovea) is the area responsible for the central vision. Thus, it seems essential when evaluating CRVO that the perfusion status of the macula as well as whether or not there is preservation or destruction of the perifoveal capillaries is determined and considered, in addition to the evaluation of the presence/absence and extension of ischemia in the midperipheral and peripheral retina. Recently introduced technologies, such as optical coherence tomography angiography (OCT-A) may facilitate, the gathering of this information (see section VI. Clinical Findings and Ancillary Studies, below).

Some studies have utilized ERG as a single tool to diagnose iCRVO and determine risk of neovascularization instead of FFA. It was observed that prolonged implicit times in the $30 \mathrm{~Hz}$ flicker ERG (33.8-42 ms) appeared to be more accurate than FFA in defining iCRVO and predicting risk of neovascular complications ${ }^{(169)}$ (See section VI. Clinical Findings and Ancillary Studies, below). It was suggested that iCRVO should be defined by an implicit time of $\geq 37 \mathrm{~ms}$ in the $30 \mathrm{~Hz}$ flicker ERG in one study ${ }^{(129,170)}$; a very similar threshold (>35ms) was proposed in another study ${ }^{(155)}$ (see section VI. Clinical Findings and Ancillary Studies, below). It was also reported that interocular amplitude difference of $23 \mu \mathrm{V}$ and interocular amplitude ratio of $60 \%$ on $30 \mathrm{~Hz}$ flicker ERG could be also used as cut-off points to differentiate between iCRVO and non-iCRVO ${ }^{(161)}$ (see section VI. Clinical Findings and Ancillary Studies, below). Other authors have suggested that a reduction of the b/a ratio on the scotopic ERG (mean \pm standard deviation of $14.8 \pm 13$ in uncomplicated CRVO compared to $3.5 \pm 2$ in CRVO which developed iris neovascularization) and/ or photopic ERG (mean \pm standard deviation of $3 \pm 2$ in uncomplicated CRVO compared to $1.5 \pm 0.5$ in those who developed iris neovascularization) is also appropriate to define iCRVO ${ }^{(312)}$ (see section VI. Clinical Findings and Ancillary Studies, below). 
Hayreh and associates found no single test to have $100 \%$ sensitivity and specificity for the distinction between iCRVO and non-iCRVO ${ }^{(123)}$. Standard FFA was informative in two thirds of patients in the acute phase of the disease ${ }^{(123)}$. A combination of the following six anatomical and functional tests was proposed by Hayreh and colleagues to establish the diagnosis of iCRVO ${ }^{(123)}$ :

1. Visual acuity (VA) of $\leq 6 / 60(20 / 200)$.

2. Peripheral visual fields (VF) defects using the I-2e, I-4e, and V-4e in the Goldmann perimeter.

3. Relative afferent pupillary defect (RAPD) of $\geq 0.9 \log$ units using neutral density filters (see section VI. Clinical Findings and Ancillary Studies, below).

4. ERG parameters: $b$-wave amplitude reduction by $\geq 60 \%$ of normal mean value (normal fellow eye) in photopic and scotopic ERG, as well as b/a ratio reduction by $\geq 60 \%$ for photopic and scotopic ERG in the CRVO eye when compared with values of the fellow normal eye.

5. Retinal capillary non-perfusion on FFA classified into mild, when the area of retinal capillary non-perfusion is $\leq 30 \mathrm{DA}$, which carries a low risk of developing neovascularization; and severe, defined by the presence of retinal capillary non-perfusion of > 75 DA and which poses a high risk of developing neovascularization.

6. Extensive retinal hemorrhage and cotton wool spots in the acute stage, and disc/retinal neovascularization in a later stage of the disease on ophthalmoscopy.

It was observed that the presence of a RAPD has the highest sensitivity and specificity for the diagnosis of iCRVO ${ }^{(123,267)}$. Combining the RAPD with ERG findings it is possible to diagnose up to $97 \%$ of cases of iCRVO in the acute phase of the disease ${ }^{(119,123)}$. 
Other studies have used different combinations of the above tests to establish the diagnosis of iCRVO, for example visual acuity, visual fields, RAPD, and ERG ${ }^{(36)}$; visual acuity, RAPD and area of capillary non-perfusion on FFA ${ }^{(255)}$; visual acuity, findings on ophthalmoscopy and FFA ${ }^{(236)}$ and visual acuity, visual field and RAPD ${ }^{(197)}$.

Clearly, there is variability on how the diagnosis of iCRVO is determined; this should be taken into consideration when appraising current literature on this disease. It may not be possible to find an agreement among clinicians and researchers with regard to how to define iCRVO. However, if a consistent evaluation of patients with iCRVO were to be agreed and used, including determining the minimum core outcome measures required for RVO studies, this would allow for a homogeneous patient assessment. The latter would facilitate future comparisons among studies and meta-analysis, it would enhance the understanding of the disease and provide a more accurate identification of phenotypes and estimation of their prognosis as well as their response to treatment. Suggestions on this regard are proposed in section IX, below.

Similar suggestions as those given to differentiate iCRVO from non-iCRVO were proposed by Hayreh \& Zimmerman ${ }^{(115)}$ to discriminate ischemic from non-ischemic hemicentral RVO. These included inability to see I-2e, and defective or absent I-4 isopter in Goldmann perimeter, extensive retinal hemorrhage and a large number of cotton wool spots, and $>10$ disc areas of retinal capillary non-perfusion, in the affected half of the retina ${ }^{(115)}$.

\section{B. Ischemic BRVO}

Ischemic BRVO was defined by the Branch Vein Occlusion Study (BVOS) group by the presence of $\geq 5$ DA of retinal capillary non-perfusion on standard FFA ${ }^{(2)}$. This definition has been widely used since by many investigators ${ }^{(45,210,226,228,264,295)}$. In the BVOS, $41 \%$ of eyes with $\geq 5$ DA of capillary non-perfusion developed neovascularization during a mean follow- 
up of 3 years. Some studies used the presence of $\geq 10$ DA of retinal capillary non-perfusion to define iBRVO ${ }^{(43,45,257)}$. The risk conferred to patients with BRVO by having a determined extension of retinal capillary non-perfusion $(\geq 5 \mathrm{DA}, \geq 10 \mathrm{DA}$ or other) has not been investigated as widely in BRVO as in CRVO.

There is no accepted definition and classification of iBRVO or of ischemic macular RVO. Like in CRVO, the area of retinal capillary non-perfusion seems to contribute to the risk of neovascular complications in patients with $\mathrm{BRVO}^{(49)}$; other factors contributing to this risk remain to be elucidated. As for iCRVO, finding consensus among clinicians and researchers on a definition of iBRVO may be challenging. An agreed standard evaluation and characterization of these patients, however, should be the starting point and suggestions on this regard are provided on this manuscript (see section IX, below).

\section{Epidemiology}

$\mathrm{RVO}$ is a common disease with an estimated 16.4 million adults affected worldwide $(2.5$ million with CRVO and 13.9 million with BRVO), based on a pooled analysis of populationbased studies from the United States, Europe, Asia, and Australia ${ }^{(252)}$. Many populationbased studies have looked at the epidemiology of RVO, such as the Gutenberg Health Study of RVO ${ }^{(237)}$, Beijing Eye study ${ }^{(323)}$, the Central India Eye and Medical Study ${ }^{(142)}$, Hisayama Study ${ }^{(15)}$, Beaver Dam Eye Study ${ }^{(157)}$, and Blue Mountains Eye Study ${ }^{(61)}$, among others; none of these, however, differentiated between iRVO and non-iRVO. In general, these studies showed that the prevalence of RVO varies between $0.40-2.2 \%{ }^{(15,61,142,157,237,323)}$, with BRVO being apparently more common than CRVO. The incidence also varied between $0.2-$ $2.3 \%$, with BRVO having a higher incidence than $\operatorname{CRVO}^{(15,61,142,157,237,323)}$. 


\section{A. Ischemic CRVO}

In a hospital-based study by Hayreh, 1,108 RVO patients (1,229 eyes) were studied and classified into ischemic (22\%) and non-ischemic (78\%) (as defined by Hayreh's criteria described above, section II: Definitions) ${ }^{(112)}$. It was found that $13.2 \%$ and $18.6 \%$ of eyes with non-iCRVO at baseline convert to iCRVO at six and 18 months, respectively ${ }^{(112)}$. During the follow-up period of three years in CVOS, 34\% of non-iCRVO converted to iCRVO (defined as an area of retinal ischemia of $>10 \mathrm{DA})^{(6)}$. It was reported that $67 \%$ of patients with iCRVO have their first onset of the disease at $\geq 65$ years compared to $44 \%$ of those with non-iCRVO with statistical significant difference between the two groups ${ }^{(112)}$. Moreover, development of the same type of RVO in the fellow eye was reported in $3.8 \%$ of patients with iCRVO in comparison to $8.8 \%$ of those with non-iCRVO ${ }^{(112)}$. In a study which included all consecutive new incident cases of RVO (557 RVO in total; 203 with CRVO and 354 with BRVO) identified between May and November 2010, which excluded RVO secondary to diabetic retinopathy or other ocular disorders, it was found that $100 \%$ of CRVO eyes presented with $\geq 5$ DA of retinal capillary non-perfusion on FFA ${ }^{(173)}$.

Ischemic hemicentral RVO was reported in 31 out of 130 eyes $(23.8 \%)$ in comparison to 99 out of 130 eyes (76.2\%) for non-ischemic hemicentral RVO in a study by Hayreh et al. which looked at the systemic diseases associated with the various types of RVO ${ }^{(120)}$.

\section{B. Ischemic BRVO}

A population-based study in Korea found a very high rate of iBRVO $(96 \%)$ using a $\geq 5$ DA of non-perfusion as definition for this disease ${ }^{(173)}$. In other epidemiological studies, data on iBRVO form, in particular, was lacking. 


\section{Risk Factors}

It is believed that RVO is a multifactorial disease, since more than one risk factor may contribute to its pathogenesis ${ }^{(74)}$. Most studies investigating the epidemiology and risk factors of CRVO and BRVO did not differentiate between ischemic and non-ischemic forms $(3,61,77,142,156,157,185,198,237,271,280,281,284,292,293,323)$. In general, risk factors for both CRVO and BRVO include increased age, hypertension, cardiovascular disease, dyslipidemia, diabetes mellitus and smoking ${ }^{(5,61,84,142,157,198,237,247,323)}$. Local ocular conditions, such as increased intraocular pressure and glaucoma, have been found to be risk factors for CRVO $(5,61,84,142,157,237,247,323)$.

\section{A. Ischemic CRVO}

The Eye Disease Case-Control Study evaluated risk factors for CRVO in 258 patients with CRVO and 1142 controls, and differentiated between the risk factors for iCRVO $(\mathrm{iCRVO}=84)$ and for non-iCRVO (non-iCRVO=148) ${ }^{(5)}$, with iCRVO defined by the presence of $\geq 10$ DA of capillary non-perfusion on FFA. The ischemic status could not be determined in 26 patients. This study found increased systolic blood pressure, increased diastolic blood pressure, and hypertension associated with both iCRVO and non-iCRVO, but with greater odds ratios for iCRVO ${ }^{(5)}$. Cardiovascular disease, electrocardiographic abnormalities (unspecified), increased albumin-globulin ratio, increased serum $\alpha 1$-globulin level, history of treatment of diabetes mellitus and high blood glucose levels were found to be associated only with iCRVO ${ }^{(5)}$. In another large study by Hayreh et al. ${ }^{(120)}$, which included 143 patients with iCRVO (as defined by Hayreh's criteria described above, section II: Definitions) and 469 patients with non-iCRVO, arterial hypertension and diabetes mellitus were significantly more prevalent in patients with iCRVO than those with non-iCRVO ${ }^{(120)}$.

In a small study including young individuals aged $<40$ years with iCRVO $(n=8)$ (defined by either the presence of RAPD, visual acuity $\leq 3 / 60$, severe retinal capillary non- 
perfusion on FFA (no definition of "severe" capillary non-perfusion given), or iris/retinal neovascularization) and non-iCRVO $(\mathrm{n}=17)$, end stage renal disease was found in three patients with iCRVO and hypercholesterolemia, $\beta$-thalassemia, and hypertension were found, each, in one patient with $\mathrm{iCRVO}^{(98)}$. Due to the very small number of patients included, the role of these systemic conditions in young patients with iCRVO remains uncertain.

Only one study, conducted by Hayreh et al, evaluated risk factors for hemicentral RVO and differentiated between ischemic and non-ischemic forms ${ }^{(120)}$. This study did not find a statistical significant difference between ischemic and non-ischemic hemi-central RVO in the prevalence rate of various systemic diseases such as arterial hypertension, ischemic heart diseases, and diabetes mellitus among others ${ }^{(120)}$.

\section{B. Ischemic BRVO}

No studies were found providing information on risk factors for iBRVO and non-iBRVO separately.

\section{Etiology and Pathogenesis}

\section{A. Etiology}

The etiology of iRVO has not been fully elucidated. A retinal vein can be occluded by thrombosis or, less commonly, by inflammation (vasculitis) ${ }^{(74)}$. According to Virchow's triad, venous thrombosis in general can develop by one or more of three mechanisms: 1) abnormal blood flow; 2) abnormal blood vessel and 3) abnormal blood components ${ }^{(305)}$. Retinal vein thrombosis is thought to develop by one of these mechanisms, namely, abnormal blood flow due to compression from an abnormal adjacent structure: the lamina cribrosa or an adjacent retinal artery ${ }^{(74,138)}$. In CRVO, abnormal blood flow is commonly due to age-related sclerosis of the lamina cribrosa, through which the central retinal vein passes, and/or a hardened retinal artery result of cardiovascular diseases ${ }^{(74,138)}$. In BRVO, abnormal blood 
flow usually occurs at an arteriovenous crossing, where the artery and vein share a common adventitial sheath, due to the degree of arteriovenous nipping caused by the arteriosclerotic artery ${ }^{(74,138)}$. A much less common cause of retinal vein thrombosis is thought to be increased blood viscosity and hyper-homocysteinemia ${ }^{(57,71,241,304,311)}$. A study by Lahiri et al. compared the levels of plasma homocysteine in adult age $\geq 50$ years old affected with iCRVO $(n=108)$ (defined by Hayreh's morphological criteria described in section II. Definitions, above), with non-iCRVO $(n=144)$ and age and sex matched healthy controls ${ }^{(166)}$. Homocysteine level was significantly increased in patients with iCRVO when compared with that in non-iCRVO patients and control subjects ${ }^{(166)}$. Other reported potential associations include deficiencies of the coagulation inhibitor proteins $\mathrm{C}$ and $\mathrm{S}$ and antithrombin III, whereas the role of reduced levels of Factor XII remains controversial with some studies suggesting an association while others do not ${ }^{(8,23,160,278)}$.

It is unclear why some patients with RVO develop retinal ischemia whereas others do not. Similarly, the factors determining the extension and location of the area of retinal ischemia, if present, are not fully determined. Much research is needed to better understand the pathogenesis of retinal ischemia in RVO.

\section{B. Pathologic Mechanisms following Retinal Venous Thrombosis and its Clinical Consequences.}

The severity of the RVO depends mainly on site of the thrombosis ${ }^{(74)}$. Once the thrombosis has formed, the retinal blood flow decreases. As a result, the intravenous hydrostatic pressure increases leading to a series of events that will damage vascular endothelial cells, disrupt the inner blood retinal barrier (BRB) and increase blood vessel permeability which, in turn, will result in retinal hemorrhages and edema throughout the extension of the retina drained by the occluded vein $^{(74,273,303)}$. 


\section{Macular edema}

Macular edema is the most common cause of visual impairment in RVO and is a complication of both ischemic and non-ischemic forms of $\mathrm{RVO}^{(1,4,38,45,243)}$. Increased levels of serum albumin in the aqueous humor have been detected in iCRVO, reflecting the breakdown of the BRB ${ }^{(32)}$. Fluid accumulates in the extracellular spaces within the retina disrupting its normal anatomy and possibly leading to retinal neural degeneration by mechanical compression ${ }^{(62,148,250,306)}$. Chronic macular edema may damage glial (Muller cells) and retinal pigment epithelial (RPE) cells, further reducing retinal fluid clearance ${ }^{(34,35,250)}$. Fluid usually accumulates within the macula in a characteristic cystic pattern, known as cystoid macular edema. In severe retinal edema, neurosensory retinal detachment may also occur which may indicate the additional breakdown in the outer retinal barrier ${ }^{(301)}$.

It has been suggested that intracellular retinal edema plays a role in the pathogenesis of ischemic retinopathies ${ }^{(34)}$, but this has not been extensively studied for iRVO and remains less well understood. In this regard, it is likely that Muller cells are implicated in the pathogenesis of iRVO ${ }^{(34)}$. Muller cells normally transport water and salt from extracellular spaces into the retinal capillaries of the inner retina. In an experimental study in which BRVO was induced in rats, a decrease in potassium currents and an altered distribution of water channels, namely the Kir4.1 protein, were observed in Muller cells resulting in an increased size of their soma and cellular swelling under hypo-osmotic stress, altering their function ${ }^{(249)}$.

Macular edema in RVO often shows a diurnal variation, with edema being worse in the morning and improving late in the day; this relates to the fact that, during sleep, nocturnal hypotension occurs resulting in a decrease in blood flow and an increase in intravenous pressure and, as a result, an increase in edema [Reviewed by Hayreh] ${ }^{(108,110)}$. 


\section{Retinal capillary non-perfusion}

The increased intravenous hydrostatic pressure occurring following an RVO leads to a decrease in the retinal capillary perfusion or, when severe, to capillary non-perfusion ${ }^{(158)}$. The capillary perfusion depends on the pressure difference between the artery/arteriole and the vein/venule proximal and distal to the capillary network respectively; when the pressure difference decreases, the capillary perfusion also decreases ${ }^{(158)}$. As a result, insufficient oxygen reaches the retina leading to retinal ischemia and hypoxia; carbon dioxide and other metabolites cannot be adequately washed out and accumulate in the affected part of the retina causing cell damage. Ischemia in CRVO is often more severe than in BRVO, as the area of the retina affected is more extensive in the former when compared with the latter. Not all patients with RVO, however, develop retinal ischemia and in those that do, the extension of the area of ischemia can vary considerably; the reasons for this remain poorly understood ${ }^{(2,6,181)}$. In humans, it has been postulated that blood is normally shunted between the collaterals of arterioles and venules in the far peripheral arcades. It is believed that these peripheral arcades are poorly perfused, as they require high perfusion pressure to push blood through them, making the peripheral retina more sensitive to changes in blood flow ${ }^{(19)}$.

\section{Retinal and vascular cell damage}

Retinal hypoxia secondary to RVO causes loss of retinal capillary pericytes and damage to mural endothelial cells which leads to their apoptosis and capillary degeneration, as reported in experimental studies on BRVO ${ }^{(63,69,126,127,321)}$. Ischemia damages the different layers of the neurosensory retina causing them to lose their transparency and leading to visual loss. Ischemia results in cell death, by necrosis and/or apoptosis, of ganglion, amacrine, bipolar, and Muller cells and loss of their function as shown in animal studies ${ }^{(64,100,101,126,159,238)}$. Although photoreceptors receive their blood supply chiefly from the choroid, photoreceptor cell loss/damage may occur in patients with macular edema secondary to RVO; the damage 
may persist even after resolution of the edema. This has been documented using OCT in eyes with BRVO in which the perfusion status was not determined ${ }^{(217,219,268)}$ and in eyes with ischemic and non-ischemic CRVO ${ }^{(218,268)}$. Similar findings were observed in an experimental study on monkeys in which RVO was induced by laser photocoagulation; loss of photoreceptors was detected distal to the site of the occlusion in histopathological studies of eyes enucleated 48 months after RVO induction ${ }^{(306)}$. An association between the integrity of foveal photoreceptors and the final visual acuity, after resolution of the macular edema, has been reported ${ }^{(217-219,268)}$. The mechanism of photoreceptor cell loss in iRVO is still unclear.

The ganglion cell layer (GCL) and nerve fiber layer (NFL) of the retina, sensitive to acute and mild hypoxic distress, are believed to be the first layers affected in iRVO, which are lost in severely ischemic cases ${ }^{(175,176,322)}$. Experimental studies showed that damage to the inner retinal layers may occur within one to three weeks following occlusion ${ }^{(70,322)}$. Both apoptotic and necrotic changes have been reported in ganglion cells in experimental models of iCRVO and iBRVO ${ }^{(70,322)}$. In CRVO, GCL loss is significant in both central and peripheral retina, whilst in BRVO GCL loss is significant only in the peripheral retina ${ }^{(322)}$. The reason behind this characteristic pattern is not clear ${ }^{(322)}$. Clinical studies suggest that, regardless of the duration of iBRVO, RGL and NFL display significant thinning when the disease is present ${ }^{(12,175)}$. Lu and Zang ${ }^{(179)}$ studied the effects of retinal ischemia on retinal NFL in 53 patients with RVO [CRVO=20; hemicentral RVO (no definition given) $=4$; BRVO=29). The definition used for ischemic CRVO was that proposed by Hayreh et al. ${ }^{(123)}$ NFL defects were found in $75.5 \%$ of patients; they were significantly more in eyes with cotton wool spots and capillary non-perfusion and significantly more severe in ischemic eyes than in non-ischemic eyes ${ }^{(179)}$. 


\section{Collateral vessels and neovascularization}

Excessive amounts of Vascular Endothelial Growth Factor (VEGF) (see below) secondary to iRVO appear to play a major role in vascular remodeling and development of collateral vessels and neovascularization ${ }^{(9,32,231,232)}$. Collateral vessels develop in eyes with RVO as a compensatory response to venous occlusion ${ }^{(60,158,191,235,256,275,289,308)}$. Neovascularization is a characteristic feature of iRVO, often leading to visual threatening complications including neovascular glaucoma, vitreous hemorrhage and tractional retinal detachment (See section VI. Clinical Findings and Ancillary Studies) ${ }^{(14,117,119,122,134,196)}$. It has been reported that aqueous and vitreous VEGF concentration is significantly higher in iRVO than that in noniRVO ${ }^{(143,211-213)}$. VEGF levels of $849-1569 \mathrm{pg} / \mathrm{ml}$ have been associated with the presence of neovascularization in iCRVO (normal values estimated $\sim 550 \mathrm{pg} / \mathrm{ml})^{(32)}$.

\section{Inflammatory, angiogenic and hypoxia induced factors}

Many inflammatory, angiogenic and hypoxia-induced factors are produced and released in response to retinal ischemia, leading to further retinal damage. These factors have been detected in vitreous, aqueous and/or serum and believed to play a major role in the complications related to RVO (summarized below).

\section{a. Vascular endothelial growth factor (VEGF)}

VEGF is the most studied cytokine in the pathogenesis of $\operatorname{iRVO}^{(9,32,231,232)}$ and is currently a therapeutic target of RVO treatments $(37,38,43,45,46,58,79,128,167,215,243,244,288)$. VEGF is an inflammatory, angiogenic and permeability factor produced by many cells, including vascular endothelial cells, pericytes, retinal pigment epithelium (RPE), Muller cells, astrocytes, and retinal ganglion cells ${ }^{(184)}$. Excessive production of VEGF secondary to iRVO further increases vascular permeability and worsens retinal and macular edema. VEGF along with other cytokines leads to increased adhesion of leukocytes to the vascular walls worsening 
blood flow and retinal ischemia ${ }^{(75,147)}$. High levels of VEGF and IL-6 correlated with both the severity of macular edema and the extent of retinal ischemia in patients with CRVO and BRVO [Reviewed by Karia, 2010] ${ }^{(147)}$.

\section{b. $\underline{\text { Other factors }}$}

Other factors including Intercellular Adhesion Molecule-1 (ICAM-1), Monocyte Chemotactic Protien-1 (MCP-1), basic Fibroblast Growth Factor (bFGF), Interleukin 6,8 \& $1 \beta$ (IL-6, IL8 \& IL-1 $\beta$ ), Erythropoietin (EPO), Tumor Necrosis Factor- $\alpha$ (TNF- $\alpha$ ), Placental Growth Factor (PGF), transforming growth factor (TGF)-beta1, matrix metalloproteinases (MMP)-2 and -9 and serum amyloid A (SAA), Nitric Oxide (NO) among others, have been reported also to play a role in the pathogenesis of the ischemic form of RVO and the associated neuronal cell death occurring within the retina ${ }^{(75,80,83,133,143,144,172,205,224,269,302)}$.

As outlined above, the pathogenesis of iRVO is complex. Although insight has been gained over the years, further research is still needed to help us to understand why dropout of retinal capillaries occurs in some but not all eyes affected with RVO as well as which factors determine the extension of this capillary loss. Deepening our understanding on how different types of neuronal and non-neuronal cells in the retina, including RPE, react to ischemia secondary to RVO and, crucially, how long it takes for the ischemic insult to cause permanent and irreversible damage beyond which therapeutic intervention may not be beneficial should be sought. Animal models of RVO are available to study its pathogenesis; these models have been used to improve the understanding of this condition and have shown their value on this regard ${ }^{(149)}$. 


\section{Clinical Findings and Ancillary Studies}

A patient with iRVO typically presents as an elderly individual with unilateral sudden blurred or deteriorated vision, and may seek care anywhere from a few days to several months after the onset of symptoms ${ }^{(74)}$. The affected individual is usually known to have one or more risk factors for RVO most commonly arterial hypertension followed by dyslipidemia, glaucoma and/or diabetes mellitus ${ }^{(5)}$ (see section IV. Risk Factors, above). The condition is usually painless unless it is complicated with neovascular glaucoma in which case the increased intraocular pressure is often accompanied of severe pain ${ }^{(6,182)}$. Visual symptoms of iRVO are usually more prominent in the morning as the patient wakes up ${ }^{(110)}$ (see V. Etiology and Pathogenesis section).

\section{A. Visual Acuity}

In general, visual impairment is more severe in iRVO than in non-iRVO and more severe in iCRVO than in iBRVO ${ }^{(107,119,196,253)}$. Best-corrected visual acuity varies widely in both CRVO and BRVO depending on the presence/absence and extension of central macular involvement, including non-perfusion, edema and retinal hemorrhage as well as whether vitreous hemorrhage or retinal detachment are present. The visual acuity is usually $\leq 20 / 200$ $(6 / 60)$ in iCRVO ${ }^{(107,119,196)}[85 \%$ of patients with iCRVO have vision of $\leq 20 / 200$ at presentation ${ }^{(119)}$. A study by Hayreh et al showed that a visual acuity of $\leq 6 / 120$ at presentation has the highest sensitivity (91-100\%) and specificity (78-88\%) as a cut-off point of visual acuity for the differentiation between iCRVO and non-iCRVO ${ }^{(123)}$. The Central Vein Occlusion study group (CVOS) reported that the median visual acuity in patients with iCRVO at baseline was $20 / 400$ with $79 \%$ of iCRVO having visual acuity of $\leq 20 / 125^{(6)}$. In hemicentral RVO, visual acuity at presentation was $\leq 20 / 40$ in all eyes $(10 / 10)$ with ischemic hemicentral RVO when compared with $47 \%$ (27/57) of eyes with non-ischemic cases ${ }^{(115)}$. In iBRVO, visual acuity is $\leq 20 / 70$ in $\sim 35 \%$ of cases ${ }^{(2)}$ and $\leq 20 / 60$ in $\sim 82-89 \%$ of cases of 
ischemic macular BRVO ${ }^{(85,228)}$ (see VII. Natural History section, below). Visual acuity at baseline is believed to be one of the most important prognostic factors in patients with RVO, with better final visual acuity in patients with better visual acuity at presentation ${ }^{(92)}$.

\section{B. Clinical Findings}

The diagnosis of iRVO is usually established by fundus examination. In general, findings on fundus examination are similar in iRVO and non-iRVO, but often more prominent in iRVO. The affected retina typically looks edematous with dilated, engorged, tortuous retinal veins and flame-shaped and dot-blot retinal hemorrhages ${ }^{(74,116)}$. Specifically, the ischemic form of RVO can demonstrate cotton wool spots, which reflect focal infarcts within the nerve fiber layer and anterior or posterior segment neovascularization in more advanced stages (74,179,196,253). Marked and extensive intraretinal hemorrhages are very suggestive of the presence of iRVO.

In iCRVO retinal hemorrhage and other fundus findings involve the entire retina. It has been reported that the presence of hemorrhages in more than one-fourth of the posterior retina has $81-84 \%$ sensitivity and $72-74 \%$ specificity for detecting iCRVO ${ }^{(123)}$.

Neovascularization secondary to iCRVO can develop in the iris, angle, optic nerve head or retina ${ }^{(122)}$. In iCRVO the neovascularization is more common in the anterior segment, which can be observed using slit lamp and gonioscopic examination ${ }^{(122)}$ than in the posterior segment (see section VII. Natural History, below). Vitreous hemorrhage and neovascular glaucoma can develop. The incidence of neovascular glaucoma in eyes with pre-existing glaucoma was found to be significantly higher in CRVO patients with intraocular pressure greater than $20 \mathrm{mmHg}$ at presentation as well as in patients with iCRVO compared to those with non-iCRVO ${ }^{(50)}$. Optic disc edema in iCRVO is more marked and takes longer to resolve than in non-iCRVO ${ }^{(116)}$. Moreover, macular edema is often more severe in iCRVO than in non-iCRVO ${ }^{(116)}$ and macular RPE degeneration, serous macular detachment and retinal 
perivenous sheathing develop also more commonly in iCRVO ${ }^{(116)}$. Optociliary vessels have been reported in about $30 \%$ of patients with CRVO without a statistically significant difference between ischemic and non-ischemic forms ${ }^{(90)}$.

In iBRVO, the retinal hemorrhage and other fundus findings are confined to the affected retinal quadrant or macula ${ }^{(118,253)}$. Unlike iCRVO, neovascularization in iBRVO involves the posterior segment, retina and optic nerve head, more commonly than the anterior segment, iris and anterior chamber angle ${ }^{(122)}$ (see section VII. Natural History, below). Neovascular complications can be detected by clinical examination and with the help of ancillary studies in patients with iBRVO (see sections VII. Natural History, and C Findings on Ancillary studies, below)

\section{Findings on Ancillary Studies}

Ancillary studies, including functional, structural examinations and patient reported outcomes (PROs) can be undertaken for the investigation of patients with iRVO. Some of these studies are routinely used in clinical practice, such as FFA and spectral domain - optical coherence tomography (SD-OCT), whereas others, although widely used for the purpose of research, such as visual fields, microperimetry, electroretinography, oximetry, flowmetry, ocular surface temperature, ophthalmodynamometry, and PROs, not commonly performed in the clinical setting to assess patients with RVO. This may be due to their impracticality, being time consuming, needing more patient cooperation and fixation, requiring specifically trained technical staff to obtain them or due to their unavailability, high cost, insufficient value to guide patient's care, and/or underestimation of their usefulness. It may be attributed also to the lack of evidence through robust diagnostic accuracy studies evaluating and comparing these different technologies and providing information on cost-effectiveness and patient acceptability and preference, which, if available, would guide clinical practice. This level of evidence is indeed not available for any of the diagnostic technologies used. Values obtained 
using some of these diagnostic tests that have been suggested to aid in the differentiation between ischemic and non-ischemic RVO have been summarized in Tables 2 and 3 .

\section{Functional tests}

\section{a. Pupillary Examination}

Pupillary examination, specifically the presence of a RAPD appears to be extremely helpful in differentiating between iCRVO and non-iCRVO; the presence of a RAPD points to the diagnosis of iCRVO ${ }^{(31,123,197,245,267)}$. To undertake this test, filters with different densities measured in $\log$ units and ranging from 0 to 3.0 log units can be used to grade the severity of the RAPD ${ }^{(294)}$. The swinging flashlight test is performed with increasing density of the filter in front of the healthy eye until RAPD disappears ${ }^{(294)}$. The eye with the RAPD is first identified. Then, filters of known densities are placed over the not affected eyes until the two eyes are equal (until there is no asymmetry of the pupillary reactivity to light) ${ }^{(267)}$.

It was found that the mean RAPD value in non-iCRVO was $0.24 \pm$ SD $0.36 \log$ units of neutral density filters, whilst that in iCRVO was $1.44 \pm 0.64 \log$ units ${ }^{(123)}$. The comparison between iCRVO and non-iCRVO showed a statistically significant difference ${ }^{(123)}$. A study by Servais et al. showed that all eyes with ocular neovascularization and/or extensive capillary non-perfusion had RAPD of $\geq 1.2 \log$ units using neutral density filter, while none had a RAPD $<0.6 \log$ units ${ }^{(267)}$. A RAPD of $\geq 0.70 \log$ units when using a neutral density filter as a cut-off provided a sensitivity of $88 \%$ and specificity of $90 \%$ to diagnose iCRVO and a RAPD $\geq 0.9 \log$ units provided a sensitivity and specificity of $80 \%$ and $97 \%$, respectively ${ }^{(123)}$. A different study reported that RAPD $\geq 0.6 \log$ units had a sensitivity of $83 \%$ and specificity of $70 \%$ for identifying patients with iris neovascularization ${ }^{(31)}$. 
Pupillary examination is non-invasive and, as summarized above, appears to be a very useful test to differentiate between iCRVO and non-iCRVO. This test is non-invasive, cheap (the neutral density filters can be purchased for $\sim \$ 60$ ), easy to undertake, gives reliable information even in the presence of hazy media, may recognize the disease (iCRVO) at an early stage (within days of onset) and is positive throughout the course of the disease ${ }^{(123,197)}$. However, the test requires a normal optic nerve and pupil in the fellow eye and, in the presence of a large central scotoma, a RAPD may be present even in the absence of iCRVO ${ }^{(123)}$. Despite the advantages mentioned above, testing for RAPD does not seem to be a routinely used test in the evaluation of patients with CRVO. It would seem important to introduce this test to clinical practice as it would contribute towards the identification of patients with the ischemic form of the disease who are clearly at higher risk of visual loss as well as development of severe complications.

\section{b. Visual fields (VF)}

Assessment of visual fields for peripheral retinal function using perimetry has been suggested to be a helpful tool in differentiating between iCRVO and non-iCRVO ${ }^{(123)}$. With the Goldmann perimeter and I-2e, I-4e, and V-4e stimuli, visual field defects were described in the majority of iCRVO patients ${ }^{(123)}$. Visual field defects were detected with the I-2e stimulus in $100 \%$ of patients with iCRVO, with the I-4-e in $96-100 \%$ and with the V-4e in $71-82 \%$ during the first year of the disease. In contrast, using I-2e, I-4e and V-4e stimulus visual field defects were present in $54-78 \%, 38-48 \%$ and $12-17 \%$ of eyes with non-iCRVO ${ }^{(123)}$. The sensitivity and specificity of identifying iCRVO with the I-2e stimulus was $92 \%$ and $72 \%$, respectively. The sensitivity and specificity of detecting iCRVO with the I-4e stimulus was $95 \%$ and $84 \%$, respectively, and $81 \%$ and $79 \%$, respectively, for the $\mathrm{V}-4 \mathrm{e}^{(123)}$. Significant differences between iCRVO and non-iCRVO were observed throughout the whole first year following diagnosis ${ }^{(123)}$. Automated perimetry, which is the standard test used currently in 
clinical practice (the use of Goldman perimetry has been abandoned in most eye clinics) has not been used for differentiating between iCRVO and non-iCRVO.

In eyes with macular BRVO central visual field defects are often detected; major BRVO presents with a peripheral field defect corresponding to the affected retinal quadrant (135). The visual field defects on central 10-2 Humphrey perimetry are more prominent in cases of iBRVO than in non-iBRVO and can become absolute scotomas in long-standing iBRVO ${ }^{(135)}$.

Visual field testing is time consuming and requires patient's cooperation and adequate fixation, which may be difficult for individuals with poor vision making it unpractical for the testing of all patients with RVO. Indeed, visual field testing is not commonly used for the evaluation of patients with RVO in the clinical setting and it would not be probably recommended with the goal of differentiating between ischemic and non-ischemic forms.

\section{c. Microperimetry}

Unlike visual acuity, which only assesses the function of the fovea, microperimetry evaluates the function of the entire macular region and, on this basis it could potentially provide important information on the evaluation of patients with iRVO.

Noma et al compared macular sensitivity in patients with iCRVO (n=6) and non$\operatorname{iCRVO}(n=4)$ and found that mean macular sensitivity was lower in iCRVO when compared with non-iCRVO, with mean sensitivity values of $0 \mathrm{~dB}$ at $4^{\circ}, 1 \mathrm{~dB}$ at $10^{\circ}$ and $2 \mathrm{~dB}$ at $20^{\circ}$ in iCRVO when compared with $8.25 \mathrm{~dB}$ at $4^{\circ}, 12 \mathrm{~dB}$ at $10^{\circ}$ and $13 \mathrm{~dB}$ at $20^{\circ}$ in non-iCRVO (207). In a study including 41 consecutive patients with unilateral BRVO, it was found that the mean macular sensitivity within the $10^{\circ}$ and $20^{\circ}$ fields was significantly correlated with the area of non-perfusion as observed on FFA, with higher macular sensitivity in eyes with smaller areas of non-perfusion ${ }^{(204)}$. Similarly, in another study by Rodolfo et al. which 
included 20 patients with CRVO and 40 with BRVO, macular sensitivity at $8^{\circ}$ was significantly influenced by the presence of macular ischemia, with lower sensitivity in patients with macular ischemia when compared to those with no macular ischemia on FFA (251).

Microperimetry may be a useful tool to assess macular sensitivity following treatments of macular edema secondary to $\mathrm{RVO}^{(208,209)}$. In a study including 23 patients with macular edema secondary to RVO, Noma and colleagues found that although at baseline there was a statistically significant lower macular sensitivity within the central $4^{\circ}, 10^{\circ}$ and $20^{\circ}$ fields in eyes with iRVO compared with those with non-iRVO, higher recovery was observed in iRVO eyes following treatment with pars plana vitrectomy ${ }^{(208)}$.

At present, there is scarce data in the literature demonstrating the value of microperimetry as diagnostic or prognostic test for the evaluation of patients with iCRVO and iBRVO and, thus, it would not be required routinely for the clinical evaluation of patients with RVO.

\section{d. Electroretinography (ERG)}

Findings on full-field ERG have been used to define iCRVO in many studies and have been shown to be a good tool to differentiate between iCRVO and non-iCRVO, as well as to predict the risk of iris neovascularization and neovascular glaucoma (see section II. Definitions, above) ${ }^{(113,123,130,132,139,154,155,161,169,170,190,199,312,315)}$.

It has been reported that the implicit times of the $30 \mathrm{~Hz}$-flicker electroretinograms (ERGs) are significantly correlated with the degree of retinal capillary non-perfusion in eyes with CRVO ${ }^{(139,154,155,169,170)}$. Hvarfner and associates, in a study including 74 patients with CRVO, reported that $75 \%$ of those with an implicit time of $>37 \mathrm{~ms}$ of the $30 \mathrm{~Hz}$ flicker ERG developed neovascular complications during a follow-up period of one year when compared 
to $7 \%$ of CRVO patients with an implicit time of $\leq 37 \mathrm{~ms}{ }^{(129)}$. Kjeka and colleagues ${ }^{(155)}$ found the mean implicit time of the $30 \mathrm{~Hz}$ flicker ERG in patients with iCRVO at baseline to be $39.8 \mathrm{~ms}$ (range 35.0-43.9) and suggested a cut-off point of $\geq 35$ to define iCRVO ${ }^{(155)}$. Kuo et al. ${ }^{(162)}$ retrospectively studied $30 \mathrm{~Hz}$ flicker ERG in iCRVO $(\mathrm{n}=11)$ and non-iCRVO $(\mathrm{n}=11)$ and reported that in iCRVO, the mean amplitude was $24 \mu \mathrm{V}( \pm 15 \mu \mathrm{V}$ SD) in affected eyes and $94 \mu \mathrm{V}( \pm 38 \mu \mathrm{V} \mathrm{SD})$ in fellow eyes, while in non-iCRVO, the mean amplitude was $79 \mu \mathrm{V}\left( \pm 25 \mu \mathrm{V}\right.$ SD) in affected eyes and $81 \mu \mathrm{V}\left( \pm 18 \mu \mathrm{V}\right.$ SD) in fellow eyes ${ }^{(162)}$. This study showed that an interocular amplitude difference of $23 \mu \mathrm{V}$ and an interocular amplitude ratio of $60 \%$ were very good cut-off points to differentiate ischemic from non-ischemic CRVO with a sensitivity and specificity of $100 \%$ for each of these measures ${ }^{(162)}$ (Table 2).

It was found that in iCRVO, the b-wave amplitude and the b:a ratio are reduced by $>60 \%$, when compared to unaffected fellow eye ${ }^{(123)}$. Hayreh et al. found that, for both, photopic and scotopic ERG, the b-wave amplitude had a sensitivity of $80-90 \%$ and a specificity of $70-80 \%$, and the b:a amplitude ratio a sensitivity of $60-70 \%$ and a specificity of $70 \%$ during the early acute phase (59\% of cases evaluated within the first 3 months from onset) for the diagnosis of iCRVO ${ }^{(123)}$. Williamson et al. ${ }^{(312)}$ found that the b:a ratio of the photopic ERG appeared to be the best predictor of iris neovascularization in patients with CRVO with a sensitivity of $87.5 \%$ and specificity of $78 \%$ (Table 2). It was reported also that a photopic b-wave amplitude of $56 \mu \mathrm{V}$ gives a sensitivity of $87.5 \%$ and specificity of $86 \%$ to discriminate patients at risk of iris neovascularization, while $76 \mu \mathrm{V}$ gives a sensitivity of $100 \%$ and specificity of $66 \%{ }^{(312)}$.

Serial full-field ERG testing, obtained within less than 24 hours after the onset of symptoms and every second to third day during the first three weeks of follow-up and during a period of six months, showed that the ERG in people with CRVO changes over time and is unstable during the first three weeks. As a result, it was recommended that the optimal time 
to perform ERG to predict development of iris neovascularization in patients with CRVO is after three weeks from the onset of symptoms ${ }^{(171)}$.

Comparison between FFA ( $\geq 10$ DA of capillary non-perfusion) and full field ERG (bwave implicit time in the $30 \mathrm{~Hz}$-flicker ERG >37 ms) in 32 patients with CRVO who were followed for at least one year showed that iris neovascularization could be predicted in $82 \%$ of patients using FFA, but in as high as $94 \%$ using full field $\mathrm{ERG}^{(168)}$.

In a prospective cohort study including 25 consecutive patients with hemicentral RVO six $(24 \%)$ developed retinal/disc neovascularization 3-12 months following RVO onset ${ }^{(130)}$. The mean photopic b-wave implicit time $( \pm \mathrm{SD})$ was $37.7 \pm 1.3 \mathrm{~ms}$ (range: $36.4-39 \mathrm{~ms})$ in people that develop neovascularization when compared with $34.0 \pm 4.6 \mathrm{~ms}$ (range 31.8-36.2) in those that did not ${ }^{(130)}$. This study did not classify patients into ischemic and non-ischemic forms ${ }^{(130)}$.

A study conducted in 62 patients with cystoid macular edema secondary to BRVO found that the implicit time of the photopic negative response of the photopic ERG was significantly correlated with the area of non-perfused retina (mean 44.3 \pm SD $3.2 \mathrm{~ms}$ in BRVO vs mean $41.9 \pm$ SD $2.2 \mathrm{~ms}$ in unaffected fellow eye) ${ }^{(206)}$. However, there was no significant correlation between other photopic full field ERG parameters and the area of non-perfusion (206)

Multifocal ERG has been used also in the evaluation of patients with RVO demonstrating local macular retinal dysfunction ${ }^{(7,132)}$. The implicit times of the multifocal ERG are prolonged in ischemic macular BRVO (defined by a break of $\geq 50 \%$ of perifoveal capillaries) $(\mathrm{n}=13)(31 \pm \operatorname{SD} 2 \mathrm{~ms})$ compared with the non-ischemic form $(\mathrm{n}=12)(29 \pm \operatorname{SD} 2$ $\mathrm{ms})^{(132)}$ and the amplitudes are reduced (ischemic macular BRVO $10 \pm$ SD $6 \mathrm{nv}$ compared with non-ischemic cases $19 \pm 13 \mathrm{nv})^{(132)}$. Similar findings was observed by Abdel-Kader et 
al. ${ }^{(7)}$, in which macular ischemia was defined broken perifoveal ring. Clear cut off values in any of the parameters of the multifocal ERG that could be used clinically to differentiate between iBRVO and non-iBRVO are not available.

Full field ERG is a non-invasive diagnostic technology that, as summarized above, appears to be very informative in the evaluation of patients with RVO specially to distinguish those with iCRVO at higher risk of developing neovascular complications. However, full field ERG is time consuming and requires equipment and trained staff able to undertake and interpret its results. Likely, for these reason, full field ERG is not obtained routinely in clinical practice for the evaluation of patients with RVO. New handheld ERG devices, which are easy to use and interpret and which have allowed reduced testing time, should facilitate the introduction of the use of ERG more routinely in clinical practice ${ }^{(318)}$.

\section{e. Oximetry}

Few studies have been conducted evaluating the oxygen saturation in retinal vessels using oximetry; this test has been suggested to be of value in the assessment of patients with RVO.

It has been shown that in eyes with CRVO the oxygen saturation in the retinal venules is lower than that in fellow unaffected eyes ${ }^{(76,103)}$, whereas in retinal arterioles, it is similar to or even higher ${ }^{(103)}$. Specifically, in iCRVO the oxygen saturation within the central retinal vein appears to be significantly lower $(<40 \%)$ than that in healthy eyes $(60-70 \%)^{(320)}$.

In a prospective controlled interventional study, oxygen partial pressure (PO2) was measured in patients with iCRVO $(n=6)$ and in those with macular hole or epiretinal membrane $(n=6)$, which were used as controls ${ }^{(314)}$. It was found that in iCRVO the mean preretinal and mid vitreous cavity $\mathrm{PO} 2$ was lower $(8.1 \pm \mathrm{SD} 3.5 \mathrm{mmHg}$ and $19.8 \pm \mathrm{SD} 7.3$ $\mathrm{mmHg}$, respectively) than that in controls $(15.0 \pm \mathrm{SD} 5.7 \mathrm{mmHg}$ and $33.7 \pm 12.8 \mathrm{mmHg}$, respectively) ${ }^{(314)}$. 
Oximetry has been used to evaluate the response to therapy in RVO (e.g. following anti-VEGF treatment and vitrectomy) ${ }^{(283,298,314)}$. Oxygen saturation in retinal veins of noniCRVO eyes was found to be improved to levels closer to normal values after anti VEGF treatment and this increase was associated with improved visual acuity and reduction in macular edema ${ }^{(298)}$. No studies were identified evaluating oxygen saturation in retinal arteries and veins in eyes with iCRVO following treatment.

Oxygen saturation in BRVO appears to be highly variable in both iBRVO and noniBRVO, which may reflect severity of disease, degree of venous occlusion, recanalization, collateral vessels, tissue atrophy, arteriovenous diffusion or vitreal transport of oxygen $(104,178)$.

Further studies, specifically longitudinal cohort studies, are required to better understand the correlation between changes in oxygen saturation in retinal blood vessels and disease severity and prognosis. Prospective longitudinal studies evaluating the ability of oximetry to identify patients with iRVO at risk of developing neovascular complications, as well as changes in oxygen saturation occurring following treatment that may predict a longterm treatment response and improved outcomes would be beneficial. The use of oximetry in clinical practice is not yet widespread; however, as oximetry is a simple, fast and noninvasive test requiring only imaging of the fundus, it could be easily introduced to clinical practice once its clinical applicability in the evaluation of patients with RVO is demonstrated.

\section{f. Retinal blood flow}

Retinal blood flow can be estimated using various technologies including color Doppler imaging (CDI), laser doppler flowmetry and doppler fourier-domain optical coherence tomography $(\mathrm{OCT})^{(17,18,20,26,282,296,307,310)}$. It has been suggested that measures of blood flow are helpful in evaluating the severity of RVO and differentiating between iCRVO and non- 
iCRVO $^{(17,18)}$, although at present time the usefulness of this technology to establish this differentiation remains controversial ${ }^{(20,26,296,310)}$.

Venous flow velocities were found to be significantly lower in iCRVO than in noniCRVO ${ }^{(17,26,296)}$. Tranquart et al. reported that means of minimum and maximum venous flow velocities using CDI were statistically significantly lower in iCRVO $(n=18)(1.83 \pm$ SD 0.94 and $2.94 \pm$ SD $1.34 \mathrm{~cm} / \mathrm{s}$, respectively), than in non-iCRVO (n=50) $(2.28 \pm \operatorname{SD} 0.73$ and $3.66 \pm$ SD $1.19 \mathrm{~cm} / \mathrm{s}$, respectively) ${ }^{(296)}$. Using CDI, a brief decrease in arterial diastolic velocity was measured in patients presenting with iCRVO, which correlated with arteriovenous passage time on FFA ${ }^{(17)}$. The impairment in venous blood flow velocity in CRVO was found to be persistent whereas the changes in the arterial velocity recovered rapidly ${ }^{(17)}$. Using a confocal scanning laser doppler flowmeter, Arvas et al. ${ }^{(18)}$ found that the blood flow of the supero-temporal retina (one of the areas selected for the measures of blood flow) was statistically significantly lower in patients with iCRVO $(n=12)$ than in fellow eyes or eyes of healthy volunteers, whereas it was not significantly different at the macula (18)

A study which included 10 patients with ischemic macular BRVO found a statistically significant reduction in the overall retinal blood flow when compared with healthy controls, as measured using the Heidelberg retinal flowmeter (HRF), in most patients tested $(n=7)^{(282)}$. Other studies including patients with iBRVO and non-iBRVO failed to identify differences in blood flow between RVO and fellow unaffected eyes; these studies did not provide separate data, however, for iBRVO and non-iBRVO ${ }^{(17,296)}$.

At the present time, literature is still scarce on the potential benefits of using measures of retinal blood flow in the evaluation of patients with iRVO. As its value is yet to be demonstrated and due to lack of availability of the instrumentation required in most eye 
clinics, measures of retinal blood flow would not be recommended currently for the clinical evaluation of patients with RVO.

\section{g. Ocular surface temperature}

Although ocular surface temperature (OST) is affected by many factors such as body and environmental temperature, it has been suggested that it could be a useful tool to assess the severity of CRVO, being potentially a good indicator of the blood flow in the posterior segment ${ }^{(277)}$. OST is an easy and non-invasive test that is undertaken using infrared thermography. OST is measured at five anatomical points: 1) the medial canthus, 2) half-way from the medial canthus and nasal limbus, 3) the center of the cornea, 4) half-way from the temporal limbus and lateral canthus and 5) at the lateral canthus. The center of the cornea was found to be the best indicator of the blood flow of the posterior segment and the most reliable measure in CRVO, since it is avascular and the point influenced least by the conjunctival blood vessels ${ }^{(277)}$. In a study including 36 patients with CRVO it was found that the mean OST at the center of cornea in iCRVO $(n=9)$ was statistically significantly lower (mean 34.7 \pm SD 0.66) than in non-iCRVO $(n=27)$ (mean $35.3 \pm$ SD 0.50) ${ }^{(277)}$. OST has not been used to evaluate BRVO. Given that this study included only a small number of patients and that results have not been confirmed by other studies the value of SOT in the evaluation of patients with RVO remains to be elucidated.

\section{h. Ophthalmodynamometry}

Ophthalmodynamometry is an easy and non-invasive test that allows measuring the pressure in the central retinal artery and central retinal vein. It has been suggested that ophthalmodynamometry can be used to differentiate iCRVO from non-iCRVO ${ }^{(140,141,194)}$. McAllister et al. ${ }^{(194)}$ studied 88 patients with iCRVO and found an association between elevated central venous pressure and low visual acuity, reduced retinal blood flow, larger area 
of capillary non-perfusion and incidence of rubeosis iridis ${ }^{(194)}$. In a study by Jonas ${ }^{(140)}$ which included 15 patients with CRVO and 4 patients with BRVO, the central retinal vein collapse pressure was, on average, 1.8 times greater in iCRVO $(n=8)$ than in non-iCRVO $(n=7)$. Central venous pressure was significantly higher in iCRVO (103 \pm SD 25.4 AU) (AU=arbitrary units) than in non-iCRVO (mean 58.1 \pm SD 37.5 AU) and BRVO (mean $43.8 \pm \mathrm{SD} 25.5 \mathrm{AU})^{(140)}$, whereas the pressure in the central retinal artery was significantly lower in iCRVO than in non-iCRVO ${ }^{(140)}$. These results were replicated in another study which included 28 patients with CRVO (7 with iCRVO and 21 with non-iCRVO) and demonstrated that central retinal venous pressure was statistically significantly higher in iCRVO than in non-iCRVO (mean $91.5 \pm$ SD 30.1 AU vs $52.4 \pm$ SD 32.5 AU) ${ }^{(141)}$. Central retinal venous pressure was higher than the diastolic central retinal arterial pressure more frequently in the iCRVO $(7 / 7$ or $100 \%)$ than in the non-iCRVO $(8 / 21$ or $38 \%){ }^{(141)}$. Central retinal arterial pressure was significantly lower in iCRVO (46.0 $\pm 10.6 \mathrm{AU})$ than in noniCRVO $(64.5 \pm 22.8 \mathrm{AU})^{(141)}$. The finding of higher pressure in the central retinal vein when compared with the diastolic pressure of the central retinal artery appears to be characteristic of the ischemic form of CRVO and could potentially be used to establish this diagnosis (141,194). Furthermore, ophthalmodynamometry appears to be helpful to predict visual outcomes in patients with CRVO ${ }^{(68)}$. Thus, in a study including 73 patients with CRVO a high venous collapse pressure (VCP) in the central retinal vein of $100 \mathrm{gm}$ or greater and a VCP greater than the arterial collapse pressure (ACP) appeared to be predictive of a worse visual outcome ${ }^{(68)}$.

The above studies suggest that ophthalmodynamometry aids in the differentiation between iCRVO and non-iCRVO and provides prognostic information. This test is not part, though, of the routine clinical evaluation of patients with RVO. However, a simplification of this test is commonly used by clinicians to elucidate whether or not the venous pressure is 
increased in patients with CRVO. It relays on the clinical maneuver of exerting pressure on the eye at the same time that the blood vessels are visualized by slit-lamp biomicroscopy. As the pressure in the eye is increased (by pressing on the eye) the central retinal artery may collapse at the same time or even before the central retinal vein does, indicating very high venous pressure (venous pressure in normal circumstances is much lower than that in arteries and, thus, veins should collapse earlier than arteries when pressure is exerted on the eye).

\section{Structural tests}

\section{a. Fluorescein angiography}

As discussed in section II. Definitions (above), fundus fluorescein angiography (FFA) is the most widely used test to establish the diagnosis of iRVO. Indeed, FFA allows the direct visualization of blood vessels and blood flow in the retina. FFA provides very useful information on the vascular status of the retina, presence of neovascularization, presence/ absence of delayed venous filling, presence/absence of retinal leakage (from breakdown of the inner or outer retinal barriers) and retinal edema and presence/absence of areas of retinal capillary non-perfusion (Figures $1 \& 2$ ).

On FFA more prominent leakage and retinal capillary dilatation are often observed in iCRVO and iBRVO than in the non-ischemic forms ${ }^{(85,181)}$. In RVO, diffuse hyperfluorescence is detected in the area affected by retinal edema in the late phase of the FFA $^{(265)}$. If there is no marked intra-retinal hemorrhaging, FFA will demonstrate capillary telangiectasis, dilated collateral vessels and a petaloid pattern of hyperfluorescence from cystoid macular edema, if these features are present ${ }^{(265)}$. Marked hyperfluorescence will be seen at the site of new vessels in the retina and optic nerve head, with blurring of their margins in late phases of the FFA ${ }^{(265)}$. Hypofluorescence is present in areas of capillary nonperfusion ${ }^{(265)}$. 
Most clinicians and researchers use the extent of the area of retinal capillary nonperfusion as the main determinant of the differentiation between ischemic and non-ischemic RVO; most, following the criteria provided by the CVOS and BVOS (i.e. > 10 DA of capillary non-perfusion $=\mathrm{iCRVO} ;>5 \mathrm{DA}$ of capillary non-perfusion $=\mathrm{iBRVO})^{(2,6)}$. It appears that the risk of developing neovascular complications, and thus, of having a more guarded prognosis, relates chiefly to the presence/extension of the area of retinal ischemia. It was reported that $16 \%$ of eyes with CRVO and area of retinal capillary non-perfusion on FFA of 10-29 DA developed anterior segment neovascularization; this risk increased to $43 \%$ and $52 \%$ in eyes with $\geq 30 \mathrm{DA}$ and $\geq 75$ DA of capillary non-perfusion, respectively ${ }^{(6)}$. A study by Magargal and colleagues found that $33 \%$ and $45 \%$ of eyes with CRVO with an ischemic index $\geq 50 \%$ (which in their study corresponded to $\geq 10 \mathrm{DA}$ ) developed retina/disc or neovascular glaucoma, respectively ${ }^{(181)} .93 \%$ of eyes with neovascular glaucoma and $91 \%$ of eyes with retina/disc neovascularization secondary to iCRVO had ischemic indices of $\geq 50 \%{ }^{(181)}$.

Wide angle FFA (WA-FFA) appears to be particularly helpful in the evaluation of patients with RVO as this imaging technology allows for the visualization of the peripheral retina, in addition to the macula and midperipheral retina, which is believed to be the first area affected by ischemia in RVO ${ }^{(11,239,290,322)}$. Using WA-FFA, Tsui, et al. ${ }^{(300)}$ studied 69 eyes with CRVO and correlated the ischemic index (see section II. Definitions, above) with the presence of neovascularization. The mean $( \pm \mathrm{SD})$ ischemic index was $25( \pm 26 \%)$; eyes with neovascularization had a mean ischemic index of $75 \%$ (range, $47-100 \%$ ) compared with eyes without neovascularization that had an ischemic index of $6 \%$ (range, $0-43 \%)^{(300)}$. The average ischemic index of eyes with anterior segment neovascularization was $78 \%$ and the average ischemic index of eyes with retinal neovascularization was 72\% (SD, 20\%; range, 47-99\%). It was found that the ischemic index significantly correlated to the presence of 
neovascularization, and eyes that had evidence of neovascularization had an ischemic index $>45 \%{ }^{(300)}$.

WA-FFA was used to evaluate the extent of retinal ischemia in 12 out of 20 patients with iCRVO included in RAVE (for further details on this trial, see section IX. Management and outcomes, below). In this study, iCRVO was defined by the presence of three out of four criteria: BCVA $\leq 20 / 200$, loss of I-2e isopter on Goldman visual field, RAPD $\geq 0.9 \log$ units and $b$-wave reduction to $\leq 60 \%$ of the corresponding a-wave. The mean total field of gradable retina was 290 DA (range, 178-452 DA) with a mean area of retinal non-perfusion of 184 DA (range 141-323 DA) which is approximately $63.4 \%$ of the total area of the retina ${ }^{(317)}$.

Recently, a stereographic projection software was introduced by Tan et al. to calculate "anatomically correct" area of retinal non-perfusion and total area of visible retina on WAFFA in $\mathrm{mm}^{2}{ }^{290)}$. WA-FA images cannot be mapped onto a flat surface without a resultant warp of the image; this is due to the projection from three-dimensional (retina) to twodimensional (retinal image) by preserving directionality from a central point. This method presents vascular landmarks accurately, but at the cost of increasing distortion of size and shape at the periphery. Tan et al. used the stereographic projection software to determine the anatomically correct area of retinal non-perfusion and total area of visible retina in $\mathrm{mm}^{2}$ in 32 patients with RVO; the authors also determined how the former compared with the "uncorrected" ISI, previously used in other studies ${ }^{(290)}$. The ISI was determined by using the central FFA image (image centered in the macula) obtained with the Optos 200Tx (Optos, Dumfermline, UK) and by manually outlining areas of capillary non-perfusion and total area of visible retina using the GRADOR software, which automatically provides the number of pixels within these established regions. Using the stereographic projection software the regions determined by the above method were then evaluated and "corrected" to determine the "anatomically correct" area of retina on these. No statistically significant differences 
were found between the "uncorrected" ISI (\% of non-perfused retina from total area of retina measured) and the "corrected" non-perfusion \%. The "corrected" area of non-perfusion measured in $\mathrm{mm}^{2}$ also correlated well with the "uncorrected" ISI. The median total area of visible retina was $690.6 \mathrm{~mm}^{2}$ and ranged from $559.4-797.7 \mathrm{~mm}^{2}$.

WA-FFA was used in a study including 32 patients with RVO, 13 with CRVO and 19 with BRVO ${ }^{(274)}$ and demonstrated that peripheral non-perfusion at baseline correlated with both baseline retinal thickness and the magnitude of reduction of edema, on SD-OCT, following ranibizumab or dexamethasone treatment ${ }^{(274)}$. An area of non-perfusion of $>10 \%$ of the total retina on WA-FFA in both CRVO and BRVO patients was statistically significantly associated with worse macular edema and worse visual acuity ${ }^{(274)}$.

WA-FFA appears to be an even more valuable tool than standard FFA to image retinal ischemia in RVO, likely to detect it at earlier stages, and to predict the likelihood of development of complications ${ }^{(274,300)}$. It should be noted, however, that properly conducted diagnostic studies comparing these two diagnostic technologies (standard FFA and WA-FFA) for the evaluation of retinal ischemia in RVO are not available. However, given that the availability of WA-FFA in clinics is increasing and that a larger extension of retina is imaged with this technology when compared with standard FFA, it would seem appropriate to incorporate its use for the evaluation of patients with RVO. Using standard fundus cameras, it was reported that the detection of areas of capillary non-perfusion could be compromised by the presence of marked and extensive intra-retinal hemorrhages. This is likely to be less of a problem now when using wide-angle scanning laser ophthalmic systems. If WA-FFA is obtained using scanning laser, the amount of fluorescein required to undertake this test is also reduced (good quality angiograms can be obtained with $2 \mathrm{ml}$ of fluorescein, from $1 \mathrm{~g}$ in $5 \mathrm{ml}$ vial), which would be expected to reduce the potential rare side effects of this test. WA-FFA appears to be widely accepted for this purpose ${ }^{(274,290,299,317)}$. 
Iris fluorescein angiography has been used also for the evaluation of patients with RVO and for the differentiation between ischemic and non-ischemic forms. In a study comparing patients with iCRVO $(n=24)$ and non-iCRVO $(n=24)$ it was found that all patients with iCRVO have dilation of the iris vessels and leakage independently of the presence or absence of iris neovascularization, while in non-iCRVO, no or minimal changes in the iris vasculature were observed $^{(164)}$.

\section{b. Spectral domain optical coherence tomography (SD-OCT)}

SD-OCT is widely used in the evaluation of patients with RVO ${ }^{(36-38,43,45,137,215,264)}$. SD-OCT allows to examine the integrity of the different retinal layers and to determine overall thickness of the central retina, individual thickness of the retinal layers and the presence of cystic intraretinal edema and subretinal fluid secondary to RVO ${ }^{(36-38,43,45,137,215,230,264)}$. SDOCT is routinely used in clinical practice and has been used to evaluate changes in central retinal thickness in patients included in RVO trials (RAVE, COPERNICUS, GALILEO, VIBRANT, BRAVO, CRUISE, SCORE; details on these studies can be found in section VIII. Management of iRVO and outcomes following treatment, below). Central subfield thickness (CST) on SD-OCT is commonly used to determine the response to current therapies for macular edema secondary to RVO ${ }^{(36-38,43,45,137,215,230,264)}$.

The mean CST on SD-OCT at baseline was reported to be statistically significant greater in patients with iCRVO $(n=203)(499.65 \mu \mathrm{m})$ when compared with those with iBRVO $(\mathrm{n}=354)(444.38 \mu \mathrm{m})$ in one study; both iCRVO and iBRVO were defined by the presence of $\geq 5$ DA of capillary non-perfusion ${ }^{(173)}$. In a retrospective study by Martinet et ${ }^{(188)}{ }^{\text {, which }}$ included 53 consecutive patients with CRVO and in which macular ischemia was defined as an enlarged foveal avascular zone (larger than $1000 \mu \mathrm{m}$ ) or a broken perifoveal capillary ring, 
CST was greater in ischemic macular RVO (mean $754 \mu \mathrm{m}$; SD not provided) when compared with non-ischemic macular RVO (mean 520 $\mu \mathrm{m}$; SD not provided). Macular ischemia was also associated with absent/incomplete IS/OS line on SD-OCT in $73 \%$ of eyes during the follow-up (mean follow-up 13 months; range 1-66 months) as well as with RPE atrophy or RPE fibrosis at last follow up ${ }^{(188)}$. Furthermore, a CST of $700 \mu \mathrm{m}$ or greater appeared to be associated with peripheral ischemia, poor visual prognosis and irreversible damage to photoreceptors cells ${ }^{(188)}$. Some of the patients included in this study $(n=11)$ received panretinal or grid laser photocoagulation therapy; none received intravitreal therapy ${ }^{(188)}$.

In a study on patients with BRVO, a non-ischemic maculae $(n=13)$ (defined as absence of any distinct area of capillary non-perfusion within one disc diameter of the center of the fovea) had an early and more rapid drop in CST during a follow-up of six months (and without intervention) when compared with an ischemic maculae $(\mathrm{n}=7)$ (defined as presence of any distinct area of capillary non-perfusion within one disc diameter of the center of the fovea $)^{(272)}$. The presence of a visible IS/OS and external limiting membrane on SD-OCT, which indicates the integrity of the photoreceptor cell layer, was correlated with a more favorable visual prognosis in patients with BRVO ${ }^{(221)}$.

SD-OCT provides an indication of damage/atrophy of photoreceptors as well as NFL, GCL, inner plexiform layer (IPL) and inner nuclear layer (INL) in the advanced stages of iCRVO and iBRVO, all of which have been associated with poor prognosis ${ }^{(175,176)}$. A loss of foveal IS/OS and a larger defect in the external limiting membrane at presentation, and a loss of inner retinal layers at six months' follow-up in patients with iCRVO correlated with poorer final visual outcomes ${ }^{(176,221)}$. In CRVO, macular ischemia, as detected by FFA, correlated with reduced CST when macular edema is absent, and loss of inner retinal layers in early stage (three months) and with presence of intraretinal fluid and loss of inner retinal layers in late stage (six months) on SD-OCT images ${ }^{(176)}$. In iBRVO, the thickness of the GCL and 
NFL (mean $86.26 \pm$ SD 5.95 and $95.53 \pm$ SD $8.87 \mu \mathrm{m}$, respectively) appeared to be significantly reduced when compared with non-iBRVO (mean 79.03 \pm SD $7.84 \mu \mathrm{m}$ and 88.83 $\pm 8.96 \mu \mathrm{m}$, respectively) ${ }^{(175)}$.

\section{c. Optical coherence tomography angiography (OCT-A)}

Unlike FFA, OCT-A is a non-invasive (i.e. does not require the injection of a dye) imaging modality that allows the visualization of retinal blood vessels ${ }^{(53,151,263)}$. Using the splitspectrum amplitude decorrelation algorithm (SSADA), detection of blood motion within the vascular lumen can be achieved by measuring the variation in reflected OCT signal amplitude between consecutive cross-sectional B-scans; high quality angiograms of the retina and choroid can be, in this manner, generated ${ }^{(53,151,263)}$. Superficial and deep retinal capillary networks can be separately visualized using OCT-A. This technology, however, has a smaller field of view than conventional FFA or WA-FFA ${ }^{(53,151,263,279)}$.

It has been suggested that OCT-A may be useful for the evaluation of areas of capillary non-perfusion, non-perfused vessels, vascular density and FAZ morphology in patients with $\operatorname{RVO}^{(59,203,214,251,259,260,287)}$. OCT-A is the first imaging technology that enables a selective evaluation of the deep retinal capillary network, which, for unexplained reasons, seems to be more severely affected than the superficial capillary network in CRVO and BRVO $^{(59)}$.

A retrospective study by Coscas and colleagues including $54 \mathrm{RVO}$ patients (29 with CRVO and 25 with BRVO) and comparing OCT-A with FFA and SD-OCT suggested that OCT-A may provide a better rate of detection of cystoid spaces, macular edema and disruption of perifoveal capillaries than FFA and SD-OCT ${ }^{(59)}$. Cardoso et al. ${ }^{(203)}$, in a retrospective study including 76 patients (81 eyes) with RVO [CRVO ( $\mathrm{n}=40$ eyes), HRVO $(n=7$ eyes) and BRVO ( $n=34$ eyes)], $36(44 \%)$ of which were of the ischemic type (no 
definition of iRVO given) and in which images were adequately assessed in an independent manner by a masked grader (i.e. the results observed in an imaging modality would not be affecting the reading of a subsequent imaging modality) found good agreement between FFA and OCT-A for determining the area of ischemia and for grading of the foveal avascular zone when using $3 \times 3 \mathrm{~mm}$ OCT-A scans but poor when using $8 \times 8 \mathrm{~mm}$ OCTA scans. Artifacts appeared to be a major limitation of OCT-A with non-gradable images in $28 \%$ and $15 \%$ of cases for $3 \times 3 \mathrm{~mm}$ and $8 \times 8 \mathrm{~mm}$ scans, respectively ${ }^{(203)}$ when compared with $3 \%$ for FFA. Motion artifacts and media opacity appeared to be a major contributing factors to obtaining good quality images on OCT-A ${ }^{(203)}$. Restrictions of OCT-A in identifying features of ischemia and retinal new vessels when present outside the $8 \mathrm{~mm}$ scan where noted ${ }^{(203)}$.

Using OCTA it was found, in a retrospective study including 12 patients with RVO (eight with BRVO, six of these ischemic; and four with CRVO, one of these ischemic), that the FAZ in the deep retinal capillary network was enlarged in eyes with RVO when compared with fellow unaffected eyes ${ }^{(287)}$. The vascular density in the macular region as detected with OCT-A was found to be significantly lower in eyes with CRVO and BRVO, affecting both superficial and deep capillary networks, than in fellow eyes; differences between ischemic and non-ischemic forms were, however, not sought ${ }^{(91,260)}$. In a prospective study including 21 eyes of 21 patients with CRVO, disruption of the ellipsoid zone was significantly correlated to a larger FAZ area in the superficial retinal capillary plexus and poorer visual acuity ${ }^{(259)}$.

To date, studies using OCT-A for the evaluation of patients with RVO are scarce, the majority retrospective and including small number of patients. The technique, however, appears to be promising to determine the area involved by edema as well as areas of nonperfusion. OCT-A has some limitations currently including the small field of view and the fact that images are prone to artefacts; these drawbacks will likely be overcome in the future 
by further development of the technology. In this regard, a recently develop technique refer to as "extended field imaging technique" (EFI) using trial frames fitted with a +20 diopter lens, seems to provide adequate OCT-A images of a larger area of the fundus, on average $188.5 \%$ more than those without EFI ${ }^{(152)}$.

Prospective, adequately powered diagnostic studies are required to determine the value of OCT-A and OCT-A EFI for the diagnosis and evaluation of patients with iCRVO and iBRVO as well as to determine how this technology compares with other imaging modalities available such as FFA and wide-angle FFA. The major restriction of OCT-A for its use in RVO, at present, is the small field of view; however, it would seem very useful for the evaluation of the perifoveal capillary network.

\section{d. Fundus autofluorescence (AF)}

Fundus autofluorescence (AF) is a non-invasive imaging modality that provides information on the status of the RPE and, indirectly, of the photoreceptors ${ }^{(89)}$. Given that the outer retinal barrier can be affected by iRVO (see section V. Etiology and Pathogenesis, above) it could be envisaged that AF could be useful in the evaluation of patients with this disorder. Indeed, foveal AF has been found to serve as a prognostic indicator in patients with RVO $(28,221,265,266)$. There have been, however, no studies evaluating fundus AF specifically in iRVO.

\section{Patients reported outcomes (PRO)}

Studies have shown that both CRVO and BRVO are associated with a significant decrease in vision related quality of life using the 25 item National Eye Institute Visual Function Questionnaire (NEI VFQ-25) ${ }^{(21,67)}$. The NEI VFQ-25 provides scores for 12 subscales: general health, general vision, near vision, distance vision, driving, peripheral vision, color 
vision, ocular pain, role limitations, dependency, social functioning and mental health, in addition to an overall composite score ${ }^{(187)}$.

NEI VFQ-25 scores are significantly lower in patients with CRVO and BRVO than in people with no ocular disease ${ }^{(21,67)}$. Scores were significantly lower in people with bilateral CRVO than in those with unilateral disease ${ }^{(67)}$. NEI-VFQ-25 scores in patients with BRVO were significantly higher in all subscales when compared with those in patients with CRVO ${ }^{(21)}$. NEI VFQ25 scores appear to be driven, predominantly, by the visual acuity in the better-seeing eye ${ }^{(67)}$. However, a decrease in NEI VFQ-25 score in BRVO correlated with visual acuity in the affected eye, even when there was good visual acuity in the non-affected fellow eye ${ }^{(21)}$.

There have been no studies evaluating visual-related quality of life, using the NEIVFQ25, or health-related quality of life, using the EQ-5D (a health-related quality of life questionnaire consisting of five domains: mobility, self-care, usual activities, pain/discomfort and anxiety/depression) specifically in patients with iRVO and how these compare with noniRVO.

\section{Natural History}

\section{A. Ischemic CRVO}

The CVOS reported that untreated patients who had poor visual acuity at presentation $(\leq 20 / 200)$ had an $80 \%$ chance of having final visual acuity of $\leq 20 / 200$, whether perfused or non-perfused initially ${ }^{(6)}$. In an large observational natural history study (iCRVO=109; non$\mathrm{iCRVO}=588$ eyes) by Hayreh and colleagues, final visual acuity, on resolution of macular edema, was reported to be $20 / 100$ or better in $83 \%$ in non-iCRVO when compared to $12 \%$ in iCRVO. Thus, in over $80 \%$ of patients with iCRVO visual acuity remained poor even after 
resolution of macular edema ${ }^{(119)}$. Thus, the iCRVO phenotype appears to confer a more guarded prognosis. In eyes with initial visual acuity of 20/70 or worse, visual acuity improved, on resolution of the macular edema, in $59 \%$ of the non-iCRVO eyes, with no significant improvement in eyes with iCRVO ${ }^{(119)}$. This study showed that 90/146 (60\%) of patients with non-iCRVO had a visual acuity >20/40 after resolution of macular edema in comparison to $0 / 13(0 \%)$ of those with iCRVO during a follow-up of $2-5$ years ${ }^{(119)}$. The median time to resolution of macular edema was found to be 29 months for patients with iCRVO and 23 months for those with non-iCRVO ${ }^{(119)}$.

COPERNICUS reported improvement of $\geq 15$ ETDRS letters in only $4.3 \%$ of untreated patients with iCRVO at six months follow up ${ }^{(38)}$ (See section VIII. Management and outcomes following treatments, below, for more details on this study). Another study by Laatikinen et al. ${ }^{(165)}$ showed improvement of $\geq 2$ Snellen lines in the same proportion, $4.3 \%$ of untreated patients with iCRVO at 12 months follow-up ${ }^{(165)}$. Kjeka et al. ${ }^{(155)}$ reported change of mean visual acuity from 1.95 to 2.74 LogMAR during a mean period of 41 months of follow-up in patients with untreated iCRVO (range 26-63 months) ${ }^{(155)}$.

A large prospective cohort study by Hayreh and Zimmermann, which involved 239 eyes with iCRVO ${ }^{(117)}$, reported that the cumulative probability, within 6 months of onset, of development of neovascularization was $49 \%$ in the iris, $37 \%$ in the anterior chamber angle, $6 \%$ in the disc and $9 \%$ in the retina. At 12 months, the corresponding rates were $10 \%$ for neovascularization in disc and $12 \%$ in retina ${ }^{(117)}$. CVOS reported that $35 \%$ of untreated eyes with iCRVO developed anterior segment neovascularisation during the first 12 months ${ }^{(6)}$. The overall incidence of posterior segment neovascularization at 3 years was $33 \%$ in a cohort study reported by Magargal et al, which included 86 eyes with iCRVO, 85 eyes with noniCRVO and 29 eyes with indeterminate RVO ${ }^{(181)}$. 
In the CVOS, untreated iCRVO showed an increase in the area of retinal capillary non-perfusion, from a median of $50 \mathrm{DA}$ at baseline to $111 \mathrm{DA}$ at the visit at which anterior segment neovascularization developed, in comparison to a median increase in non-perfusion of only four DAs in those who did not develop anterior segment neovascularization at the first annual visit ${ }^{(6)}$. The greatest risk of developing anterior segment neovascularization in eyes with iCRVO appears to be during the first year of follow up (usually within the first three months) in untreated iCRVO patients ${ }^{(6)}$. Hayreh et al. reported that anterior segment neovascularization commonly develops during the first 6-7 months following diagnosis of $\operatorname{iCRVO}^{(117,122)}$.

The cumulative probability of development of neovascular glaucoma in eyes with iCRVO was reported by Hayreh and Zimmerman to be $29 \%$ within 6 months of onset ${ }^{(117)}$ and by Magargal et al to be $60 \%$ within 24 months of onset ${ }^{(182)}$. Vitreous hemorrhage was reported in $10 \%$ of iCRVO by nine months after onset of the occlusion ${ }^{(196)}$. Hayreh et al reported that $9 / 67(\sim 13 \%)$ of untreated patients with iCRVO developed vitreous hemorrhage during a follow-up of 10 years ${ }^{(121)}$. Vitreous detachment was identified in 38 out of $52(73 \%)$ iCRVO eyes; patients with complete vitreous detachment did not develop vitreous hemorrhage in comparison with $57 \%$ in whom absent or incomplete vitreous detachment was detected ${ }^{(125)}$. Retinociliary collaterals developed in $41 \%$ of patients with iCRVO in a median period of 13 months ${ }^{(119)}$.

In an observational natural history study including 67 patients with hemicentral RVO classified into ischemic and non-ischemic ${ }^{(115)}$ (for definition, see II. Definitions), Hayreh and Zimmerman found that when the presenting vision was $\geq 20 / 60,75 \%$ of patients maintained or experienced improvement in vision; if the presenting vision was $\leq 20 / 70$, visual acuity improved in $60 \%^{(115)}$. 
The incidence of neovascularization in patients with hemicentral RVO at 12 months follow up was reported to be $12 \%, 10 \%, 12 \%$ and $29 \%$ in iris, anterior chamber angle, disc and retina, respectively ${ }^{(117)}$. Neovascular glaucoma was reported to occurred in $5 \%$ of eyes within 6 months of onset ${ }^{(117)}$.

\section{B. Ischemic BRVO}

Although information on the natural history of BRVO is available ${ }^{(118,253)}$, there is very scarce data specifically on iBRVO; this applies to most aspects of this type of RVO.

A study by Parodi et al. ${ }^{(228)}$ showed that none of the untreated patients with exudative retinal detachment secondary to iBRVO (defined by presence of $\geq 5$ DA of retinal capillary non-perfusion on FFA) gained $\geq 3$ Snellen lines of visual acuity whereas $93 \%$ lost $\geq 3$ Snellen lines during a follow-up of 24 months ${ }^{(228)}$ (Parodi et al. 2008). However, reabsorption of exudative retinal detachment was observed in all patients after a mean of $15.8 \pm 3.4$ months follow-up ${ }^{(228)}$.

Finkelstein followed a group of 30 patients (30 eyes) with macular edema secondary to BRVO; 23 patients with macular capillary non-perfusion (20 of which had a broken perifoveal capillary ring) and seven with good macular perfusion (one of the latter had a broken perifoveal capillary ring). Finkelstein found that a greater improvement in visual acuity occurred in eyes with macular ischemia, which achieved a median final visual acuity of 20/30, when compared with eyes with a perfused macula (29\%), which achieved a median final visual acuity of 20/80, after a mean follow up of 39 months ${ }^{(85)}$.

According to BVOS study, $41 \%$ of untreated patients with at least 5 DA of retinal capillary non-perfusion (group X) developed neovascularization (unspecified) during the follow-up ${ }^{(2)}$. A cohort study by Hayreh et al. ${ }^{(122)}$ reported the incidence of neovascularization in eyes with major BRVO to be $1.6 \%, 0.5 \%, 11.5 \%$ and $24.1 \%$ in the iris, 
anterior chamber angle, disc and retina, respectively (range 3 months-20 years)".

Approximate incidence of retinal and disc neovascularization, extracted from Kaplan-Meier survival curves presented in this study, were $10 \%$ at $\sim 2$ years and $20 \%$ at $\sim 4$ years, respectively ${ }^{(122)}$. Vitreous hemorrhage developed in $61-73 \%$ of patients with iBRVO and neovascularization during follow-up periods between $2-4$ years, ${ }^{(2,111)}$ with $28 \%$ of patients with untreated retinal or disc neovascularization experiencing recurrent vitreous hemorrhage (111)

\section{Management and outcomes following treatments}

\section{A. Current treatments of ischemic RVO}

Currently, there is no effective treatment for patients with iRVO. The present therapeutic options are aimed at treating the complications of iRVO, namely macular edema and neovascularization and its results, rather than at re-vascularizing the ischemic retina (33,86,87). Local treatments include laser photocoagulation, intravitreal anti-VEGF, corticosteroids and vitrectomy, or combination of these therapies. Each of these treatments has advantages and inconveniences as well as potential complications; these are reviewed below.

Management of underlying medical conditions is important ${ }^{(150)}$. Therefore, it is recommended to evaluate patient's medical history, blood pressure, serum glucose, lipid profile, full blood cell count (FBC) and erythrocyte sedimentation rate (ESR) "A,H".

Patients with iRVO will require follow-up at different intervals depending on the type of occlusion (CRVO or BRVO), presence/absence and severity of retinal non-perfusion, presence/absence of complications or high risk of developing them, and the requirement and type of treatment selected. 
Monthly follow up during the first six months was recommended for patients with iCRVO, with slit lamp examination and gonioscopy, to detect signs of anterior segment neovascularization ${ }^{(6)}$. Follow-up would be guided by whether or not complications develop and by the need for treatments and type of therapy chosen (see below) "H". Similarly, the follow-up in patients with BRVO would be determined by clinical findings, such as the presence or absence of macular edema or neovascularization and the need and type of treatment selected (see below) ${ }^{(40)}$.

\section{Treatment for macular edema secondary to iRVO}

Treatment for macular edema secondary to iRVO includes macular laser photocoagulation, intravitreal injections of anti-VEGF, local corticosteroid therapies and vitrectomy. Ten studies on CRVO (2 RCTs and 8 prospective interventional studies) and nine studies on BRVO (5 RCTs and 4 prospective interventional studies) which addressed outcomes of these therapies on the ischemic form of RVO were identified and included in this review and are summarized below.

\section{a. Macular laser photocoagulation}

The CVOS and BVOS were the first large, randomized clinical trials (RCTs) evaluating the effect of laser treatment in patients with CRVO and BRVO ${ }^{(1,4)}$. The CVOS did not find macular laser photocoagulation of value for the treatment of macular edema secondary to CRVO $^{(4)}$. The CVOS (group M) ${ }^{(4)}$ excluded patients with macular non-perfusion (no definition of macular non-perfusion was given), retinal new vessels and vitreous hemorrhage; among the included eyes only $21 / 155(14 \%)$ had $\geq 10$ DA of retinal capillary non-perfusion on FFA (13 treated and 8 untreated) and the outcomes of macular laser were not addressed separately for ischemic and non-ischemic cases. In contrast, for patients with macular edema secondary to BRVO, laser photocoagulation was proved to be beneficial ${ }^{(1)}$. The BVOS 
recommended macular laser after three months of the onset of symptoms, given the possibility of spontaneous resolution of the macular edema during this period of time, in patients with visual acuity of 20/40 or worse with absence of foveal capillary non-perfusion on FFA and absence of blood involving the fovea ${ }^{(1)}$. Retreatment was required in some patients (range, 1-5 treatments given) when macular edema persisted ${ }^{(1)}$. The BVOS showed a mean 3-year improvement of 1.33 Snellen lines of vision following macular laser in comparison to 0.23 lines of vision in untreated patients; visual acuity improved $>2$ Snellen lines in $65 \%$ of patients and $60 \%$ attained visual acuity of $>20 / 40$ or better, in comparison to $37 \%$ and $34 \%$ of untreated patients, respectively ${ }^{(1)}$. The BVOS ${ }^{(1)}$ excluded patients with foveal non-perfusion and outcomes of macular laser were not given specifically for the group with iBRVO ${ }^{(1)}$.

Macular laser photocoagulation has been proposed as a potential treatment for patients with iBRVO, defined by the presence of $\geq 5$ DA of retinal capillary non-perfusion on FFA, and exudative retinal detachment based on the results of a small $(n=31)$ prospective $\mathrm{RCT}^{(228)}$. In this study, 16 patients were assigned to grid laser photocoagulation and 15 to observation. A visual acuity improvement of $>3$ lines on ETDRS charts was observed in $37 \%$ of patients in the laser treated group when compared to no patients in the untreated group, while visual acuity deterioration of $\geq 3$ ETDRS lines occurred in $93 \%$ of untreated eyes when compared with none in laser treated eyes ${ }^{(228)}$. Mean final visual acuity was $20 / 125$ Snellen equivalent in the treated group and 20/400 in the untreated group at 24-months follow-up from a mean baseline of $20 / 160$ in both groups ${ }^{(228)}$. Resolution of subretinal fluid occurred in all patients, both treated and untreated, with an earlier resolution observed in the treated group (9.1 \pm 1.7 months; range 6-12 months) when compared with the untreated group (15.8 \pm 3.4 months; range $12-24$ months). 
In another prospective RCT, Tomomatsu et al. ${ }^{(295)}$ compared combined targeted laser photocoagulation and intravitreal bevacizumab $(1.25 \mathrm{mg})(\mathrm{n}=19)$ with bevacizumab $(1.25$ $\mathrm{mg})$ alone $(\mathrm{n}=19)$ in patients with macular edema secondary to iBRVO, defined by the presence of $\geq 5$ DA of retinal capillary non-perfusion. Significant reduction of CST was observed 2 and 3 months following combined therapy in comparison to intravitreal bevacizumab monotherapy, which showed increase in CST three months following treatment ${ }^{(295)}$. The number of injections in the bevacizumab monotherapy group was statistically significantly greater (mean $1.57 \pm$ SD 0.69 ) than that in the combined laser + bevacizumab group (mean $0.83 \pm$ SD 0.62) ${ }^{(295)}$. Moreover, the visual acuity improved significantly with combination therapy at six months (0.6 Log MAR at baseline to 0.3 LogMAR), but not with bevacizumab monotherapy (0.65 LogMAR at baseline to 0.5 LogMAR) ${ }^{(295)}$.

\section{b. Anti-VEGF}

Intravitreal anti-VEGF has become the first line therapy for patients with macular edema secondary to both CRVO and BRVO. Intravitreal anti-VEGF therapies routinely used in clinical practice include ranibizumab, aflibercept and bevacizumab. Intravitreal ranibizumab and aflibercept are licensed for the treatment of macular edema secondary to RVO; in the United Kingdom these treatments have been appraised and are recommended by the National Institute for Health and Care Excellence (NICE) for people with visual impairment caused by macular edema following CRVO or BRVO "B-E". Aflibercept is recommended by NICE as an option for the treatment of visual impairment in adults caused by macular edema after BRVO "D" or CRVO "E". Ranibizumab is recommended as an option for treating visual impairment caused by macular edema following CRVO or following BRVO, the latter only if treatment with laser photocoagulation has not been beneficial, or when laser photocoagulation is not suitable because of the extent of macular hemorrhage "B, C". Intravitreal bevacizumab is used 
also as an off-label alternative. Anti-VEGF drugs, by inhibiting the effects of VEGF; decrease blood vessel and possibly RPE permeability leading to reduction in macular edema.

Several studies, including RCTs have been conducted to investigate the efficacy and safety of anti-VEGF therapies in patients with CRVO and BRVO. Most of these, however, excluded or included only a very scarce number of patients with the ischemic forms of RVO (Table-1). For example, the CRUISE (Central Retinal Vein OcclUsIon: Evaluation of Efficacy and Safety study), which evaluated the effect of ranibizumab on CRVO, excluded patients with brisk RAPD ${ }^{(37)}$ and, thus, would have excluded patients with severe retinal ischemia $^{(123)}$ (See section VI. Clinical Findings and Ancillary Studies, above). Furthermore, of the 392 patients included in CRUISE only two had $\geq 10$ DA of capillary non-perfusion on FFA $(0.5 \%)^{(37)}$. Similarly, ROCC, an RCT comparing ranibizumab to sham in patients with macular edema secondary to CRVO, included only five out of 29 patients (17\%) with $\geq 5$ DA of capillary non-perfusion on FFA ${ }^{(153)}$. Moreover, none of the BRVO patients in BRAVO (RanibizumaB for the treatment of macular edema following BRAnch retinal Vein Occlusion) had $\geq 10$ DA of retinal capillary non-perfusion ${ }^{(43)}$. The branch Retinal vein occlusion Associated Macular Edema Study (RABAMES), which also evaluated ranibizumab for the treatment of macular edema secondary to BRVO, excluded patients with macular ischemia and did not classify or give separate data for iBRVO and non-iBRVO ${ }^{(234)}$. Other studies that may have included patients with iRVO did not provide data separately for ischemic and non-ischemic forms ${ }^{(46,79)}$. Studies providing information, specifically, in iRVO are summarized below.

RAVE (the Rubeosis Anti-VEGF) was an open-label clinical trial in which treatment with intravitreal ranibizumab was investigated in 20 patients with iCRVO. iCRVO was defined by the presence of three out of four criteria: visual acuity $\leq 20 / 200$, loss of I-2e isopter on Goldman visual field, RAPD $\geq 0.9 \log$ units and reduction of $b$ :a ratio by $\geq 60 \%$ of the 
corresponding a-wave ${ }^{(36)}$. All patients received monthly intravitreal ranibizumab $(0.3 \mathrm{mg}$ in 5 patients; $0.5 \mathrm{mg}$ in 10 patients; $1 \mathrm{mg}$ in 5 patients; no separate outcomes were given for these three groups) during the first nine months and as needed during the remaining study period of 36 months. Eighteen patients (90\%) were followed for 9 months; 17 (85\%), 15 (75\%) and $13(65 \%)$ were followed for 12, 24 and 36 months, respectively. The mean visual acuity at baseline was 15 ETDRS letters (range 0-37 ETDRS letters). At 36 months, the mean visual acuity gain was +21.4 (range -23 to +40 ) ETDRS letters with five out of 13 patients (38\%) who completed the 36 months follow-up gaining $\geq 15$ ETDRS letters. The high loss of follow-up at 36 months should be taken into consideration when interpreting this data. Seven eyes $(39 \%)$ had a final visual acuity worse than $20 / 400^{(36)}$. Mean reduction of CST was $-294 \mu \mathrm{m}$ (range, -47 to $-652 \mu \mathrm{m}$ ) at nine months of follow-up from baseline. However, subsequently, after a three months-period of observation (12 months- follow-up) recurrence of macular edema was observed in $44 \%$ of patients and retreatment required. After retreatment (as needed), the CST improved by $-163 \mu \mathrm{m}$ (range, -636 to $-602 \mu \mathrm{m}$ ) at 24 months and $-191 \mu \mathrm{m}$ (range, -623 to $-58 \mu \mathrm{m}$ ) at 36 months-follow-up compared to values at 12 months ${ }^{(36)}$.

CRYSTAL was an open-label, single arm, multicenter prospective study which included 357 patients with CRVO. ${ }^{(167)}$ Patients were treated with monthly $0.5 \mathrm{mg}$ ranibizumab for a minimum of three injections and until stable visual acuity was maintained for three consecutive months. Macular ischemia, defined by presence of any capillary nonperfusion on FFA (mild, moderate, severe or completely destroyed) in at least one of the three subfields using ETDRS grid (central, inner ring subfield or outer ring subfield) on the macular region at baseline in 107 patients $(30 \%){ }^{(167)}$. Of the eyes included, 54 eyes had iCRVO (definition was not given); data was not provided separately for iCRVO and noniCRVO. Intravitreal ranibizumab resulted in a significant improvement of visual acuity, with 
$63.8 \%$ of patients gaining $\geq 10$ letters, $49.2 \%$ gaining $\geq 15$ letters and $9 \%$ gaining $\geq 30$ letters at 12 months- follow-up ${ }^{(167)}$. In this study, an exploratory analysis showed that the mean gain in visual acuity was not statistically significantly different between CRVO patients with

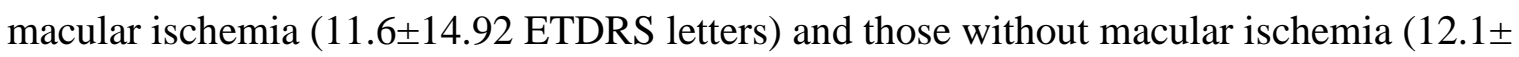
18.10 ETDRS letters) ${ }^{(167)}$. The number of intravitreal ranibizumab injections from baseline to 12 months was also not statistically significant different between patients with macular ischemia (7.5 \pm 2.9$)$ and those without macular ischemia $(8 \pm 2.9)^{(167)}$.

BRIGHTER $^{(288)}$ was an RCT that evaluated the effect of monthly $0.5 \mathrm{mg}$ ranibizumab until stable visual acuity was maintained for three consecutive months $(n=183)$, ranibizumab $(0.5 \mathrm{mg})$ combined with macular laser $(\mathrm{n}=180)$ and macular laser monotherapy $(n=92)$ in patients with macular edema secondary to BRVO ${ }^{(288)}$. BRIGHTER included patients with macular ischemia, defined as the in CRYSTAL study (see above); macular ischemia was present in 113 out of 455 patients (24.8\%) (ranibizumab, $n=47$; ranibizumab combined with macular laser, $n=42$; and macular laser monotherapy, $n=24)^{(288)}$. Of the eyes included 47 eyes had iBRVO (definition was not given), but data was not provided separately for iBRVO and non-iBRVO. The mean visual acuity at baseline was $57.7 \pm 12.88$ ETDRS letters. Improvement in visual acuity was greater following six months ranibizumab therapy with or without laser therapy $(14.8 \pm 10.7$ and $14.8 \pm 11.13$ ETDRS letters, respectively) when compared to macular laser monotherapy $(6.0 \pm 14.7 \text { ETDRS letters })^{(288)}$. At six months, $65 \%$ and $54.5 \%$ of patients attained a visual acuity of $\geq 73$ letters in the ranibizumab and ranibizumab plus laser treatment groups, respectively, in comparison to $31 \%$ of patients receiving laser monotherapy ${ }^{(288)}$. An exploratory analysis found no statistically significant difference in outcomes between patients with and without macular ischemia ${ }^{(288)}$.

COPERNICUS ${ }^{(38)}$, GALILEO ${ }^{(128,215)}$ and VIBRANT ${ }^{(45,58)}$ evaluated the effect of intravitreal aflibercept on macular edema secondary to CRVO and BRVO. A statistically 
significant reduction of macular edema as well as improvement in visual acuity and visionrelated quality of life was demonstrated following intravitreal aflibercept therapy (38,45,58,128,215) . COPERNICUS and VIBRANT provided data on visual outcomes for patients with iRVO and non-iRVO separately, but not for macular edema or vision related quality of life ${ }^{(38,45,58)}$, while GALILEO did not provide separate data on any of these outcomes for iRVO and non-iRVO cases ${ }^{(128,215)}$.

COPERNICUS included 187 patients with CRVO; only 29 (15\%) of these had retinal ischemia, defined by the presence of $\geq 10$ DA of capillary non-perfusion (127 patients had perfused retina and 31 had an indeterminate perfusion status) ${ }^{(38)}$. Patients were randomized to monthly injections of $2 \mathrm{mg}$ aflibercept for six months followed by PRN (pro re nata) for the remaining period of the study of 12 months $(n=115$, with 17 non-perfused CRVO) or to monthly sham for six months and PRN aflibercept thereafter $(n=73$, with 12 non-perfused CRVO). In this study the mean visual acuity at baseline was 50.0 \pm 14.09 ETDRS letters. At six months-follow-up, a gain of $\geq 15$ ETDRS letters was observed in a statistically significantly higher number of patients $(56.1 \%)$ in the aflibercept arm when compared with the sham-treated group $(12.3 \%)^{(38)}$. A secondary analysis showed that in patients with iCRVO, the proportion of eyes that gained $\geq 15$ letters at six months was $51.4 \%$ in the aflibercept group and $4.3 \%$ in the sham group; in non-iCRVO, these proportions were $58.4 \%$ and $16 \%$ in aflibercept and sham groups, respectively ${ }^{(38)}$.

GALILEO also studied the effect of aflibercept on macular edema secondary to CRVO and included a total of 177 patients; 14 (8\%) had non-perfused retina, defined by the presence of $\geq 10$ DA of capillary non-perfusion, 143 patients had good retinal perfusion and in 14 retinal perfusion was indeterminate ${ }^{(128,215)}$. Patients were randomized to monthly $2 \mathrm{mg}$ aflibercept for six months ( $\mathrm{n}=103$, with 7 non-perfused CRVO) or monthly sham for six months ( $\mathrm{n}=68$, with 7 non-perfused CRVO) ${ }^{(128)}$. Due to the small number of patients 
included with iCRVO outcomes were not evaluated separately for iCRVO and non-iCRVO $(128,215)$

VIBRANT evaluated the effect of aflibercept $(2 \mathrm{mg})$ versus macular laser photocoagulation for the treatment of patients with macular edema secondary to $\operatorname{BRVO}{ }^{(45,58)}$. Of the 181 patients included in this study, iBRVO, defined as $\geq 10$ DA of capillary nonperfusion on FFA, was present in 36 patients (20\%). Patients were randomized to receive monthly aflibercept $(2 \mathrm{mg})$ for six months $(\mathrm{n}=91$, with 16 iBRVO) or macular laser $(\mathrm{n}=90$, with 20 iBRVO). At six months a gain of $\geq 15$ ETDRS letters occurred in a statistically significant higher number of patients treated with aflibercept $(52.7 \%)$ than laser $(26.7 \%)^{(45)}$. A secondary analysis showed that eyes with iBRVO experienced a mean change in visual acuity of 19.1 EDTRS letters at six months-follow-up following aflibercept and of 11.3 ETDRS letters following laser, with no statistically significant differences between these two treatment groups ${ }^{(45)}$. In contrast, the mean change in visual acuity in non-iBRVO was significantly higher in the aflibercept group (14.3 EDTRS letters) when compared with the laser-treated group (5.7 ETDRS letters) ${ }^{(45)}$.

Two RCTs compared the effects of intravitreal bevacizumab and intravitreal triamcinolone acetonide (IVTA) in patients with macular edema secondary to CRVO $(n=86)$ ${ }^{(244)}$ and BRVO $(\mathrm{n}=86)^{(243)}$. Patients were randomized to receive intravitreal bevacizumab (three monthly injections of $1.25 \mathrm{mg}$ ) or intravitreal triamcinolone acetonide (IVTA) (two injections of $2 \mathrm{mg}$ IVTA 2 months apart). Ischemic CRVO was defined by the presence of $\geq 10$ DA of capillary non-perfusion on FFA and was identified in 40 patients $(46 \%)^{(244)}$. In iCRVO, visual acuity significantly improved in both intravitreal bevacizumab $(1.09 \pm 0.62$ $\log$ MAR at baseline to $0.57 \pm 0.44 \log$ MAR at six months $)$ and IVTA groups $(0.95 \pm 0.35$ $\log$ MAR at baseline to $0.79 \pm 0.31 \log$ MAR at six months) with the improvement being significantly greater following intravitreal bevacizumab ${ }^{(244)}$. Similarly, significant reduction 
in CST was observed in both intravitreal bevacizumab $(200 \pm 126 \mu \mathrm{m})$ and IVTA $(77 \pm 104$ $\mu \mathrm{m})$ groups at six months, with greater CST reduction following intravitreal bevacizumab (244). No statistically significant differences in visual acuity or CST were observed between iCRVO and non-iCRVO ${ }^{(244)}$. In patients with BRVO, iBRVO was present in 52 patients $(60 \%)$, as defined by the presence of $\geq 5$ DA of capillary non-perfusion on FFA ${ }^{(243)}$. In iBRVO, visual acuity significantly improved in both the intravitreal bevacizumab group $(0.77$ $\pm 0.24 \log$ MAR at baseline to $0.37 \pm 0.19 \log$ MAR at six months $)$ and the IVTA group $(0.75$ $\pm 0.31 \log$ MAR at baseline to $0.58 \pm 0.29 \log$ MAR at six months) with improvement in visual acuity being significantly greater following intravitreal bevacizumab ${ }^{(243)}$. Similarly, significant reduction in CST was observed in both intravitreal bevacizumab $(125 \pm 101 \mu \mathrm{m})$ and IVTA $(68 \pm 175 \mu \mathrm{m})$ groups at six months, with CST reduction being significantly greater following intravitreal bevacizumab ${ }^{(243)}$. A statistically significant difference in CST between iBRVO and non-iBRVO was detected, but no statistically significant difference in visual acuity was observed between iBRVO and non-iBRVO ${ }^{(243)}$.

A prospective interventional study evaluated the effect of intravitreal bevacizumab $(1.25 \mathrm{mg})$ in 16 patients with iCRVO defined by the presence of $>30$ DA of retinal capillary non-perfusion and 30 patients with non-iCRVO ( $\leq 30$ DA of retinal capillary non-perfusion) ${ }^{(240)}$. In both, iCRVO and non-iCRVO, mean visual acuity and CST improved from baseline to six months with no statistically significant difference between these groups in both outcomes ${ }^{(240)}$.

Anti-VEGFs improve visual acuity and reduce macular edema in patients with CRVO and BRVO. Intravitreal injections of anti-VEGF, however, are unpleasant for patients, carry a small risk of complications such as endophthalmitis, and require repeated treatments and close and long-term follow-up over many years to preserve vision ${ }^{(44,124)}$. At present time, 
there is insufficient data available on the efficacy and cost -effectiveness of anti-VEGFs for the treatment of iCRVO and iBRVO.

\section{c. $\underline{\text { Steroids }}$}

Corticosteroids reduce retinal capillary permeability and leakage as well as inflammation and, hence, could provide benefit in reducing macular edema in patients with RVO $(30,47,48,99,136,137,220,257,264)$. Intravitreal corticosteroids used for the treatment of patients with macular edema secondary to RVO include triamcinolone acetonide (TA) and dexamethasone (DEX). TA is not licensed for intraocular use in these patients. In the United Kingdom DEX implants were appraised by NICE who recommends this therapeutic option for patients with macular edema secondary to CRVO and for patients with BRVO unsuitable or unresponsive to laser treatment "F,G". Corticosteroids are associated with potential adverse effects including elevated intraocular pressure and cataract $(30,47,48,99,136,137,220,257,264)$.

SCORE (Standard Care vs COrticosteroid for REtinal vein occlusion) ${ }^{(137,264)}$ compared IVTA with standard care (observation in $\mathrm{CRVO}^{(137)}$ and macular laser in BRVO $\left.{ }^{(264)}\right)$ for the treatment of patients with macular edema secondary to CRVO $(n=271)^{(137)}$ and BRVO $(n=411)^{(264)}$. SCORE included only three patients with iCRVO, defined by the presence of $\geq 10$ DA of capillary non-perfusion on FFA, and 41 patients with iBRVO, defined by the presence of $\geq 5$ DA of capillary non-perfusion. No separate data was given for iRVO and non-iRVO with regards to clearance of macular edema or visual acuity improvement $(137,264)$

The use of IVTA (4 mg) was evaluated in patients with iCRVO (n=11) (defined by the presence of $\geq 10$ DA of retinal capillary non-perfusion) and was compared to non-iCRVO $(n=11)$ in a prospective interventional study by Ozdek et al. ${ }^{(220)}$. The study showed a significant reduction of CST in both iCRVO (from $766 \pm 320 \mu \mathrm{m}$ at baseline to $441.7 \pm 166.9$ 
$\mu \mathrm{m}$, at nine months) and non-iCRVO (from $667 \pm 223 \mu \mathrm{m}$ at presentation to $320 \pm 175.5 \mu \mathrm{m}$, at nine months) following treatment, with no statistically significant difference between these groups ${ }^{(220)}$. Complete resolution of macular edema was reported in seven patients with noniCRVO and four patients with iCRVO ${ }^{(22)}$. Improvement in visual acuity was also observed in both iCRVO and non-iCRVO, but was significant in non-iCRVO only ${ }^{(220)}$. An improvement of $\geq 3$ Snellen lines of visual acuity was observed in $81.8 \%$ of the eyes with non-iCRVO but in only $18.2 \%$ of those with iCRVO at nine months-follow-up ${ }^{(220)}$. Moreover, the mean final visual acuity among patients with iCRVO was very poor (20/800 Snellen/ 1.61 LogMAR) ${ }^{(220)}$.

In a prospective interventional study including 18 patients with BRVO and macular ischemia (defined by a broken perifoveal capillary ring at the border of the FAZ associated with a distinct area of capillary non-perfusion within one disk diameter of the foveal center) a single injection of IVTA (4 mg) led to a significant reduction in macular edema (CST on SDOCT) at one month $(n=17,94 \%)$ and three months $(n=13,72 \%)$ follow-up ${ }^{(51)}$. There was, however, no significant improvement observed at six, nine or 12 months follow-up ${ }^{(51)}$. Improvement of visual acuity was significant at one month follow-up only, but not at the other time points ${ }^{(51)}$. Only six out of the 12 patients that completed the 12-months follow-up (50\%) showed improvement in visual acuity, ranging from one to six lines, and five out of these 12 had a final visual acuity of $\leq 20 / 200^{(51)}$.

In another prospective study of 17 patients with macular edema secondary to BRVO, iBRVO, defined as the presence of $\geq 5 \mathrm{DA}$ of capillary non-perfusion on FFA, was present in 10 patients ${ }^{(209)}$. In this small study there were no statistically significant differences found in changes from baseline to six months follow-up in macular thickness, macular volume, macular sensitivity within the central $4^{\circ}, 10^{\circ}$, and $20^{\circ}$ fields or visual acuity when comparing cases with iBRVO and non-iBRVO ${ }^{(209)}$. 
Treatment of macular edema with DEX implant in patients with CRVO and BRVO was evaluated in the GENEVA RCT (Global Evaluation of implaNtable dExamethasone in retinal Vein occlusion with macular edemA) ${ }^{(99)}$. This study, however, did not provide data separately for perfused and non-perfused cases ${ }^{(99)}$. In a prospective interventional study which included 29 patients with iCRVO, defined by the presence of $\geq 10$ DA of capillary nonperfusion $(n=15)$ and iBRVO, defined by the presence of $\geq 5$ DA of capillary non-perfusion $(n=14)$, DEX implant showed a statistically significant reduction in macular edema and an improvement in visual acuity at 12 months following treatment ${ }^{(25)}$. In this study, $87 \%$ of iCRVO and 92\% of iBRVO patients showed stabilization or improvement in vision at 12 months, with $80 \%$ of eyes affected by iCRVO gaining more than one ETDRS line and $46 \%$ improving by over three lines, while $85 \%$ of eyes with iBRVO improved by one line and $35 \%$ by three lines ${ }^{(25)}$. Despite this improvement, the mean final visual acuity was $\leq 20 / 200$ in iCRVO and $\leq 20 / 63$ in iBRVO ${ }^{(25)}$. In iCRVO, the median CST was reduced from $749 \mu \mathrm{m}$ at baseline to $363 \mu \mathrm{m}$ at 12 months. Similarly, the median CST in those with iBRVO improved from $459 \mu \mathrm{m}$ at baseline to $323 \mu \mathrm{m}$ at 12 months ${ }^{(25)}$.

\section{d. Pars plana vitrectomy}

Pars plana vitrectomy with or without adjuvant procedures such as internal limiting membrane peeling was found to be effective in treating macular edema secondary to iCRVO and iBRVO in several prospective interventional studies and retrospective case series $(27,66,146,174,186,210,246,270)$. However, none of these studies were RCTs and all had a small number of patients.

Vitrectomy with posterior hyaloid removal appeared to confer benefit improving macular edema and reducing CST (from $976 \pm$ SD $196 \mu \mathrm{m}$ at baseline to $640 \pm$ SD $191 \mu \mathrm{m}$ at six months) in a prospective interventional study that included 10 eyes with iCRVO ${ }^{(174)}$. 
Visual acuity improved in six patients from a median of 20/600 to 20/300, while did not change in the remaining four $(20 / 1600)^{(174)}$.

A small study evaluated outcomes of pars plana vitrectomy in patients with macular edema secondary to iBRVO $(n=13)$ and non-iBRVO $(n=10)$ and showed statistically significant improvement in visual acuity (from 0.85 to $0.5 \log \mathrm{MAR}$ ), macular thickness and macular volume on SD-OCT, and mean macular sensitivity on microperimetry within the central $4^{\circ}$ (from 3 to $8 \mathrm{~dB}$ ), $10^{\circ}$ (from 4.5 to $10.5 \mathrm{~dB}$ ) and $20^{\circ}$ fields (from 5.5 to $10 \mathrm{~dB}$ ) at six months following treatment ${ }^{(210)}$. There were no significant differences between iBRVO and non-iBRVO regarding macular thickness, macular volume, and visual acuity. However, there was a significant difference in the macular sensitivity within the central $4^{\circ}, 10^{\circ}$, and $20^{\circ}$ fields between iBRVO and non-iBRVO, with better sensitivity in non-iBRVO ${ }^{(210)}$.

\section{Therapies to treat or prevent proliferative retinopathy secondary to} $i R V O$

Studies have been conducted to test the effect of panretinal photocoagulation to prevent or treat neovascularization and its consequences in patients with iRVO. Anti-VEGFs and steroids have not been adequately tested in powered RCTs for this purpose. However, several studies that aimed at determining the effect of these treatments on macular edema in patients with RVO evaluated the occurrence of new vessels and complications related to these and, thus, provided information on this regard. The studies identified have been summarized below.

\section{a. Pan-retinal photocoagulation (PRP)}

Panretinal photocoagulation (PRP) leads to regression of neovascularization in iCRVO $(6,97,121,155,165,183,201,248)$. PRP was associated with regression of angle and iris neovascularization in patients with iCRVO in which this complication was present ${ }^{(6)}$. 
Prophylactic PRP (i.e. prior to the development of anterior segment neovascularization), however, did not prevent the neovascular complications in patients with iCRVO in the CVOS (6). Although PRP lowered the incidence of neovascular complications, the difference between treated and observed groups was not statistically significant and, thus, it was recommended that PRP should be undertaken only as soon as neovascularization develops $(6,121,155,165,183)$. A study by Hayreh et al. ${ }^{(121)}$ comparing PRP-laser treated and observed untreated eyes of patients with iCRVO $(n=123)$ over a period of ten years found no statistical significant differences in visual acuity or incidence of neovascular complications including angle neovascularization, neovascular glaucoma, posterior segment neovascularization and vitreous hemorrhage between the two groups ${ }^{(121)}$. The incidence of iris neovascularization in PRP-treated patients, however, was reduced if PRP was performed within the first 90 days of iCRVO onset ${ }^{(121)}$. Using Goldmann perimetry, the peripheral visual fields showed a statistically significant worsening in the laser-treated eyes in comparison with the untreated eyes ${ }^{(121)}$.

Retinal arterial blood flow was evaluated using color Doppler flowmetry one month following PRP in patients with iCRVO ( $n=13$ ) (defined by the presence of $\geq 10$ cotton wool spots in a $45^{\circ}$ fundus photography, $\geq 10$ DA of capillary non-perfusion on FFA, and/or presence of neovascularization of the iris) and compared to that in patients with non-iCRVO $(n=20)$ and healthy controls $(n=22)^{(20)}$. Patients with iCRVO had statistically significantly lower blood flow within the ophthalmic and central retinal artery than those with non-iCRVO and healthy controls; PRP in iCRVO group was found to further reduce the arterial blood flow ${ }^{(20)}$. In contrast, it was observed in another study which involved 12 patients with iCRVO, defined by the presence of $\geq 10$ DA of capillary non-perfusion on FFA, that there was a significant increase in the retinal blood flow, using Heidelberg retinal flowmetry, one month following laser photocoagulation, but the blood flow was still lower than in control 
subjects ${ }^{(18)}$. Hence, it is not clear how PRP affects the retinal blood flow in patients with iCRVO as different technologies used have shown different results.

The BVOS showed that prophylactic sector laser photocoagulation prior to development of neovascularization and vitreous hemorrhage in patients with iBRVO lowered the risk but did not completely prevent the development of new vessel formation and its complications. Thus, like in the case of iCRVO, laser photocoagulation is recommended only when neovascularization is established in iBRVO ${ }^{(2)}$. Hayreh et al. ${ }^{(111)}$ reported that untreated BRVO patients have 3.5 times higher risk in developing retinal neovascularization than laser-treated patients ${ }^{(111)}$, but noted that treatment with laser did not have a beneficial effect in the visual acuity and resulted in worsening of the visual field defects in comparison to no treatment ${ }^{(111)}$.

\section{a. Anti-VEGF}

Treatment with intravitreal ranibizumab did not eliminate the risk of developing ocular neovascularization in patients with CRVO ${ }^{(36,37)}$. However, CRUISE reported lower incidence of iris neovascularization and neovascular glaucoma in CRVO patients in ranibizumab-treated eyes when compared with sham-treated eyes ${ }^{(37)}$. In the RAVE, neovascular complication still occurred in $50 \%$ of patients with iCRVO following intravitreal ranibizumab during a follow-up period of 36 months ${ }^{(36)}$. Of these, $33 \%$ developed posterior segment neovascularization, $28 \%$ anterior segment neovascularization and $11 \%$ both ${ }^{(36)}$. In this study, 12 patients with iCRVO were assessed with WA-FFA and the extension of the area of non-perfusion continued to progress over time even with ranibizumab therapy ${ }^{(317)}$. In contrast, a retrospective post hoc analysis of CRUISE and BRAVO ${ }^{(42)}$ evaluating the effect of ranibizumab therapy on the area of retinal capillary non-perfusion on standard FFA found that in CRVO the percentage of patients with no capillary non-perfusion increased in 
ranibizumab-treated groups at six months (from $77.1 \%$ at baseline to $84 \%$ with $0.3 \mathrm{mg}$ ranibizumab and from 78.8 at baseline to $82 \%$ with $0.5 \mathrm{mg}$ ranibizumab) and was significantly greater than that of the sham group, which showed a decrease in the percentage of patients with no capillary non-perfusion from $83.0 \%$ at baseline to $67.0 \%$ at six months (42). Reperfusion of non-perfused retina was rare (1\%) in sham-treated patients with CRVO, but occurred in $6 \%$ to $8 \%$ of patients treated with ranibizumab ${ }^{(42)}$.

In BRVO, the percentage of patients with no capillary non-perfusion decreased in both ranibizumab-treated and sham treated groups over time but was significantly greater in the ranibizumab-treated group when compared to the sham-treated group ${ }^{(42)}$. Thus, $67 \%$ of sham-treated eyes had retinal capillary non-perfusion compared with approximately $50 \%$ of ranibizumab-treated eyes ${ }^{(42)}$. In BRIGHTER, none of the patients with BRVO developed iris or retinal neovascularization or neovascular glaucoma during the six-months follow-up period of the study; vitreous hemorrhage occurred in $0.06 \%$ of patients treated with ranibizumab, $1.1 \%$ of those receiving combined ranibizumab and laser photocoagulation and in none of those receiving laser monotherapy ${ }^{(288)}$.

A RCT by Epstein et al. ${ }^{(79)}$ that included a total of 60 patients with CRVO reported development of iris neovascularization in $16.7 \%$ of patients with CRVO at six months in the sham-treated group in comparison to none in the bevacizumab-treated group ${ }^{(79)}$.

Similar to the effects observed following intravitreal ranibizumab and bevacizumab, intravitreal aflibercept does not eliminate the risk of neovascularization in patients with iRVO but may reduce the risk of its development. Thus, GALILEO reported occurrence of anterior as well as posterior segment neovascularization secondary to CRVO in $2.9 \%$ of aflibercepttreated eyes in comparison to $4.4 \%$ of eyes in the sham-treated group at 24 -weeks; fourweekly aflibercept injections were given for the first 20 weeks in aflibercept treated eyes ${ }^{(128)}$. 
This difference was no longer observed at 76-weeks but aflibercept was administered as needed after 24 weeks in both groups. At 76-weeks, a higher incidence of anterior and posterior segment neovascularization than at 24 weeks follow-up was detected in both aflibercept-treated $(7.8 \%)$ and sham-treated eyes $(8.8 \%)^{(215)}$. COPERNICUS, which also administered four-weekly aflibercept for the first 20 weeks in the aflibercept treated group and as needed afterward in both groups, reported development of anterior segment neovascularization in none of the aflibercept-treated group, in comparison to $6.8 \%$ of patients with CRVO in the sham-treated group, at 12 months-follow-up, who then received PRP to treat the neovascularization ${ }^{(38)}$.

VIBRANT also administered aflibercept four-weekly for the first 20 weeks in the aflibercept group and as needed afterwards in both aflibercept and macular laser groups (see above), and reported retinal neovascularization secondary to BRVO in $3 \%$ of patients in the laser-treated group at six months but in none in the aflibercept-treated group ${ }^{(45)}$. The proportion of patients with a perfused retina (defined by the presence of $<10$ DA of capillary non-perfusion on FFA) at baseline was $60 \%$ in the aflibercept group and $69 \%$ in the laser group whereas at six months it increased to $80 \%$ in the aflibercept group but decreased to $67.1 \%$ in the laser treated group ${ }^{(45)}$.

A small RCT including 19 patients with iCRVO evaluated the effect on neovascular glaucoma, defined by the presence of iris or anterior chamber angle neovascularization and IOP greater than $22 \mathrm{mmHg}$, of a single intravitreal bevacizumab injection (1.25 $\mathrm{mg}$ ) followed by PRP one week after injection $(n=10)$ and compared it to that of PRP alone $(n=9)^{(315)}$. This study reported faster regression of iris/ angle neovascularization with the bevacizumab/PRP group than in the PRP group suggesting that intravitreal bevacizumab in combination with PRP is useful in the treatment of neovascular glaucoma by speeding up the resolution of iris/ angle neovascularization ${ }^{(315)}$. 
b. Steroids

In SCORE, intravitreal triamcinolone acetonide did not appear to modify the risk of development of ocular neovascularization, including iris neovascularization, neovascular glaucoma, posterior segment neovascularization and vitreous hemorrhage/pre-retinal hemorrhage, when compared with laser ${ }^{(49)}$. A multivariable analysis in SCORE-BRVO estimated a $9 \%$ increased risk of a neovascular event for each disc area of increase in retinal capillary non-perfusion at baseline ${ }^{(49)}$. Further analysis was undertaken in which disc areas of retinal capillary non-perfusion were considered a time-varying covariate from baseline and throughout the course of the follow-up using a multivariate Cox regression model. In this analysis for the SCORE-BRVO, there was a 5\% increase in hazard of a neovascular event for each disc area of increased retinal capillary non-perfusion, and 3.8 times increase in hazard for a neovascular event when comparing eyes with $\geq 5.5$ disc areas versus $<5.5$ disc areas of retinal capillary non-perfusion ${ }^{(49)}$. In contrast, in SCORE-CRVO multivariable analysis did not show significant associations of any baseline factors with neovascular events ${ }^{(49)}$.

In GENEVA, the incidence of retinal neovascularization was statistically significantly lower in the $0.7 \mathrm{mg}$ and $0.35 \mathrm{mg}$ DEX-treated groups $(0.7 \%$ and $1 \%$, respectively) than in the sham group $(2.6 \%)$ at six months for CRVO and BRVO ${ }^{(99)}$. However, a post-hoc analysis showed an increase in the mean area of overall non-perfusion and in the mean area of macular capillary non-perfusion from baseline to six months in both DEX and sham groups with no statistically significant differences between the two ${ }^{(257)}$. In a small prospective interventional study by Parodi et al. ${ }^{(25)}$ none of the 29 eyes with iCRVO $(\mathrm{n}=15)$ or iBRVO $(n=14)$ treated with DEX implant developed ocular neovascularization at 12 months following treatment ${ }^{(25)}$.

\section{c. Pars plana vitrectomy}


Vitrectomy could be expected to reduce, at least temporarily, the concentrations of intraocular angiogenic and inflammatory cytokines, such as VEGF and, subsequently may lower the risk of development of ocular neovascularization secondary to iRVO. Data, however, on the potential benefit of pars plana vitrectomy in patients with iCRVO is very scarce.

A prospective interventional study of 10 patients with iCRVO demonstrated that none of the patients treated with pars plana vitrectomy developed new vessels in the retina or disc, but iris neovascularization was still observed in $30 \%$ of patients at six months following surgery ${ }^{(174)}$. Neovascular glaucoma was reported in a prospective interventional study in five of 31 patients with CRVO (iCRVO=15; non-iCRVO=16) but in none of 19 patients with BRVO (iBRVO=6; non-iBRVO=13) following vitrectomy and internal limiting membrane peeling ${ }^{(186)}$. The very scarce data available, thus, suggests that pars plana vitrectomy does not prevent the occurrence of neovascularization.

Vitrectomy is, however, very useful to manage complications associated with RVO such as tractional retinal detachment, vitreous hemorrhage and epiretinal membrane and can result in improvement of the visual acuity in patients with BRVO with these complications ${ }^{(13,258,291,319)}$. It was also suggested that early vitrectomy before development of vitreoretinal proliferation and retinal detachment maybe beneficial for management of BRVO in patients with high risk of developing complications ${ }^{(291)}$. However, further studies are needed to confirm the benefit of early vitrectomy in these cases.

\section{B. Other therapies for ischemic RVO}

Several studies have been conducted to evaluate the role of other therapies, besides those mentioned above, for the treatment of iBRVO and iCRVO, but have not been approved either 
because they are still under investigation, they are impractical, have adverse effects or have no or limited benefit. Examples of these therapies are summarized below.

\section{Photodynamic therapy}

Photodynamic therapy (PDT) with verteporfin as a photosensitizer was evaluated for the treatment of anterior segment neovascularization secondary to iCRVO in an RCT and in a prospective interventional study ${ }^{(227,229)}$. The laser energy in PDT was directed to the anterior chamber angle and the iris using a Goldmann three-mirror contact lens ${ }^{(227,229)}$. In the RCT, patients with iCRVO, defined by the presence of $\geq 10$ DA of capillary non-perfusion on FFA and reduced $b$-wave amplitude on ERG, were randomized to PDT $(n=17)$, standard PRP $(n=19)$ and selective PRP $(n=20)$, the latter being performed only if iris/angle neovascularization showed progression on weekly follow-up ${ }^{(229)}$. At 12-months follow-up, the extension of iris neovascularization expressed in clock hours was 2.27, 0.52 and 2.55 in PDT, standard PRP and selective PRP groups, respectively, while the extension of anterior chamber angle neovascularization was $1.27,0.57$ and 1.50 clock hours, respectively. Regression of iris/ angle neovascularization was statistically significant only in the PRP group; the incidence of neovascular glaucoma did not differ between treatment groups ${ }^{(229)}$. A prospective interventional study including ten patients with iCRVO and iris/angle neovascularization suggested that PDT can partially obliterate anterior segment neovascularization ${ }^{(227)}$.

\section{Radial optic neurotomy (RON)}

Radial optic neurotomy (RON) was designed to release the pressure from the occluded central retinal vein. In RON, vitrectomy is performed and then an incision is made in the lamina cribrosa ${ }^{(216)}$. Several studies evaluated the efficacy and safety of RON $(10,16,24,41,88,186,189,216,262,313)$. ROVO (Radial Optic neurotomy for central Vein Occlusion study) randomized 83 patients with CRVO (both iCRVO, defined by the presence of $\geq 10$ DA of 
capillary non-perfusion on FFA and non-iCRVO) to three treatment groups, $\mathrm{RON}(\mathrm{n}=38)$, $\operatorname{IVTA}(\mathrm{n}=25)$ and sham $(\mathrm{n}=20)^{(10)}$. At 12-months, a statistically significant increase in visual acuity was detected in $47 \%$ of patients following RON when compared to $10 \%$ of sham and $20 \%$ of triamcinolone treated patients ${ }^{(10)}$. A statistically significantly higher number of patients in the sham group experienced visual acuity deterioration $(35 \%)$ (>3 logMAR lines of visual acuity loss) compared with those treated with RON $\left(8 \%{ }^{(10)}\right.$. In non-iCRVO, the median vision increased from $1 \log$ MAR (range, $0.72-1.35$ ) to $0.75 \log$ MAR (range, $0.45-$ 1.55) after 12 months; in iCRVO, the median visual acuity also increased from 1.09 logMAR (range, 0.97-2) to 0.9 logMAR (range, 0.71-2) after 12 months, with no statistically significant differences between iCRVO and non-iCRVO ${ }^{(10)}$. Smaller studies have provided mixed results with regard to benefits of $\mathrm{RON}$, and high rates of complications have been noted $^{(16,189,313)}$. In a prospective interventional study which included 13 patients with iCRVO, defined by the presence of $\geq 10$ DA of capillary non-perfusion, a significant improvement in visual acuity and retinal perfusion on FFA from baseline to one year were observed in 10 patients; chorioretinal anastomosis at the surgical site was also observed in ten patients following $\mathrm{RON}^{\left({ }^{88}\right)}$. A prospective interventional study including 13 patients with CRVO (iCRVO $=10$, indeterminate $=2$, perfused $=1$ ) showed an improvement of $\geq 2$ Snellen lines in six patients; in two of these the final visual acuity was $\leq 20 / 200^{(262)}$. Two patients developed neovascularization and underwent PRP, six showed visual field loss using Goldmann perimetry and three of those showed an absolute nerve fiber bundle defect at the surgical site ${ }^{(262)}$. Hence, beneficial effects of RON on vision have not been clearly demonstrated and RON is associated with its own potential complications and costs and has not been shown to prevent complications resulting from CRVO. Thus, RON is not a standard treatment for patients with iCRVO. 


\section{Chorioretinal Anastomosis}

Chorioretinal anastomosis was developed to allow blood to bypass the occluded vein into the choroidal blood vessels ${ }^{(52,73,163,192,193,195,233)}$. This procedure has been used to treat both CRVO and BRVO and can be undertaking by means of laser or surgery ${ }^{(52,73,163,192,193,195,233)}$. In non-iCRVO, a functionally effective chorioretinal anastomosis can be achieved in around one third to a half of patients; this however, is considerably more challenging and difficult to achieve in iCRVO ${ }^{(163)}$. Although a successful anastomosis may prevent ischemia from getting worse ${ }^{(193)}$, the visual results of chorioretinal anastomosis are poor ${ }^{(81,192,193)}$. Chorioretinal anastomosis is associated with many complications including vitreous hemorrhage, choroidal neovascularization, and pre-retinal fibrosis which were more pronounced in the ischemic form of CRVO ${ }^{(81,193)}$.

\section{Thrombolysis}

Thrombolysis using intravitreal or endovascular recombinant tissue plasminogen activator (rt-PA) has also been evaluated in small studies including patients with iCRVO $(78,82,105,106,254)$. These studies showed significant improvement of visual acuity in $36-71 \%$ of patients with iCRVO ${ }^{(78,82,93,105,106)}$ and a reduction in the area of retinal capillary nonperfusion if thrombolysis is initiated in the acute phase of $i \operatorname{RVO}^{(78,105,106)}$. However sufficient evidence is lacking to justify thrombolysis for RVO in clinical practice.

\section{Isovolemic hemodilution}

Isovolemic hemodilution has been investigated for the treatment of iRVO in several RCTs and prospective interventional studies ${ }^{(94,102,297,309,316)}$. This treatment aims at reducing the viscosity of the blood and increasing its fluidity ${ }^{(94,102,297,309,316)}$. Although many of these studies suggested an improvement in visual acuity following isovolumetric hemodilution $(94,102,297,309,316)$ due to the impracticality and complexity of this procedure, this treatment has not been adopted in clinical practice ${ }^{(40)}$. 


\section{Neuroprotective agents}

The efficacy of neuroprotective agents such as, minocycline, activated protein-C, glutamate antagonists and free radical scavengers (Edaravone MCI-186) has been evaluated in patients with iRVO ${ }^{(72,145,180,200,286)}$.

Minocycline is a broad-spectrum tetracycline antibiotic which was found to have neuroprotective effects and is currently under investigation in patients with BRVO.

Preliminary results on experimental studies suggest that minocycline can inhibit apoptosis of retinal ganglion cells and it has been suggested that using minocyclin in the acute stage of the disease could preserve retinal function ${ }^{(286)}$. A RCT on the effect of minocycline on RVO patients is currently under way (ClinicalTrials.gov Identifier: NCT01468844 and NCT01468831).

Experimental and clinical studies using intravitreal activated protein-C have shown reduction in retinal cell apoptosis secondary to iCRVO by blocking the activation of caspase$3,-8$ and $-9^{(72,145)}$. In a prospective interventional study of ten patients with macular edema secondary to iCRVO, significant reduction in central foveal thickness was reported in all patients following administration of intravitreal activated protein- ${ }^{(145)}$. Moreover, visual acuity significantly improved in $60 \%$ of patients and complete reperfusion of non-perfused retina was observed in $30 \%$ one year following treatment ${ }^{(145)}$. Thus, intravitreal protein-C appears to be a promising new therapy but requires further investigation.

\section{Cell therapy}

Cell therapy using bone marrow-derived stem cells or endothelial progenitor cells has also been suggested for the treatment of ischemic retinopathies ${ }^{(222,223,276,285)}$. These cells are believed to play an important role in tissue regeneration by promoting the repair of damaged retinal blood vessels to re-perfuse the ischemic areas of the retina. To date, there are only two 
case reports with only one patient with iCRVO in each, both suggest benefit of bone-marrow stem cells for the treatment of patients with iCRVO ${ }^{(222,276)}$. Further research into this area is warranted.

\section{Summary - Proposed characterization of the disease and practical points for the} clinician.

Ischemic retinal vein occlusion (iRVO) [including central (iCRVO), branch (iBRVO), hemicentral RVO and hemispheric RVO] poses significant risk of visual loss to those suffering from this vascular retinal disorder. Data available, contained in this review, suggests a more guarded prognosis for the natural history of patients with iRVO when compared with those with non-iRVO, independently of the definition of iRVO used. This appears also to be true for outcomes following treatment, although scarce data are available.

There is no widely accepted definition for iCRVO and iBRVO; the lack of agreement in diagnostic criteria used may explain reported differences in functional and anatomical outcomes observed as a result of the natural history of the disease or that modified by treatment. The CVOS and BVOS defined iCRVO and iBRVO by the presence of $>10 \mathrm{DA}$ and >5 DA of retinal capillary non-perfusion respectively. These definitions, which have been the ones most widely used in published studies, were based on risk of development of neovascularization.

Data available strongly suggest that the larger the area of retinal ischemia the higher the risk of visual loss and development of neovascular complications; it is unclear whether this risk depends not only on the extent but also on the location of the ischemia (i.e. peripheral, midperipheral, macular, perifoveal) and further information on this is needed. An agreement as to whether iRVO (iCRVO, iBRVO and ischemic hemi-central and hemispheric 
RVO) could be considered as a separate entity from non-iRVO and, if so, whether iRVO could be defined by a particular threshold of area of retinal ischemia would require an international consensus. In any case, the authors of the current review strongly encourage clinicians and researchers to determine the presence/absence, extent and location of areas of retinal ischemia in patients with any RVO. This information should be provided consistently in RVO studies and should be considered when evaluating outcomes of therapies. A proposed characterization of patients with RVO is provided in Figure 3.

Currently and until other imaging modalities (e.g. OCT-A) allow visualization of the entire retinal vascular tree, identification of areas of retinal ischemia by WA-FFA is the preferred method to be used. Determining the extent of the area of retinal ischemia in $\mathrm{mm}^{2}$ would be advisable; appropriate software that allows this measure to be obtained would be of great help. This and aiming to image as much of the retina as possible, even when using WA-FFA, is essential for adequate interpretation of the data and comparison between studies to be made. Ideally a WA-FFA should be obtained at presentation in patients with RVO, unless very marked and extensive retinal hemorrhages which could prevent adequate visualization of the retinal capillaries were present. Hemorrhages may be less of a problem when using scanning laser WA-FFA systems. Automated detection of areas of retinal ischemia would be ideal but, at present, this remains challenging. Determining the integrity of the perifoveal capillaries may be done now more accurately with the use of OCT-A than with WA-FFA (Figure 3).

With the evidence available and considering the time and staff limitations often encountered in clinical practice, the authors of this review recommend patients with CRVO at presentation to undergo visual acuity testing, testing of the pupillary reflex, preferably using neutral density filters (see section VI. Clinical Findings and Ancillary Studies above), WAFFA and SD-OCT. Presence/absence and degree of RAPD has been shown to strongly 
predict risk and, thus, should be included in clinical studies on CRVO. From the clinical perspective, current knowledge suggests that patients with CRVO and visual acuity of $<6 / 60$, an RAPD (of $\geq 0.9 \log$ units using neutral density filters) and extensive retinal capillary nonperfusion (ISI $\geq 45 \%$ on WA-FFA or $\geq 30$ DA if using standard FFA) are at high risk of developing neovascular complications (if not already present) and should be followed closely so timely treatment can be initiated. Patients should be also considered at high risk if marked and extensive retinal hemorrhages in four quadrants are present as these are likely to be associated with extensive retinal ischemia. Electrophysiology testing and visual fields have been shown to be also of prognostic value in CRVO but they are less accessible to clinicians and more difficult to obtain in busy retinal clinics. If obtained, several electrophysiology parameters are highly suggestive of patients with iCRVO having a higher risk of neovascular complications: prolonged implicit times in the $30 \mathrm{~Hz}$ flicker $(>37 \mathrm{~ms})$, reduction of $>60 \%$ of values obtained in the fellow healthy eye in the b-wave amplitude or b/a ratio of scotopic and/or photopic ERG, or photopic b-wave amplitude values of $<56 \mu \mathrm{V}$. Hand-held portable electrophysiology devices recently developed (RETeval $\left.{ }^{\circledR}\right)$ may facilitate electroretinography in clinical practice. As the risk of anterior segment neovascularization in iCRVO is highest in the first year following onset, especially during the first three months, monthly follow-up during this period has been recommended. Besides controlling underlying risk factors (hypertension, intraocular pressure), laser panretinal photocoagulation should be applied immediately if new vessels in the iris or anterior chamber angle, or posterior segment are detected. Data on the effect of therapeutic strategies for macular edema in patients with CRVO and retinal capillary non-perfusion is very scarce; most randomized clinical trials (RCTs) on CRVO did not include or included very few of these patients. Anti-VEGFs are advised to treat macular edema secondary to CRVO; their efficacy and cost-effectiveness in patients with retinal ischemia, however, remains to be elucidated. 
For patients presenting with BRVO, visual acuity, WA-FFA and OCT are advisable. Prognostic indicators for retinal ischemia and its complications have been less extensively studied in BRVO when compared with CRVO. Lower levels of vision at presentation $(<20 / 60)$ are most commonly observed in patients with retinal ischemia; the lower the presenting vision the more guarded the visual prognosis for the patient. Sector panretinal photocoagulation should be applied if new vessels develop but not prophylactically, just like for CRVO. In the presence of macular edema patients with BRVO should be treated with anti-VEGF therapy; the efficacy and cost-effectiveness of this treatment, in patients with retinal ischemia, however, remains to be elucidated.

\section{Conclusion}

Finding consensus on a definition of iRVO may be challenging. A separation between iRVO and non-iRVO may not be required, provided there is homogeneity on the phenotyping of patients with this disease and that important features determining risk are measured and are considered when managing patients with RVO and undertaking studies on this condition. Many studies have shown that retinal ischemia confers increased risk of sight loss and neovascular complications in patients with RVO. Information on the presence, extent and location of areas of retinal ischemia should be provided in studies evaluating RVO. To date, no treatments are available to prevent or treat retinal ischemia; research on this area is urgently needed. 


\section{Method of Literature Search}

Five databases were searched including Medline, EMBASE, SCOPUS, Web of Science and Cochrane library with no years' limitations. Keywords included retinal vein occlusion, retinal venous thrombosis, retinal venous obstruction, central retinal vein occlusion, and branch retinal vein occlusion which were combined with ischemic, non-perfused or proliferative terms. Further search was conducted combining the stated keywords with epidemiology, prevalence, incidence, risk factors for the epidemiology and risk factors sections;

mechanisms, pathogenesis, macular edema, neovascularization, the different retinal cells, and experimental models for the etiology and pathogenesis section; the different ancillary technologies for the ancillary studies section; natural history for the natural history section; and the different therapies for the management section. From the literature retrieved, only articles that provided data on the ischemic form of RVO, specifically, or differentiated between iRVO and non-iRVO were included. For the current treatments section, priority was given to RCTs while prospective interventional studies were included only if $\geq 10$ patients with iRVO were studied. Retrospective studies that reviewed $\geq 100$ patients' records were planned to be included but none of the retrieved articles met this criterion. All articles included were limited to the English language.

\section{Acknowledgement}

The Authors would like to acknowledge the support of King Abdulaziz University, the Saudi Arabian Cultural Bureau in London (grant number R8384CEM), and of Miss Elizabeth Sloan. 
Figure-1: Fluorescein angiogram (left) obtained from the right eye of a patient with ischemic central retinal vein occlusion. Marked retinal capillary drop out is observed. A relative preservation of the capillaries around the foveal avascular zone is, however, observed. Marked intraretinal edema was evident on spectral domain optical coherence tomography (right). Visual acuity was 9 ETDRS letters.

Figure-2: Fluorescein angiogram of a patient with ischemic branch retinal vein occlusion. Note marked macular and midperipheral retinal non-perfusion. Breakdown of the perifoveal capillary network was noted (inset).

Figure-3: (A) Diagram depicting the proposed strategy to identify and classify retinal ischaemia in retinal vein occlusion (RVO). Wide angle fundus fluorescein angiography (FFA) would allow visualisation of a large proportion of retina. Then, areas of retinal ischaemia within the midperipheral / peripheral retina (all areas outside the central red circle) could be marked and measured in $\mathrm{mm}^{2}$ using appropriate software. In order to determine the area of macular ischemia, a central area with a diameter of $5.5 \mathrm{~mm}$ centered at the fovea could be drawn (red circle) and retinal capillary drop-out within this region measured in $\mathrm{mm}^{2}$. Magnification of the centre of the macula showing the perifoveal capillary network (top, right). Drop-out of perifoveal capillaries could be then specified in clock hours (yellow circle). For this purpose, optical coherence tomography angiography (OCT-A) could be also used (B). For all patients with RVO, total area of visible retina, total area of capillary dropout in the midperipheral/peripheral retina and macula and extent of drop-out of perifoveal capillaries in clock hours, should be provided. 


\begin{tabular}{|c|c|c|}
\hline Author & Year & Information provided on the ischemic status of patients included \\
\hline BVOS $^{(1)}$ group III & 1984 & $\begin{array}{l}\text { Excluded patients with foveal capillary non-perfusion } \\
\text { No data available separately iBRVO and non-iBRVO }\end{array}$ \\
\hline $\mathrm{CVOS}^{(4)}$ group M & 1995 & $\begin{array}{l}\text { Excluded patients with macular non-perfusion, retinal neovascularization and vitreous } \\
\text { hemorrhage } \\
\text { Only } 21 / 155(14 \%) \text { eyes had } \geq 10 \text { DA of retinal capillary non-perfusion } \\
\text { No data available separately for iCRVO and non-iCRVO }\end{array}$ \\
\hline $\begin{array}{l}\text { SCORE-CRVO } \\
\text { Ip et al. }{ }^{(137)}\end{array}$ & 2009 & $\begin{array}{l}\text { Only } 3 / 271(1 \%) \text { patients had } \geq 10 \text { DA of retinal capillary non-perfusion } \\
\text { No data available separately for iCRVO and non-iCRVO }\end{array}$ \\
\hline $\begin{array}{l}\text { SCORE-BRVO } \\
\text { Scott et al. }\end{array}$ & 2009 & $\begin{array}{l}\text { Only } 41 / 411(10 \%) \text { patients with } \geq 5 \text { DA of retinal capillary non-perfusion } \\
\text { No data available separately for iBRVO and non-iBRVO }\end{array}$ \\
\hline $\begin{array}{l}\text { CRUISE } \\
\text { Brown et al. }{ }^{(37)}\end{array}$ & 2010 & $\begin{array}{l}\text { Excluded patients with RAPD } \\
\text { Only } 2 / 392(0.5 \%) \text { patients had } \geq 10 \text { DA of retinal capillary non-perfusion }\end{array}$ \\
\hline $\begin{array}{l}\text { BRAVO } \\
\text { Campochiaro et } \\
\text { al. }^{\left({ }^{3}\right)}\end{array}$ & 2010 & 0/397 (0\%) patients had $\geq 10 \mathrm{DA}$ of retinal capillary nonperfusion \\
\hline $\begin{array}{l}\text { GENEVA } \\
\text { Haller et al. }{ }^{(99)}\end{array}$ & 2010 & $\begin{array}{l}\text { Excluded patients with ocular neovascularization } \\
\text { No data available separately for iRVO and non-iRVO }\end{array}$ \\
\hline $\begin{array}{l}\text { ROCC } \\
\text { Kinge et al. }{ }^{(153)}\end{array}$ & 2010 & $\begin{array}{l}\text { Only } 5 / 24(21 \%) \text { patients with } \geq 10 \text { DA of retinal capillary non-perfusion } \\
\text { No data available separately for iCRVO and non-iCRVO }\end{array}$ \\
\hline Epstein et al. ${ }^{(79)}$ & 2012 & No data available separately for iCRVO and non-iCRVO \\
\hline $\begin{array}{l}\text { HORIZON } \\
\text { Heier et al. }{ }^{(124)}\end{array}$ & 2012 & No data available separately for $\mathrm{iRVO}$ and non-iRVO \\
\hline $\begin{array}{l}\text { GALILEO } \\
\text { Holz et al. }{ }^{(128)}\end{array}$ & 2013 & $\begin{array}{l}\text { Only } 14 / 177(8 \%) \text { patients with } \geq 10 \text { DA of retinal capillary non-perfusion } \\
\text { No data available separately for iCRVO and non-iCRVO }\end{array}$ \\
\hline $\begin{array}{l}\text { RETAIN } \\
\text { Campochiaro et } \\
\text { al. }{ }^{(44)}\end{array}$ & 2014 & No data available separately for iRVO and non-iRVO \\
\hline $\begin{array}{l}\text { RELATE } \\
\text { Campochiaro et } \\
\text { al. }{ }^{(46)}\end{array}$ & 2015 & No data available separately for $\mathrm{iRVO}$ and non-iRVO \\
\hline $\begin{array}{l}\text { MARVEL } \\
\text { Narayanan et al. }{ }^{(202)}\end{array}$ & 2015 & No data available separately for iBRVO and non-iBRVO \\
\hline $\begin{array}{l}\text { RABAMES } \\
\text { Pielen et al. }\end{array}$ & 2015 & $\begin{array}{l}\text { Excluded patients with macular ischemia and neovascular complications } \\
0 / 30 \text { patients }(0 \%) \text { had } \geq 10 \text { DA of retinal capillary non-perfusion }\end{array}$ \\
\hline
\end{tabular}

$\mathrm{iBRVO}=$ ischemic branch retinal vein occlusion; $\mathrm{iCRVO}=$ ischemic central retinal vein occlusion; $\mathrm{DA}=\mathrm{disc}$ areas; RAPD = relative afferent pupillary defect 


\begin{tabular}{|c|c|c|c|}
\hline $\begin{array}{l}\text { Diagnostic } \\
\text { modality }\end{array}$ & Parameter & Findings & Study \\
\hline \multirow[t]{2}{*}{ Visual acuity } & $\leq 6 / 120$ & $\begin{array}{l}\text { Sensitivity } 91-100 \% \\
\text { Specificity } 78-88 \%\end{array}$ & Hayreh et al., $1990^{(123)}$ \\
\hline & $\leq 6 / 60$ & $\begin{array}{l}85 \% \text { of patients with iCRVO } \\
\text { have visual acuity } \leq 6 / 60\end{array}$ & Hayreh et al., $2011^{(119)}$ \\
\hline \multirow[t]{4}{*}{$\begin{array}{l}\text { Pupillary } \\
\text { examination }\end{array}$} & RAPD $\geq 0.6$ Log unit & $\begin{array}{l}\text { Sensitivity } 83 \% \\
\text { Specificity } 70 \%\end{array}$ & Bloom et al., $1993^{(31)}$ \\
\hline & RAPD $\geq 0.7$ Log unit & $\begin{array}{l}\text { Sensitivity } 88 \% \\
\text { Specificity } 90 \%\end{array}$ & Hayreh et al., $1990^{(123)}$ \\
\hline & PAPD $\geq 0.9$ Log unit & $\begin{array}{l}\text { Sensitivity } 80 \% \\
\text { Specificity } 97 \%\end{array}$ & Hayreh et al $1990^{(123)}$ \\
\hline & RAPD $\geq 1.2$ Log Unit & $\begin{array}{l}\text { All eyes with ocular NV and/or } \\
\text { extensive retinal CNP had RAPD } \\
\text { of } \geq 1.2 \log \text { units ND }\end{array}$ & Servias et al., $1986^{(267)}$ \\
\hline \multirow{3}{*}{$\begin{array}{l}\text { Visual field } \\
\text { Goldmann } \\
\text { perimetry }\end{array}$} & I2e defect & $\begin{array}{l}\text { Sensitivity } 94-100 \% \\
\text { Specificity } 67-78 \%\end{array}$ & \multirow[t]{3}{*}{ Hayreh et al., $1990^{(123)}$} \\
\hline & I4e defect & $\begin{array}{l}\text { Sensitivity } 92 \% \\
\text { Specificity } 87 \%\end{array}$ & \\
\hline & V4e defect & $\begin{array}{l}\text { Sensitivity } 71-82 \% \\
\text { Specificity } 83-88 \%\end{array}$ & \\
\hline \multirow[t]{9}{*}{ ERG } & $\begin{array}{l}\text { Reduction of b-wave } \\
\text { amplitude by }>60 \% \text { of } \\
\text { normal fellow eye } \\
\text { (in photopic and scotopic } \\
\text { ERG) }\end{array}$ & $\begin{array}{l}\text { Sensitivity } 80-90 \% \\
\text { Specificity } 71-80 \% \\
\end{array}$ & \multirow[t]{2}{*}{ Hayreh et al., $1990^{(123)}$} \\
\hline & $\begin{array}{l}\text { Reduction of b/a ratio by }> \\
60 \% \text { of normal fellow eye } \\
\text { (in photopic and scotopic } \\
\text { ERG) }\end{array}$ & $\begin{array}{l}\text { Sensitivity } 60-70 \% \\
\text { Specificity } 70 \%\end{array}$ & \\
\hline & $\begin{array}{l}\mathrm{b} / \mathrm{a} \text { ratio }=0.88 \\
\text { in photopic ERG }\end{array}$ & $\begin{array}{l}\text { Sensitivity } 87.5 \% \\
\text { Specificity } 78 \%\end{array}$ & \multirow[t]{3}{*}{ Williamson et al., $1997^{(312)}$} \\
\hline & $\begin{array}{l}\text { b-wave amplitude }=56 \mu \mathrm{V} \\
\text { in photopic ERG }\end{array}$ & $\begin{array}{l}\text { Sensitivity } 87.5 \% \\
\text { Specificity } 86 \%\end{array}$ & \\
\hline & $\begin{array}{l}\text { b-wave amplitude }=76 \mu \mathrm{V} \\
\text { in photopic ERG }\end{array}$ & $\begin{array}{l}\text { Sensitivity } 100 \% \\
\text { Specificity } 66 \%\end{array}$ & \\
\hline & $\begin{array}{l}\text { Implicit time of }>35 \mathrm{~ms} \\
\text { in } 30 \mathrm{~Hz} \text { flicker }\end{array}$ & $\begin{array}{l}\text { All patients with iCRVO had } \\
\text { implicit time } \geq 35.0 \mathrm{~ms}\end{array}$ & Kjeka et al., $2013^{(155)}$ \\
\hline & $\begin{array}{l}\text { Implicit time of } \geq 37 \mathrm{~ms} \\
\text { in } 30 \mathrm{~Hz} \text { flicker }\end{array}$ & $\begin{array}{l}75 \% \text { of patients with an implicit } \\
\text { time of }>37 \text { ms developed ocular } \\
\mathrm{NV} \text { during the follow-up period } \\
\text { of one year compared to } 7 \% \text { of } \\
\text { CRVO patients with an implicit } \\
\text { time of } \leq 37 \mathrm{~ms}\end{array}$ & Hvarfner et al., $2003^{(131)}$ \\
\hline & $\begin{array}{l}\text { Interocular amplitude } \\
\text { difference }=23 \mu \mathrm{V} \\
\text { in } 30 \mathrm{~Hz} \text { flicker }\end{array}$ & $\begin{array}{l}\text { Sensitivity } 100 \% \\
\text { Specificity } 100 \%\end{array}$ & \multirow[t]{2}{*}{ Kuo et al., $2010^{(162)}$} \\
\hline & $\begin{array}{l}\text { Interocular amplitude ratio of } \\
60 \% \text { in } 30 \mathrm{~Hz} \text { flicker }\end{array}$ & $\begin{array}{l}\text { Sensitivity } 100 \% \\
\text { Specificity } 100 \%\end{array}$ & \\
\hline $\begin{array}{l}\text { RAPD and ERG } \\
\text { combined }\end{array}$ & $\begin{array}{l}\geq 0.7 \text { log unit RAPD and } \\
\leq 60 \% \text { b-wave amplitude }\end{array}$ & $\begin{array}{l}\text { Sensitivity } 97-100 \% \\
\text { Specificity } 71 \%\end{array}$ & Hayreh et al., $1990^{(123)}$ \\
\hline
\end{tabular}




\begin{tabular}{|l|l|l|l|}
\hline $\begin{array}{l}\text { Ophthalmo- } \\
\text { dynamometry }\end{array}$ & $\begin{array}{l}\text { Central retinal venous } \\
\text { pressure }>\text { diastolic central } \\
\text { retinal arterial pressure }\end{array}$ & $\begin{array}{l}\text { All patients with iCRVO had } \\
\text { central retinal venous pressure } \\
\text { diastolic central retinal arterial } \\
\text { pressure }\end{array}$ & $\begin{array}{l}\text { McAllister et al., 2014; Jonas } \\
\text { \& Harder, 2007; Do et al., } \\
\text { 2008 (68,141,194) }\end{array}$ \\
\hline
\end{tabular}

$\mathrm{iCRVO}=$ ischemic central retinal vein occlusion; $\mathrm{DA}=$ disc areas; RAPD = relative afferent pupillary defect; $\mathrm{NV}=$ neovascularization; $\mathrm{CNP}=$ capillary non-perfusion; $\mathrm{ND}=$ natural density; $\mathrm{ERG}=$ electroretinography; $\mu \mathrm{V}=$ microvolt; $\mathrm{ms}=$ millisecond; $\mathrm{Hz}=$ Hertz unit. 
ACCEPTED MANUSCRIPT

\begin{tabular}{|c|c|c|c|}
\hline $\begin{array}{l}\text { Diagnostic } \\
\text { modality }\end{array}$ & Parameter & Finding & Study \\
\hline Ophthalmoscopy & $\begin{array}{l}\text { Retinal hemorrhage } \geq 1 / 4 \text { of } \\
\text { posterior retina }\end{array}$ & $\begin{array}{l}\text { Sensitivity } 81-84 \% \\
\text { Specificity } 72-74 \%\end{array}$ & Hayreh et al., $2014^{(116)}$ \\
\hline \multirow[t]{4}{*}{ FFA } & $\begin{array}{l}\geq 10 \text { DA of retinal CNP } \\
\text { (ischemic index } \geq 50 \% \text { ) }\end{array}$ & $\begin{array}{l}* 93 \% \text { of eyes with NVG } \\
\text { secondary to iCRVO have } \\
\text { ischemic index } \geq 50 \% \\
* 91 \% \text { of eyes with retina/disc NV } \\
\text { secondary to iCRVO have } \\
\text { ischemic index } \geq 50 \% \\
* 33 \% \text { and } 45 \% \text { of eyes with } \\
\text { ischemic index } \geq 50 \% \text { developed } \\
\mathrm{NV} \text { in retina/disc and NVG, } \\
\text { respectively }\end{array}$ & Magargal et al., $1982^{(183)}$ \\
\hline & 10-29 DA of retinal CNP & $\begin{array}{l}16 \% \text { of patients with iCRVO } \\
\text { developed anterior segment NV }\end{array}$ & \multirow[t]{2}{*}{ CVOS, $1997^{(6)}$} \\
\hline & $\geq 75$ DA of retinal CNP & $\begin{array}{l}52 \% \text { of patients developed } \\
\text { anterior segment NV }\end{array}$ & \\
\hline & $\begin{array}{l}\text { Ischemic index } \geq 45 \% \text { on } \\
\text { WA-FFA }\end{array}$ & $\begin{array}{l}\text { All patients with NV (any) had } \\
\text { ischemic index } \geq 45 \% \text {. }\end{array}$ & Tsui et al., $2011^{(300)}$ \\
\hline
\end{tabular}

$\mathrm{iCRVO}=$ ischemic central retinal vein occlusion; $\mathrm{FFA}=$ fundus fluorescein angiography; $\mathrm{DA}=$ disc areas; $\mathrm{CNP}=$ capillary non-perfusion; $\mathrm{NVG}=$ Neovascular glaucoma; $\mathrm{NV}=$ neovascularization; WA-FFA $=$ wide-angle fundus fluorescein angiography. 


\section{References}

1. Argon laser photocoagulation for macular edema in branch vein occlusion. A randomized clinical trial. the branch vein occlusion study group. Am J Ophthalmol. 1984 Sep;98(3):27182 .

2. Argon laser scatter photocoagulation for prevention of neovascularization and vitreous hemorrhage in branch vein occlusion. A randomized clinical trial. the branch vein occlusion study group. Arch Ophthalmol. 1986 Jan;104(1):34-41.

3. Risk factors for branch retinal vein occlusion. the eye disease case-control study group. Am J Ophthalmol. 1993 Sep;116(3):286-96.

4. Evaluation of grid pattern photocoagulation for macular edema in central vein occlusion. the central vein occlusion study group M report. Ophthalmology. 1995 Oct;102(10):1425-33.

5. Risk factors for central retinal vein occlusion. the eye disease case-control study group. Arch Ophthalmol. 1996 May;114(5):545-54.

6. A randomized clinical trial of early panretinal photocoagulation for ischemic central vein occlusion. the central vein occlusion study group $\mathrm{N}$ report. Ophthalmology. 1997 Oct;102(10):1434-44.

7. AbdelKader M., ElDessouky WM. Multifocal electroretinogram in retinal vein occlusion. Saudi Journal of Ophthalmology. 2010 Oct;24(4):125-32.

8. Abu el-Asrar AM, al-Momen AK, al-Amro S, Abdel Gader AG, Tabbara KF. Prothrombotic states associated with retinal venous occlusion in young adults. Int Ophthalmol. 1996 Jul;20(4):197-204.

9. Adamis AP, Shima DT, Tolentino MJ, Gragoudas ES, Ferrara N, Folkman J, et al. Inhibition of vascular endothelial growth factor prevents retinal ischemia-associated iris neovascularization in a nonhuman primate. Arch Ophthalmol. 1996 Jan;114(1):66-71.

10. Aggermann T, Brunner S, Krebs I, Haas P, Womastek I, Brannath W, et al. A prospective, randomised, multicenter trial for surgical treatment of central retinal vein occlusion: Results of the radial optic neurotomy for central vein occlusion (ROVO) study group. Graefes Arch Clin Exp Ophthalmol. 2013 Apr;251(4):1065-72.

11. Aghdam KA, Reznicek L, Sanjari MS, Framme C, Bajor A, Klingenstein A, et al. Peripheral retinal non-perfusion and treatment response in branch retinal vein occlusion. Int $\mathbf{J}$ Ophthalmol. 2016 Jun;9(6):858-62.

12. Alshareef RA, Chhablani J. Neurodegeneration in branch retinal vein occlusion. Neural Regeneration Research. 2016 Sep;11(9):1414.

13. Amirikia A, Scott I, Murray T, Flynn JH, Smiddy W, Feuer W. Outcomes of vitreoretinal surgery for complications of branch retinal vein occlusion. Ophthalmology. 2001 Feb;108(2):372-6. 
14. Apostolopoulos M, Koutsandrea C, Chatjoulis D, Ladas J, Theodossiadis G. Late complications in branch retinal vein occlusion. Int Ophthalmol. 1995 Sep;19(5):281-5.

15. Arakawa S, Yasuda M, Nagata M, Ninomiya T, Hirakawa Y, Doi Y, et al. Nine-year incidence and risk factors for retinal vein occlusion in a general japanese population: The hisayama study. Invest Ophthalmol Vis Sci. 2011 Jul;52(8):5905-9.

16. Arevalo JF, Garcia RA, Wu L, Rodriguez FJ, Dalma-Weiszhausz J, Quiroz-Mercado H, et al. Radial optic neurotomy for central retinal vein occlusion: Results of the pan-american collaborative retina study group (PACORES). Retina. 2008 Oct;28(8):1044-52.

17. Arsene S, Giraudeau B, Le Lez M, Pisella PJ, Pourcelot L, Tranquart F. Follow up by colour doppler imaging of 102 patients with retinal vein occlusion over 1 year. Br J Ophthalmol. 2002 Nov;86(11):1243-7.

18. Arvas S, Ocakoglu O, Ozkan S. The capillary blood flow in ischemic type central retinal vein occlusion: The effect of laser photocoagulation. Acta Ophthalmol Scand. 2002 Oct;80(5):490-4.

19. Attariwala R, Jensen PS, Glucksberg MR. The effect of acute experimental retinal vein occlusion on cat retinal vein pressures. Invest Ophthalmol Vis Sci. 1997 Dec;38(13):2742-9.

20. Avunduk AM, Dinc H, Kapicioglu Z, Ugurlu S, Dayanir V, Korkmaz E. Arterial blood flow characteristics in central retinal vein occlusion and effects of panretinal photocoagulation treatment: An investigation by colour doppler imaging. Br J Ophthalmol. 1999 Jan;83(1):50-3.

21. Awdeh RM, Elsing SH, Deramo VA, Stinnett S, Lee PP, Fekrat S. Vision-related quality of life in persons with unilateral branch retinal vein occlusion using the 25-item national eye institute visual function questionnaire. Br J Ophthalmol. 2010 Mar;94(3):319-23.

22. Bajric J, Bakri SJ. Outcomes of patients initially treated with intravitreal bevacizumab for central retinal vein occlusion: Long-term follow-up. Seminars in ophthalmology. 2016 Nov;31(6):542-7.

23. Bandello F, Vigano D'Angelo S, Parlavecchia M, Tavola A, Della Valle P, Brancato R, et al. Hypercoagulability and high lipoprotein(a) levels in patients with central retinal vein occlusion. Thrombosis \& Haemostasis. 1994 Jul;72(1):39-43.

24. Barak A, Kesler A, Gold D, Loewenstein A. Visual field defects after radial optic neurotomy for central retinal vein occlusion. Retina. 2006 May-Jun;26(5):549-54.

25. Battaglia Parodi M, Iacono P, Sacconi R, Parravano M, Varano M, Bandello F. Dexamethason implant for macular edema secondary to central retinal vein occlusion in patients younger than 50 years. Retina. $2015 \mathrm{Jul} ; 35(7): 1381-6$.

26. Baxter GM, Williamson TH. The value of serial doppler imaging in central retinal vein occlusion: Correlation with visual recovery. Clin Radiol. 1996 Jun;51(6):411-4. 
27. Bertelmann T, Kicova N, Mennel S, Schmidt J, Irle S, Sekundo W, et al. The impact of posterior vitreous adhesion on ischemia in eyes with retinal vein occlusion. Acta Ophthalmol. $2016 \mathrm{Feb} ; 94(1): \mathrm{e} 43-8$.

28. Bessho K, Gomi F, Harino S, Sawa M, Sayanagi K, Tsujikawa M, et al. Macular autofluorescence in eyes with cystoid macula edema, detected with $488 \mathrm{~nm}$-excitation but not with 580 nm-excitation. Graefes Arch Clin Exp Ophthalmol. 2009 Jun;247(6):729-34.

29. Beutel J, Ziemssen F, Luke M, Partsch M, Bartz-Schmidt K, Bevacizumab Study Group, et al. Intravitreal bevacizumab treatment of macular edema in central retinal vein occlusion: One-year results. Int Ophthalmol. 2010 Feb;30(1):15-22.

30. Bezatis A, Spital G, Hohn F, Maier M, Clemens CR, Wachtlin J, et al. Functional and anatomical results after a single intravitreal ozurdex injection in retinal vein occlusion: A 6month follow-up -- the SOLO study. Acta Opthalmologica. 2013 Aug;91(5):e340-7.

31. Bloom PA, Papakostopoulos D, Gogolitsyn Y, Leenderz JA, Papakostopoulos S, Grey RH. Clinical and infrared pupillometry in central retinal vein occlusion. Br J Ophthalmol. $1993 \mathrm{Feb} ; 77(2): 75-80$.

32. Boyd SR, Zachary I, Chakravarthy U, Allen GJ, Wisdom GB, Cree IA, et al. Correlation of increased vascular endothelial growth factor with neovascularization and permeability in ischemic central vein occlusion. Arch Ophthalmol. 2002 Dec;120(12):1644-50.

33. Bradshaw SE, Gala S, Nanavaty M, Shah A, Mwamburi M, Kefalas P. Systematic literature review of treatments for management of complications of ischemic central retinal vein occlusion. BMC ophthalmology. 2016;16(1):104.

34. Bringmann A, Uckermann O, Pannicke T, Iandiev I, Reichenbach A, Wiedemann P. Neuronal versus glial cell swelling in the ischemic retina. Acta Ophthalmol Scand. 2005 Sep;83(5):528-38.

35. Bringmann A, Reichenbach A, Wiedemann P. Pathomechanisms of cystoid macular edema. Ophthalmic Res. 2004 Sep-Oct;36(5):241-9.

36. Brown DM, Wykoff CC, Wong TP, Mariani AF, Croft DE, Schuetzle KL, et al. Ranibizumab in preproliferative (ischemic) central retinal vein occlusion: The rubeosis antiVEGF (RAVE) trial. Retina. 2014 Sep;34(9):1728-35.

37. Brown DM, Campochiaro PA, Singh RP, Li Z, Gray S, Saroj N, et al. Ranibizumab for macular edema following central retinal vein occlusion: Six-month primary end point results of a phase III study. Ophthalmology. 2010 Jun;117(6):1124-33.

38. Brown DM, Heier JS, Clark WL, Boyer DS, Vitti R, Berliner AJ, et al. Intravitreal aflibercept injection for macular edema secondary to central retinal vein occlusion: 1-year results from the phase 3 COPERNICUS study. Am J Ophthalmol. 2013 Mar;155(3):429-37.

39. Browning D. Ischemia and retinal vein occlusions. In: Browning D, editor. Retinal Vein Occlusion Evidence-based Management. 1st ed. New York: Springer Science+Business Media; 2012. p. 223-36. 
40. Browning D. Treatment of retinal vein occlusions. In: Retinal Vein Occlusion Evidencebased Management. New York: Springer Science+Business Media; 2012. p. 279-322.

41. Callizo J, Kroll P, Mennel S, Schmidt JC, Meyer CH. Radial optic neurotomy for central retinal vein occlusion: Long-term retinal perfusion outcome. Ophthalmologica.

2009;223(5):313-9.

42. Campochiaro PA, Bhisitkul RB, Shapiro H, Rubio RG. Vascular endothelial growth factor promotes progressive retinal nonperfusion in patients with retinal vein occlusion. Ophthalmology. 2013 Apr;120(4):795-802.

43. Campochiaro PA, Heier JS, Feiner L, Gray S, Saroj N, Rundle AC, et al. Ranibizumab for macular edema following branch retinal vein occlusion: Six-month primary end point results of a phase III study. Ophthalmology. 2010 Jun;117(6):1102-12.

44. Campochiaro PA, Sophie R, Pearlman J, Brown DM, Boyer DS, Heier JS, et al. Longterm outcomes in patients with retinal vein occlusion treated with ranibizumab: The RETAIN study. Ophthalmology. 2014 Jan;121(1):209-19.

45. Campochiaro PA, Clark WL, Boyer DS, Heier JS, Brown DM, Vitti R, et al. Intravitreal aflibercept for macular edema following branch retinal vein occlusion: The 24-week results of the VIBRANT study. Ophthalmology. 2015 Mar;122(3):538-44.

46. Campochiaro PA, Hafiz G, Mir TA, Scott AW, Solomon S, Zimmer-Galler I, et al. Scatter photocoagulation does not reduce macular edema or treatment burden in patients with retinal vein occlusion: The RELATE trial. Ophthalmology. 2015 Jul;122(7):1426-37.

47. Campochiaro PA, Hafiz G, Mir TA, Scott AW, Sophie R, Shah SM, et al. Propermeability factors after dexamethasone implant in retinal vein occlusion; the ozurdex for retinal vein occlusion (ORVO) study. Am J Ophthalmol. 2015 Aug;160(2):313,321.e19.

48. Capone AJ, Singer MA, Dodwell DG, Dreyer RF, Oh KT, Roth DB, et al. Efficacy and safety of two or more dexamethasone intravitreal implant injections for treatment of macular edema related to retinal vein occlusion (shasta study). Retina. 2014 Feb;34(2):342-51.

49. Chan CK, Ip MS, Vanveldhuisen PC, Oden NL, Scott IU, Tolentino MJ, et al. SCORE study report \#11: Incidences of neovascular events in eyes with retinal vein occlusion. Ophthalmology. 2011 Jul;118(7):1364-72.

50. Chen H, Chen M, Lai C, Yeung L, Wang N, Chen H, et al. Neovascular glaucoma after central retinal vein occlusion in pre-existing glaucoma. BMC Ophthalmol. 2014 Oct;14(1):119.

51. Chen SDM, Sundaram V, Lochhead J, Patel CK. Intravitreal triamcinolone for the treatment of ischemic macular edema associated with branch retinal vein occlusion. Am J Ophthalmol. 2006 May;141(5):876-83.

52. Chen S, Huang Y. Full-thickness retinochoroidal incision in the management of central retinal vein occlusion. J Ophthalmol. 2015 Jan;2015:e1-7. 
53. Choi W, Mohler KJ, Potsaid B, Lu CD, Liu JJ, Jayaraman V, et al. Choriocapillaris and choroidal microvasculature imaging with ultrahigh speed OCT angiography. PLoS One. 2013 Dec;8(12):e81499.

54. Chopdar A. Hemispheric retinal vein occlusion or hemicentral retinal vein occlusion. Arch Ophthalmol. 1986 Aug;104(8):1128.

55. Chopdar A. Hemi-central retinal vein occlusion. pathogenesis, clinical features, natural history and incidence of dual trunk central retinal vein. Trans Ophthalmol Soc UK. 1982 Jul;102(2):241-8.

56. Chopdar A. Dual trunk central retinal vein incidence in clinical practice. Arch Ophthalmol. 1984 Jan;102(1):85-7.

57. Chua B, Kifley A, Wong TY, Mitchell P. Homocysteine and retinal vein occlusion: A population-based study. Am J Ophthalmol. 2005 Jan;139(1):181-2.

58. Clark WL, Boyer DS, Heier JS, Brown DM, Haller JA, Vitti R, et al. Intravitreal aflibercept for macular edema following branch retinal vein occlusion 52-week results of the VIBRANT study. Ophthalmology. 2016 Feb;123(2):330-6.

59. Coscas F, Glacet-Bernard A, Miere A, Caillaux V, Uzzan J, Lupidi M, et al. Optical coherence tomography angiography in retinal vein occlusion: Evaluation of superficial and deep capillary plexa. Am J Ophthalmol. 2016 Jan;161:160-71.

60. Coscas G, Gaudric A. Collateral circulations and new vessels in retinal branch vein occlusions. II. new vessels. Arch Ophtalmol Rev Gen Ophtalmol. 1977 Jan;37(10):597-612.

61. Cugati S, Wang JJ, Rochtchina E, Mitchell P. Ten-year incidence of retinal vein occlusion in an older population: The blue mountains eye study. Arch Ophthalmol. 2006 May;124(5):726-32.

62. Cunha-Vaz J, Travassos A. Breakdown of the blood-retinal barriers and cystoid macular edema. Surv Ophthalmol. 1984 May;28(2):485-92.

63. Danis R, Wallow I. Microvascular changes in experimental branch retinal vein occlusion. Ophthalmology. 1987 Oct;94(10):1213-21.

64. Danis R, Yang Y, Massicotte S, Boldt H. Preretinal and optic nerve head neovascularization induced by photodynamic venous thrombosis in domestic pigs. Arch Ophthalmol. 1993 Apr;111(4):539-43.

65. DeCroos FC, Todorich B, Alshareef R, Khuthaila M, Fekrat S, Ho AC, et al. Neovascular events in eyes with central retinal vein occlusion undergoing serial bevacizumab or ranibizumab intravitreal injections: A retrospective review. J Ophthalmic Vis Res. 2014 OctDec;9(4):461-8.

66. DeCroos FC, Shuler RKJ, Stinnett S, Fekrat S. Pars plana vitrectomy, internal limiting membrane peeling, and panretinal endophotocoagulation for macular edema secondary to central retinal vein occlusion. Am J Ophthalmol. 2009 Apr;147(4):627-33. 
67. Deramo VA, Cox TA, Syed AB, Lee PP, Fekrat S. Vision-related quality of life in people with central retinal vein occlusion using the 25 -item national eye institute visual function questionnaire. Arch Ophthalmol. 2003 Sep;121(9):1297-302.

68. Do H, Kang HK, Beaumont PE. Prognostic significance of ophthalmodynamometry in central retinal vein occlusion. Invest Ophthalmol Vis Sci. 2008 May;49(13):5438.

69. Dominguez E, Raoul W, Calippe B, Sahel J, Guillonneau X, Paques M, et al. Experimental branch retinal vein occlusion induces upstream pericyte loss and vascular destabilization. PLoS ONE. 2015 Jul;10(7):e0132644.

70. Donati G, Kapetanios A, Dubois-Dauphin M, Pournaras CJ. Caspase-related apoptosis in chronic ischemic microangiopathy following experimental vein occlusion in mini-pigs. Acta Opthalmologica. 2008 May;86(3):302-6.

71. Dong N, Xu B, Tang X. Plasma homocysteine concentrations in acute and convalescent changes of central retinal vein occlusion in a chinese population. Invest Ophthalmol Vis Sci. 2014 Jul;55(7):4057-62.

72. Du Z, Yamamoto T, Ueda T, Suzuki M, Tano Y, Kamei M. Activated protein C rescues the retina from ischemia-induced cell death. Invest Ophthalmol Vis Sci. 2011 Feb;52(2):98793.

73. Eckstein M, McAllister I. Laser-induced chorioretinal venous anastomosis for nonischemic hemi-central vein occlusion. Clin Experiment Ophthalmol. 2000 Feb;28(1):18-21.

74. Ehlers J, Fekrat S. Retinal vein occlusion: Beyond the acute event. Surv Ophthalmol. 2011 July-August;56(4):281-99.

75. Ehlken C, Grundel B, Michels D, Junker B, Stahl A, Schlunck G, et al. Increased expression of angiogenic and inflammatory proteins in the vitreous of patients with ischemic central retinal vein occlusion. PLoS One. 2015;10(5):e0126859.

76. Eliasdottir TS, Bragason D, Hardarson SH, Kristjansdottir G, Stefansson E. Venous oxygen saturation is reduced and variable in central retinal vein occlusion. Graefes Arch Clin Exp Ophthalmol. 2015 Aug;253(10):1653-61.

77. Elman MJ. Systemic associations of retinal vein occlusion. Int Ophthalmol Clin. 1991 Jul;31(3):15-22.

78. Elman M, Raden R, Carrigan A. Intravitreal injection of tissue plasminogen activator for central retinal vein occlusion. Trans Am Ophthalmol Soc. 2001;99:219-21.

79. Epstein DL, Algvere PV, VonWendt G, Seregard S, Kvanta A. Bevacizumab for macular edema in central retinal vein occlusion: A prospective, randomized, double-masked clinical study. Ophthalmology. 2012 Jun;119(6):1184-9.

80. Fard MA, Lashey A, Dehpour A-. Aqueous humor nitric oxide in patients with central retinal vein occlusion. Nitric Oxide - Biology and Chemistry. 2010 Dec;23(4):332-4. 
81. Fekrat S, Finkelstein D. Current concepts in the management of central retinal vein occlusion. Curr Opin Ophthalmol. 1997 Jun;8(3):50-4.

82. Feltgen N, Junker B, Agostini H, Hansen LL. Retinal endovascular lysis in ischemic central retinal vein occlusion: One-year results of a pilot study. Ophthalmology. 2007 Apr;114(4):716-23.

83. Feng J, Zhao T, Zhang Y, Ma Y, Jiang Y. Differences in aqueous concentrations of cytokines in macular edema secondary to branch and central retinal vein occlusion. PLoS One. 2013;8(7):e68149.

84. Fiebai B, Ejimadu CS, Komolafe RD. Incidence and risk factors for retinal vein occlusion at the university of port harcourt teaching hospital, port harcourt, nigeria. Nigerian Journal of Clinical Practice. 2014 Jul-Aug;17(4):462-6.

85. Finkelstein D. Ischemic macular edema. recognition and favorable natural history in branch vein occlusion. Arch Ophthalmol. 1992 Oct;110(10):1427-34.

86. Ford JA, Shyangdan D, Uthman OA, Lois N, Waugh N. Drug treatment of macular oedema secondary to central retinal vein occlusion: A network meta-analysis. BMJ Open. 2014;4(7):e005292.

87. Ford JA, Clar C, Lois N, Barton S, Thomas S, Court R, et al. Treatments for macular oedema following central retinal vein occlusion: Systematic review. BMJ Open.

2014;4(2):e004120.

88. Fortunato P, Pollazzi L, Baroni M, Evangelisti A, La Torre A. Venous retinal flow reperfusion mechanisms following radial optic neurotomy with adjunctive intraocular triamcinolone in central retinal vein occlusion. Graefes Arch Clin Exp Ophthalmol. 2010 Feb;248(2):167-73.

89. Francois D. Lipofuscin: The origin of the autofluorescence signal. In: Lois N, Forrester J, editors. Fundus Autofluorescence . 2nd ed. Philadelphia: Wolters Kluwer; 2016. p. 14-20.

90. Giuffre G, Palumbo C, Randazzo-Papa G. Optociliary veins and central retinal vein occlusion. Br J Ophthalmol. 1993 Dec;77(12):774-7.

91. Glacet-Bernard A, Sellam A, Coscas F, Coscas G, Souied EH. Optical coherence tomography angiography in retinal vein occlusion treated with dexamethasone implant: A new test for follow-up evaluation. Eur J Ophthalmol. 2016 Aug 4;26(5):460-8.

92. Glacet-Bernard A, Coscas G, Chabanel A, Zourdani A, Lelong F, Samama MM.

Prognostic factors for retinal vein occlusion: Prospective study of 175 cases. Ophthalmology. 1996 Apr;103(4):551-60.

93. Glacet-Bernard A, Kuhn D, Vine AK, Oubraham H, Coscas G, Soubrane G. Treatment of recent onset central retinal vein occlusion with intravitreal tissue plasminogen activator: A pilot study. Br J Ophthalmol. 2000 Jun;84(6):609-13. 
94. Glacet-Bernard A, Atassi M, Fardeau C, Romanet J, Tonini M, Conrath J, et al. Hemodilution therapy using automated erythrocytapheresis in central retinal vein occlusion: Results of a multicenter randomized controlled study. Graefes Arch Clin Exp Ophthalmol. 2011 Apr;249(4):505-12.

95. Gokce G, Sobaci G, Durukan AH, Erdurman FC. Intravitreal triamcinolone acetonide compared with bevacizumab for the treatment of patients with macular edema secondary to central retinal vein occlusion. Postgrad Med. 2013 Sep;125(5):51-8.

96. GomezUlla de Irazazabal F, Suarez L, Domingo E. Hemispheric retinal branch vein occlusions. Ophthalmologica. 1986;193(1):14-22.

97. Gomolin JE. Efficacy of panretinal photocoagulation in central retinal vein occlusion. Ophthalmologica. 1989;199(1):24-7.

98. Gupta A, Agarwal A, Bansal RK, Agarwal A, Chugh KS. Ischemic central retinal vein occlusion in the young. Eye. 1993 Jan;7(Pt 1):138-42.

99. Haller JA, Bandello F, Belfort RJ, Blumenkranz MS, Gillies M, Heier J, et al.

Randomized, sham-controlled trial of dexamethasone intravitreal implant in patients with macular edema due to retinal vein occlusion. Ophthalmology. 2010 Jun;117(6):1134-46.

100. Ham DI, Chang K, Chung H. Preretinal neovascularization induced by experimental retinal vein occlusion in albino rats. Korean Journal of Ophthalmology. 1997 Jun;11(1):60-4.

101. Hamilton A, Marshall J, Kohner E, Bowbyes J. Retinal new vessel formation following experimental vein occlusion. Exp Eye Res. 1975 Jun;20(6):493-7.

102. Hansen LL, Wiek J, Schade M, Muller-Stolzenburg N, Wiederholt M. Effect and compatibility of isovolaemic haemodilution in the treatment of ischemic and non-ischemic central retinal vein occlusion. Ophthalmologica. 1989;199(2-3):90-9.

103. Hardarson SH, Stefansson E. Oxygen saturation in central retinal vein occlusion. Am J Ophthalmol. 2010 Dec;150(6):871-5.

104. Hardarson SH, Stefansson E. Oxygen saturation in branch retinal vein occlusion. Acta Ophthalmol. 2012 Aug;90(5):466-70.

105. Hattenbach LO, Steinkamp G, Scharrer I, Ohrloff C. Fibrinolytic therapy with low-dose recombinant tissue plasminogen activator in retinal vein occlusion. Ophthalmologica. 1998;212(6):394-8.

106. Hattenbach L, Wellermann G, Steinkamp G, Scharrer I, Koch FH, Ohrloff C. Visual outcome after treatment with low-dose recombinant tissue plasminogen activator or hemodilution in ischemic central retinal vein occlusion. Ophthalmologica. 1999;213(6):3606.

107. Hayreh SS. Classification of central retinal vein occlusion. Ophthalmology. 1983 May;90(5):458-74. 
108. Hayreh SS, Zimmerman MB, Podhajsky P, Alward WL. Nocturnal arterial hypotension and its role in optic nerve head and ocular ischemic disorders. Am J Ophthalmol. 1994 May;117(5):603-24.

109. Hayreh S, Hayreh M. Hemi-central retinal vein occlusion. pathogenesis, clinical features, and natural history. Arch Ophthalmol. 1980 Sep;98(9):1600-9.

110. Hayreh SS. Retinal vein occlusion. Indian J Ophthalmol. 1994 Sep;42(3):109-32.

111. Hayreh SS, Rubenstein L, Podhajsky P. Argon laser scatter photocoagulation in treatment of branch retinal vein occlusion. A prospective clinical trial. Ophthalmologica. 1993;206(1):1-14.

112. Hayreh SS, Zimmerman MB, Podhajsky P. Incidence of various types of retinal vein occlusion and their recurrence and demographic characteristics. Am J Ophthalmol. 1994 Apr;117(4):429-41.

113. Hayreh SS, Klugman MR, Podhajsky P, Kolder HE. Electroretinography in central retinal vein occlusion. correlation of electroretinographic changes with pupillary abnormalities. Graefes Arch Clin Exp Ophthalmol. 1989;227(6):549-61.

114. Hayreh SS. Retinal vein occlusion. Indian J Ophthalmol. 1994 Sep;42(3):109-32.

115. Hayreh SS, Zimmerman MB. Hemicentral retinal vein occlusion: Natural history of visual outcome. Retina. 2012 Jan;32(1):68-76.

116. Hayreh SS, Zimmerman MB. Fundus changes in central retinal vein occlusion. Retina. 2015;35(1):29-42.

117. Hayreh SS, Zimmerman MB. Ocular neovascularization associated with central and hemicentral retinal vein occlusion. Retina. 2012 Sep;32(8):1553-65.

118. Hayreh SS, Zimmerman MB. Branch retinal vein occlusion: Natural history of visual outcome. JAMA Ophthalmology. 2014 Jan;132(1):13-22.

119. Hayreh SS, Podhajsky PA, Zimmerman MB. Natural history of visual outcome in central retinal vein occlusion. Ophthalmology. 2011 Jan;118(1):119-33.

120. Hayreh S, Zimmerman B, McCarthy M, Podhajsky P. Systemic diseases associated with various types of retinal vein occlusion. Am J Ophthalmol. 2001 Jan;131(1):61-77.

121. Hayreh S, Klugman M, Podhajsky P, Servais G, Perkins E. Argon laser panretinal photocoagulation in ischemic central retinal vein occlusion. A 10-year prospective study. Graefe's Arch Clin Exp Ophthalmol. 1990;228(4):281-96.

122. Hayreh S, Rojas P, Podhajsky P. Ocular neovascularization with retinal vascular occlusion. III. incidence of ocular neovascularization with retinal vein occlusion.

Ophthalmology. 1983 May;90(5):488-506. 
123. Hayreh S, Klugman M, Beri M, Kimura A, Podhajsky P. Differentiation of ischemic from non-ischemic central retinal vein occlusion during the early acute phase. Graefes Arch Clin Exp Ophthalmol. 1990 May;228(3):201-17.

124. Heier JS, Campochiaro PA, Yau L, Li Z, Saroj N, Rubio RG, et al. Ranibizumab for macular edema due to retinal vein occlusions: Long-term follow-up in the HORIZON trial. Ophthalmology. 2012 Apr;119(4):802-9.

125. Hikichi T, Konno S, Trempe CL. Role of the vitreous in central retinal vein occlusion. Retina. 1995;15(1):29-33.

126. Hockley D, Tripathi R, Ashton N. Experimental retinal branch vein occlusion in the monkey. histopathological and ultrastructural studies. Trans Ophthalmol Soc UK. 1976 Jul;96(2):202-9.

127. Hockley D, Tripathi R, Ashton N. Experimental retinal branch vein occlusion in rhesus monkeys. III. histopathological and electron microscopical studies. Br J Ophthalmol. 1979 Jun;63(6):393-411.

128. Holz FG, Roider J, Ogura Y, Korobelnik J, Simader C, Groetzbach G, et al. VEGF trapeye for macular oedema secondary to central retinal vein occlusion: 6-month results of the phase III GALILEO study. Br J Ophthalmol. 2013 Mar;97(3):278-84.

129. Hvarfner C, Larsson J. Is optic nerve head swelling of prognostic value in central retinal vein occlusion?. Graefes Arch Clin Exp Ophthalmol. 2003 Jun;241(6):463-7.

130. Hvarfner C, Larsson J. Cone B-wave implicit time as a predictor of neovascular complications in hemi retinal vein occlusion. Retina. 2005 Feb-Mar;25(2):214-6.

131. Hvarfner C, Andreasson S, Larsson J. Multifocal electroretinogram in branch retinal vein occlusion. Am J Ophthalmol. 2003 Dec;136(6):1163-5.

132. Hvarfner C, Andreasson S, Larsson J. Multifocal electroretinography and fluorescein angiography in retinal vein occlusion. Retina. 2006 Mar;26(3):292-6.

133. Iannaccone A, Letizia C, Pazzaglia S, Vingolo EM, Clemente G, Pannarale MR. Plasma endothelin-1 concentrations in patients with retinal vein occlusions. Br J Ophthalmol. 1998 May;82(5):498-503.

134. Ikuno Y, Ikeda T, Sato Y, Tano Y. Tractional retinal detachment after branch retinal vein occlusion. influence of disc neovascularization on the outcome of vitreous surgery. Ophthalmology. 1998 Mar;105(3):417-23.

135. Imasawa M., Iijima H., Morimoto T. Perimetric sensitivity and retinal thickness in eyes with macular edema resulting from branch retinal vein occlusion. Am J Ophthalmol. 2001 Jan;131(1):55-60.

136. Ip MS, Gottlieb JL, Kahana A, Scott IU, Altaweel MM, Blodi BA, et al. Intravitreal triamcinolone for the treatment of macular edema associated with central retinal vein occlusion. Arch Ophthalmol. 2004 Aug;122(8):1131-6. 
137. Ip MS, Scott IU, VanVeldhuisen PC, Oden NL, Blodi BA, Fisher M, et al. A randomized trial comparing the efficacy and safety of intravitreal triamcinolone with observation to treat vision loss associated with macular edema secondary to central retinal vein occlusion: The standard care vs corticosteroid for retinal vein occlusion (SCORE) study report 5. Arch Ophthalmol. 2009 Sep;127(9):1101-14.

138. Jaulim A, Ahmed B, Khanam T, Chatziralli IP. Branch retinal vein occlusion: Epidemiology, pathogenesis, risk factors, clinical features, diagnosis, and complications. an update of the literature. Retina. 2013 May;33(5):901-10.

139. Johnson MA, Marcus S, Elman MJ, McPhee TJ. Neovascularization in central retinal vein occlusion: Electroretinographic findings. Arch Ophthalmol. 1988 Mar;106(3):348-52.

140. Jonas JB. Ophthalmodynamometric assessment of the central retinal vein collapse pressure in eyes with retinal vein stasis or occlusion. Graefes Arch Clin Exp Ophthalmol. 2003 May;241(5):367-70.

141. Jonas JB, Harder B. Ophthalmodynamometric differences between ischemic vs nonischemic retinal vein occlusion. Am J Ophthalmol. 2007 Jan;143(1):112-6.

142. Jonas JB, Nangia V, Khare A, Sinha A, Lambat S. Prevalence and associations of retinal vein occlusions: The central india eye and medical study. Retina. 2013 Jan;33(1):152-9.

143. Jung SH, Kim K, Sohn SW, Yang SJ. Association of aqueous humor cytokines with the development of retinal ischemia and recurrent macular edema in retinal vein occlusion. Invest Ophthalmol Vis Sci. 2014 Apr;55(4):2290-6.

144. Kaja S, Shah AA, Haji SA, Patel KB, Naumchuk Y, Zabaneh A, et al.

Nampt/PBEF/visfatin serum levels: A new biomarker for retinal blood vessel occlusions. Clin Ophthalmol. 2015 Apr;9:611-8.

145. Kamei M, Matsumura N, Suzuki M, Sakimoto S, Sakaguchi H, Nishida K. Reperfusion of large ischemic areas associated with central retinal vein occlusion: A potential novel treatment with activated protein C. JAMA Ophthalmology. 2014 Mar;132(3):361-2.

146. Kang J, Lee H, Chung H, Kim HC. Correlation between optical coherence tomographic hyperreflective foci and visual outcomes after intravitreal bevacizumab for macular edema in branch retinal vein occlusion. Graefes Arch Clin Exp Ophthalmol. 2014 Sep;252(9):1413-21.

147. Karia N. Retinal vein occlusion: Pathophysiology and treatment options. Clin Ophthalmol. $2010 \mathrm{Jul} ; 4(1): 809-16$.

148. Kaur C, Foulds WS, Ling EA. Blood-retinal barrier in hypoxic ischemic conditions:

Basic concepts, clinical features and management. Progress in Retinal \& Eye Research. 2008 Nov;27(6):622-47.

149. Khayat M, Lois N, Williams M, Stitt A. Animal models of retinal vein occlusion. Invest Ophthalmol Vis Sci. 2017 Dec;58(14):6175-92. 
150. Kida T., Morishita S., Kakurai K., Suzuki H., Oku H., Ikeda T. Treatment of systemic hypertension is important for improvement of macular edema associated with retinal vein occlusion. Clin Ophthalmol. 2014 May;8:955-8.

151. Kim SE, Giglio RF, Reese DJ, Reese SL, Bacon NJ, Ellison GW. Comparison of computed tomographic angiography and ultrasonography for the detection and characterization of portosystemic shunts in dogs. Vet Radiol Ultrasound. 2013 NovDec;54(6):569-74.

152. Kimura M, Nozaki M, Yoshida M, Ogura Y. Wide-field optical coherence tomography angiography using extended field imaging technique to evaluate the nonperfusion area in retinal vein occlusion. Clin Ophthalmol. 2016 Jul;10:1291-5.

153. Kinge B, Stordahl PB, Forsaa V, Fossen K, Haugstad M, Helgesen OH, et al. Efficacy of ranibizumab in patients with macular edema secondary to central retinal vein occlusion:

Results from the sham-controlled ROCC study. Am J Ophthalmol. 2010 Sep;150(3):310-4.

154. Kjeka O, Bredrup C, Krohn J. Photopic 30 hz flicker electroretinography predicts ocular neovascularization in central retinal vein occlusion. Acta Ophthalmol Scand. 2007

Sep;85(6):640-3.

155. Kjeka O, Jansson RW, Bredrup C, Krohn J. Early panretinal photocoagulation for ERGverified ischemic central retinal vein occlusion. Acta Opthalmologica. 2013 Feb;91(1):37-41.

156. Klein R, Klein BE, Moss SE, Meuer SM. The epidemiology of retinal vein occlusion: The beaver dam eye study. Trans Am Ophthalmol Soc. 2000;98:133-41.

157. Klein R, Moss SE, Meuer SM, Klein BEK. The 15-year cumulative incidence of retinal vein occlusion: The beaver dam eye study. Arch Ophthalmol. 2008 Apr;126(4):513-8.

158. Kohner E. Morphological, circulatory, and histopathological response to retinal vein occlusion. pathophysiology of retinal vein occlusion. Trans Ophthalmol Soc UK. 1976 Jan;96(2):189.

159. Kohner E, Dollery C, Shakib M, Henkind P, Paterson J, deOliveira L, et al. Experimental retinal branch vein occlusion. Am J Ophthalmol. 1970 May;69(5):778-825.

160. Kuhli C, Scharrer I, Koch F, Ohrloff C, Hattenbach L. Factor XII deficiency: A thrombophilic risk factor for retinal vein occlusion. Am J Ophthalmol. 2004 Mar;137(3):45964.

161. Kuo H, Kuo M, Chen Y, Wu P, Chen C, Chen Y. The flicker electroretinogram interocular amplitude ratio is a strong prognostic indicator of neovascularization in patients with central retinal vein occlusion. Graefes Archive for Clinical \& Experimental Ophthalmology. 2010 Feb;248(2):185-9.

162. Kuo JZ, Lai C, Ong FS, Shih C, Yeung L, Chen T, et al. Central retinal vein occlusion in a young chinese population: Risk factors and associated morbidity and mortality. Retina. 2010 Mar;30(3):479-84. 
163. Kwok AKH, Lee VYW, Lai TYY, Hon C. Laser induced chorioretinal venous anastomosis in ischemic central retinal vein occlusion. Br J Ophthalmol. 2003 Aug;87(8):1043-4.

164. Laatikainen L, Blach RK. Behaviour of the iris vasculature in central retinal vein occlusion: A fluorescein angiographic study of the vascular response of the retina and the iris. Br J Ophthalmol. 1977 Apr;61(4):272-7.

165. Laatikainen L, Kohner EM, Khoury D, Blach RK. Panretinal photocoagulation in central retinal vein occlusion: A randomised controlled clinical study. Br J Ophthalmol. 1977 Dec;61(12):741-53.

166. Lahiri K, Dutta J, Datta H, Das H. Hyperhomocysteinemia, a biochemical tool for differentiating ischemic and nonischemic central retinal vein occlusion during the early acute phase. Korean J Ophthalmol. 2015;29(2):68-91.

167. Larsen M, Waldstein SM, Boscia F, Gerding H, Monés J, Tadayoni R, et al. Individualized ranibizumab regimen driven by stabilization criteria for central retinal vein occlusion: Twelve-month results of the CRYSTAL study. Ophthalmology. 2016 May;123(5):1101-11.

168. Larsson J., Bauer B., CavallinSjoberg U., Andreasson S. Fluorescein angiography versus ERG for predicting the prognosis in central retinal vein occlusion. Acta Ophthalmol Scand. 1998 Aug;76(4):456-60.

169. Larsson J, Andreasson S. Photopic $30 \mathrm{hz}$ flicker ERG as a predictor for rubeosis in central retinal vein occlusion. Br J Ophthalmol. 2001 Jun;85(6):683-5.

170. Larsson J, Andreasson S, Bauer B. Cone b-wave implicit time as an early predictor of rubeosis in central retinal vein occlusion. Am J Ophthalmol. 1998 Feb;125(2):247-9.

171. Larsson J, Bauer B, Andreasson S. The 30-hz flicker cone ERG for monitoring the early course of central retinal vein occlusion. Acta Ophthalmol Scand. 2000 Apr;78(2):187-90.

172. Lee W, Kang M, Seong M, Cho H. Comparison of aqueous concentrations of angiogenic and inflammatory cytokines in diabetic macular oedema and macular oedema due to branch retinal vein occlusion. Br J Ophthalmol. 2012 Nov;96(11):1426-30.

173. Lee JY, Yoon YH, Kim HK, Yoon HS, Kang SW, Kim J, et al. Baseline characteristics and risk factors of retinal vein occlusion: A study by the korean RVO study group. J Korean Med Sci. 2013 Jan;28(1):136-44.

174. Leizaola-Fernandez C, Suarez-Tata L, Quiroz-Mercado H, Colina-Luquez J, FromowGuerra J, Jimenez-Sierra J, et al. Vitrectomy with complete posterior hyaloid removal for ischemic central retinal vein occlusion: Series of cases. BMC Ophthalmol. 2005 May;5:10.

175. Lim H, Kim M, Jo Y, Kim J. Prediction of retinal ischemia in branch retinal vein occlusion: Spectral-domain optical coherence tomography study. Invest Ophthalmol Vis Sci. 2015 Oct;56(11):6622-9. 
176. Lima VC, Yeung L, Castro LC, Landa G, Rosen RB. Correlation between spectral domain optical coherence tomography findings and visual outcomes in central retinal vein occlusion. Clin Ophthalmol. 2011;5(1):299-305.

177. Lin J, Chiu Y, Hung P, Tsai Y. Early treatment of severe cystoid macular edema in central retinal vein occlusion with posterior sub-tenon triamcinolone acetonide. Retina. 2007 Feb;27(2):180-9.

178. Lin LL, Dong YM, Zong Y, Zheng QS, Fu Y, Yuan YG, et al. Study of retinal vessel oxygen saturation in ischemic and non-ischemic branch retinal vein occlusion. Int $\mathbf{J}$ Ophthalmol. 2016;9(1):99-107.

179. Lu H, Zang Q. The effects of retinal ischemia on retinal nerve fiber layers of patients with retinal vein occlusion. Yen Ko Hsueh Pao [Eye Science]. 1997 Mar;13(1):21-4.

180. Maeno T, Tano R, Takenaka H, Mano T. Edaravone (MCI-186) is effective as a free radical scavenger following arteriovenous sheathotomy for treatment of macular oedema associated with branch retinal vein occlusion. Br J Ophthalmol. 2009 Nov;93(11):1479-82.

181. Magargal LE, Donoso LA, Sanborn GE. Retinal ischemia and risk of neovascularization following central retinal vein obstruction. Ophthalmology. 1982 Nov;89(11):1241-5.

182. Magargal LE, Brown GC, Augsburger JJ, Parrish RK. Neovascular glaucoma following central retinal vein obstruction. Ophthalmology. 1981 Nov;88(11):1095-101.

183. Magargal LE, Brown GC, Augsburger JJ, Donoso LA. Efficacy of panretinal photocoagulation in preventing neovascular glaucoma following ischemic central retinal vein obstruction. Ophthalmology. 1982 Jul;89(7):780-4.

184. Maharaj AS, D'Amore PA. Roles for VEGF in the adult. Microvasc Res. 2007 SepNov;74(2):100-13.

185. Malayan AS, Shakhsuvaryan ML, Grigoryan GL, Melkonyan AK. Retinal vein occlusion in armenia. Eur J Ophthalmol. 1999 Jul-Sep;9(3):196-201.

186. Mandelcorn MS, Mandelcorn E, Guan K, Adatia FA. Surgical macular decompression for macular edema in retinal vein occlusion. Canadian Journal of Ophthalmology. 2007 Feb;42(1):116-22.

187. Mangione CM, Lee PP, Pitts J, Gutierrez P, Berry S, Hays RD. Psychometric properties of the national eye institute visual function questionnaire (NEI-VFQ). Arch Ophthalmol. 1998 Nov;116(11):1496-504.

188. Martinet V, Guigui B, Glacet-Bernard A, Zourdani A, Coscas G, Soubrane G, et al. Macular edema in central retinal vein occlusion: Correlation between optical coherence tomography, angiography and visual acuity. Int Ophthalmol. 2012 Aug;32(4):369-77.

189. Martinez-Jardon CS, Meza-de Regil A, Dalma-Weiszhausz J, Leizaola-Fernandez C, Morales-Canton V, Guerrero-Naranjo JL, et al. Radial optic neurotomy for ischemic central vein occlusion. Br J Ophthalmol. 2005 May;89(5):558-61. 
190. Matsui Y, Katsumi O, Sakaue H, Hirose T. Electroretinogram b/a wave ratio improvement in central retinal vein obstruction. Br J Ophthalmol. 1994 Mar;78(3):191-8.

191. McAllister I, Barry C. Collateral formation in hemicentral retinal vein occlusion. Aust $\mathrm{N}$ Z J Ophthalmol. 1991 Aug;19(3):239-41.

192. McAllister IL, Constable IJ. Laser-induced chorioretinal venous anastomosis for treatment of nonischemic central retinal vein occlusion. Arch Ophthalmol. 1995 Apr;113(4):456-62.

193. McAllister IL, Douglas JP, Constable IJ, Yu DY. Laser-induced chorioretinal venous anastomosis for nonischemic central retinal vein occlusion: Evaluation of the complications and their risk factors. Am J Ophthalmol. 1998 Aug;126(2):219-29.

194. McAllister IL, Tan MH, Smithies LA, Wong WL. The effect of central retinal venous pressure in patients with central retinal vein occlusion and a high mean area of nonperfusion. Ophthalmology. 2014 Nov;121(11):2228-36.

195. McAllister IL, Gillies ME, Smithies LA, Rochtchina E, Harper CA, Daniell MD, et al. The central retinal vein bypass study: A trial of laser-induced chorioretinal venous anastomosis for central retinal vein occlusion. Ophthalmology. 2010 May;117(5):954-65.

196. McIntosh RL, Rogers SL, Lim L, Cheung N, Wang JJ, Mitchell P, et al. Natural history of central retinal vein occlusion: An evidence-based systematic review. Ophthalmology. 2010 Jun;117(6):1113-23.

197. Menon V, Nachiketa MS, Kumar A. Relative afferent pupillary defect and edge light pupil cycle time in the early differentiation of central retinal vein occlusion. Indian J Ophthalmol. 1995 Sep;43(3):127-30.

198. Mitchell P, Smith W, Chang A. Prevalence and associations of retinal vein occlusion in australia. the blue mountains eye study. Arch Ophthalmol. 1996 Oct;114(10):1243-7.

199. Moschos M, Brouzas D, Moschou M, Theodossiadis G. The a- and b-wave latencies as a prognostic indicator of neovascularisation in central retinal vein occlusion. Documenta Ophthalmologica. 1999 Oct;99(2):123-33.

200. Mosinger JL, Price MT, Bai HY, Xiao H, Wozniak DF, Olney JW. Blockade of both NMDA and non-NMDA receptors is required for optimal protection against ischemic neuronal degeneration in the in vivo adult mammalian retina. Exp Neurol. 1991 $\mathrm{Jul} ; 113(1): 10-7$.

201. Murdoch IE, Rosen PH, Shilling JS. Neovascular response in ischemic central retinal vein occlusion after panretinal photocoagulation. Br J Ophthalmol. 1991 Aug;75(8):459-61.

202. Narayanan R, Panchal B, Das T, Chhablani J, Jalali S, Ali MH, et al. A randomised, double-masked, controlled study of the efficacy and safety of intravitreal bevacizumab versus ranibizumab in the treatment of macular oedema due to branch retinal vein occlusion:

MARVEL report no. 1. Br J Ophthalmol. 2015 Jul;99(7):954-9. 
203. Nobre Cardoso J., Keane P.A., Sim D.A., Bradley P., Agrawal R., Addison P.K., et al. Systematic evaluation of optical coherence tomography angiography in retinal vein occlusion. Am J Ophthalmol. 2016 Mar;163:93-107.

204. Noma H, Funatsu H, Mimura T, Shimada K. Influence of ischemia on visual function in patients with branch retinal vein occlusion and macular edema. Clin Ophthalmol. 2011 May;5(1):679-85.

205. Noma H, Mimura T, Tatsugawa M, Shimada K. Aqueous flare and inflammatory factors in macular edema with central retinal vein occlusion: A case series. BMC Ophthalmol, 2013 Dec;13(78):e1-6.

206. Noma H, Mimura T, Kuse M, Yasuda K, Shimura M. Photopic negative response in branch retinal vein occlusion with macular edema. Int Ophthalmol. 2015 Feb;35(1):19-26.

207. Noma H, Mimura T, Shimada K. Changes of macular sensitivity and morphology after pars plana vitrectomy for macular edema with central retinal vein occlusion: A case series. BMC Ophthalmology. 2013 Feb;13(2):e1-7.

208. Noma H, Shimada K, Mimura T. Visual function after pars plana vitrectomy in macular edema with branch retinal vein occlusion. Int Ophthalmol. 2013 Jun;33(3):227-36.

209. Noma H, Funatsu H, Mimura T, Shimada K. Macular sensitivity and morphology after intravitreal injection of triamcinolone acetonide for macular edema with branch retinal vein occlusion. Retina. 2012 Oct;32(9):1844-52.

210. Noma H, Funatsu H, Shimada K, Mimura T. Influence of pars plana vitrectomy on macular sensitivity and morphology in patients with branch retinal vein occlusion and serous retinal detachment. Ophthalmic Surgery, Lasers \& Imaging Retina. 2013 Mar-Apr;44(2):1607.

211. Noma H, Mimura T, Yasuda K, Shimura M. Role of soluble vascular endothelial growth factor receptors- 1 and -2 , their ligands, and other factors in branch retinal vein occlusion with macular edema. Invest Ophthalmol Vis Sci. 2014 Jun;55(6):3878-85.

212. Noma H, Funatsu H, Mimura T, Harino S, Hori S. Aqueous humor levels of vasoactive molecules correlate with vitreous levels and macular edema in central retinal vein occlusion. Eur J Ophthalmol. 2010 Mar-Apr;20(2):402-9.

213. Noma H, Funatsu H, Mimura T, Eguchi S, Shimada K, Hori S. Vitreous levels of pigment epithelium-derived factor and vascular endothelial growth factor in macular edema with central retinal vein occlusion. Curr Eye Res. 2011 Mar;36(3):256-63.

214. Novais EA, Waheed NK. Optical coherence tomography angiography of retinal vein occlusion. In: Bandello F, Souied EH, Querques G, editors. OCT Angiography in Retinal and Macular Diseases. 1st ed. Basel: Karger; 2016. p. 132-8.

215. Ogura Y, Roider J, Korobelnik J, Holz FG, Simader C, Schmidt-Erfurth U, et al. Intravitreal aflibercept for macular edema secondary to central retinal vein occlusion: 18month results of the phase 3 GALILEO study. Am J Ophthalmol. 2014 Nov;158(5):1032-8. 
216. Opremcak EM, Bruce RA, Lomeo MD, Ridenour CD, Letson AD, Rehmar AJ. Radial optic neurotomy for central retinal vein occlusion: A retrospective pilot study of 11 consecutive cases. Retina. 2001;21(5):408-15.

217. Ota M, Tsujikawa A, Murakami T, Kita M, Miyamoto K, Sakamoto A, et al. Association between integrity of foveal photoreceptor layer and visual acuity in branch retinal vein occlusion. Br J Ophthalmol. 2007 Dec;91(12):1644-9.

218. Ota M, Tsujikawa A, Kita M, Miyamoto K, Sakamoto A, Yamaike N, et al. Integrity of foveal photoreceptor layer in central retinal vein occlusion. Retina. 2008 NovDec;28(10):1502-8.

219. Ota M, Tsujikawa A, Murakami T, Yamaike N, Sakamoto A, Kotera Y, et al. Foveal photoreceptor layer in eyes with persistent cystoid macular edema associated with branch retinal vein occlusion. Am J Ophthalmol. 2008 Feb;145(2):273-80.

220. Ozdek SC, Aydin B, Gurelik G, Bahceci U, Hasanreisoglu B. Effects of intravitreal triamcinolone injection on macular edema and visual prognosis in central retinal vein occlusion. Int Ophthalmol. 2005 Feb-Apr;26(1-2):27-34.

221. Park B, Kim J, Chung H, Kim HC. Correlation of fundus autofluorescence with foveal microstructures and vision in branch retinal vein occlusion. Retina. 2014 Mar;34(3):531-8.

222. Park SS, Bauer G, Abedi M, Pontow S, Panorgias A, Jonnal R, et al. Intravitreal autologous bone marrow cd34+ cell therapy for ischemic and degenerative retinal disorders: Preliminary phase 1 clinical trial findings. Invest Ophthalmol Vis Sci. 2015;56(1):81-9.

223. Park S. Cell therapy applications for retinal vascular diseases: Diabetic retinopathy and retinal vein occlusion. Invest Ophthalmol Visual Sci. 2016 Apr;57(5):1-10.

224. Park SP, Ahn JK, Mun GH. Aqueous vascular endothelial growth factor levels are associated with serous macular detachment secondary to branch retinal vein occlusion. Retina. 2010 Feb;30(2):281-6.

225. Parodi MB, Moretti G, Ravalico G. Hemicentral and hemispheric retinal vein occlusions. Metabolic, Pediatric \& Systemic Ophthalmology. 1992 Jan;15(4):64-7.

226. Parodi MB, Iacono P, Petruzzi G, Parravano M, Varano M, Bandello F. Dexamethasone implant for macular edema secondary to ischemic retinal vein occlusion. Retina. 2015 Jul;35(7):1387-92.

227. Parodi MB, Iacono P, Ravalico G. Verteporfin photodynamic therapy for anterior segment neovascularization secondary to ischemic central retinal vein occlusion. Clin Experiment Ophthalmol. 2008 Apr;36(3):232-7.

228. Parodi M, Stefano G, Ravalico G. Grid laser treatment for exudative retinal detachment secondary to ischemic branch retinal vein occlusion. Retina. 2008 Jan;28(1):97-102.

229. Parodi M, Friberg T, Pedio M, Fiotti N, Stefano G, Ravalico G. Panretinal photocoagulation and photodynamic therapy for anterior segment neovascularization 
secondary to ischemic central retinal vein occlusion. Ophthalmic Surg Lasers Imaging. 2007 Mar-Apr;38(2):94-9.

230. Paulose R, Chhablani J, Dedhia CJ, Stewart MW, Mansour AM. Intravitreal zivaflibercept for macular edema following retinal vein occlusion. Clin Ophthalmol. 2016 Sep;22(10):1853-8.

231. Pe'er J, Shweiki D, Itin A, Hemo I, Gnessin H, Keshet E. Hypoxia-induced expression of vascular endothelial growth factor by retinal cells is a common factor in neovascularizing ocular diseases. Laboratory Investigation. 1995 Jun;72(6):638-45.

232. Pe'er J, Folberg R, Itin A, Gnessin H, Hemo I, Keshet E. Vascular endothelial growth factor upregulation in human central retinal vein occlusion. Ophthalmology. 1998 Mar;105(3):412-6.

233. Peyman GA, Kishore K, Conway MD. Surgical chorioretinal venous anastomosis for ischemic central retinal vein occlusion. Ophthalmic Surgery \& Lasers. 1999 SepOct;30(8):605-14.

234. Pielen A, Mirshahi A, Feltgen N, Lorenz K, Korb C, Junker B, et al. Ranibizumab for branch retinal vein occlusion associated macular edema study (RABAMES): Six-month results of a prospective randomized clinical trial. Acta Ophthalmologica. 2015 Feb;93(1):e2937.

235. Pieris S, Hill D. Collateral vessels in branch retinal vein occlusion. Trans Ophthalmol Soc U K. 1982 Apr;102(1):178-81.

236. Pikkel YY, Sharabi-Nov A, Beiran I, Pikkel J. Comparison of anti-vascular endothelial growth factors, laser treatments and a combination of the both for treatment of central retinal vein occlusion. Int J Ophthalmol. 2016 Mar;9(3):431-3.

237. Ponto KA, Elbaz H, Peto T, Laubert-Reh D, Binder H, Wild PS, et al. Prevalence and risk factors of retinal vein occlusion: The gutenberg health study. Journal of Thrombosis \& Haemostasis. 2015 Jul;13(7):1254-63.

238. Pournaras C, Tsacopoulos M, Strommer K, Gilodi N, Leuenberger P. Experimental retinal branch vein occlusion in miniature pigs induces local tissue hypoxia and vasoproliferative microangiopathy. Ophthalmology. 1990 Oct;97(10):1321-8.

239. Prasad PS, Oliver SCN, Coffee RE, Hubschman J, Schwartz SD. Ultra wide-field angiographic characteristics of branch retinal and hemicentral retinal vein occlusion. Ophthalmology. 2010 Apr;117(4):780-4.

240. Priglinger SG, Wolf AH, Kreutzer TC, Kook D, Hofer A, Strauss RW, et al. Intravitreal bevacizumab injections for treatment of central retinal vein occlusion: Six-month results of a prospective trial. Retina. 2007 Oct;27(8):1004-12.

241. Prisco D, Marcucci R. Retinal vein thrombosis: Risk factors, pathogenesis and therapeutic approach. Pathophysiol Haemost Thromb. 2002 Sep-Dec;32(5-6):308-11. 
242. Puche N, Glacet A, Mimoun G, Zourdani A, Coscas G, Soubrane G. Intravitreal ranibizumab for macular oedema secondary to retinal vein occlusion: A retrospective study of 34 eyes. Acta Opthalmologica. 2012 Jun;90(4):357-61.

243. Ramezani A, Esfandiari H, Entezari M, Moradian S, Soheilian M, Dehsarvi B, et al. Three intravitreal bevacizumab versus two intravitreal triamcinolone injections in recentonset branch retinal vein occlusion. Graefes Arch Clin Exp Ophthalmol. 2012 Aug;250(8):1149-60.

244. Ramezani A, Esfandiari H, Entezari M, Moradian S, Soheilian M, Dehsarvi B, et al. Three intravitreal bevacizumab versus two intravitreal triamcinolone injections in recent onset central retinal vein occlusion. Acta Ophthalmol. 2014 Nov;92(7):e530-9.

245. Ramsay A, Williamson TH, Parks S, Keating D. Crossed polarising filters to measure relative afferent pupillary defects: Reproducibility, correlation with neutral density filters and use in central retinal vein occlusion. Eye. 1995 Sep;9(5):624-8.

246. Raszewska-Steglinska M, Gozdek P, Cisiecki, S., Michalewska, Z., Michalewski, J., Nawrocki, J. Pars plana vitrectomy with ILM peeling for macular edema secondary to retinal vein occlusion. Eur J Ophthalmol. 2009 Nov-Dec;19(6):1055-62.

247. Rath EZ, Frank RN, Shin DH, Kim C. Risk factors for retinal vein occlusions. A casecontrol study. Ophthalmology. 1992 Apr;99(4):509-14.

248. Recupero SM, Perdicchi A, Scuderi GL, Amodeo S, Medori EM, Leonardi A. Visual acuity in central and branch vein retinal occlusion in the presence of macular edema: 1 year of follow-up. Ann Ophthalmol. 2006 Jun;38(2):107-10.

249. Rehak M, Hollborn M, Iandiev I, Pannicke T, Karl A, Wurm A, et al. Retinal gene expression and muller cell responses after branch retinal vein occlusion in the rat. Invest Ophthalmol Vis Sci. 2009 May;50(5):2359-67.

250. Reichenbach A, Wurm A, Pannicke T, Iandiev I, Wiedemann P, Bringmann A. Müller cells as players in retinal degeneration and edema. Graefes Arch Clin Exp Ophthalmol. 2007 May;245(5):627-36.

251. Rodolfo M, Lisa T, Luca DA, Enrico B, Alfonso S, Marta DN, et al. Optical coherence tomography angiography microvascular findings in macular edema due to central and branch retinal vein occlusions. Sci Rep. 2017 Jan;7:e40763.

252. Rogers S, McIntosh RL, Cheung N, Lim L, Wang JJ, Mitchell P, et al. The prevalence of retinal vein occlusion: Pooled data from population studies from the united states, europe, asia, and australia. Ophthalmology. 2010 Feb;117(2):313-9.

253. Rogers SL, McIntosh RL, Lim L, Mitchell P, Cheung N, Kowalski JW, et al. Natural history of branch retinal vein occlusion: An evidence-based systematic review.

Ophthalmology. 2010 Jun;117(6):1094-101.

254. Rumelt S, Karatas M, Pikkel J, Majlin M, Ophir A. Optic disc traction syndrome associated with central retinal vein occlusion. Arch Ophthalmol. 2003 Aug;121(8):1093-7. 
255. Ryu CL, Elfersy A, Desai U, Hessburg T, Edwards P, Gao H. The effect of antivascular endothelial growth factor therapy on the development of neovascular glaucoma after central retinal vein occlusion: A retrospective analysis. J Ophthalmol. 2014 Apr;2014:e1-6.

256. Sabates R, Jalkh A, Freeman H. Collateral circulation in hemicentral retinal vein occlusion. Ann Ophthalmol. 1983 Jul;15(7):604-8.

257. Sadda S, Danis RP, Pappuru RR, Keane PA, Jiao J, Li X, et al. Vascular changes in eyes treated with dexamethasone intravitreal implant for macular edema after retinal vein occlusion. Ophthalmology. $2013 \mathrm{Jul} ; 120(7): 1423-31$.

258. Saika S, Tanaka T, Miyamoto T, Ohnishi Y. Surgical posterior vitreous detachment combined with gas/air tamponade for treating macular edema associated with branch retinal vein occlusion: Retinal tomography and visual outcome. Graefes Arch Clin Exp Ophthalmol. 2001 Oct;239(10):729-32.

259. Salles MC, Kvanta A, Amrén U, Epstein D. Optical coherence tomography angiography in central retinal vein occlusion: Correlation between the foveal avascular zone and visual acuity. Invest Ophthalmol Vis Sci. 2016 Jul;57(9):242-6.

260. Samara WA, Shahlaee A, Sridhar J, Khan MA, Ho AC, Hsu J. Quantitative optical coherence tomography angiography features and visual function in eyes with branch retinal vein occlusion. Am J Ophthalmol. 2016 Jun;166:76-83.

261. Sanborn GE, Magargal LE. Characteristics of the hemispheric retinal vein occlusion. Ophthalmology. 1984 Dec;91(12):1616-26.

262. Schneider U, Inhoffen W, Grisanti S, Bartz-Schmidt KU. Characteristics of visual field defects by scanning laser ophthalmoscope microperimetry after radial optic neurotomy for central retinal vein occlusion. Retina. 2005 Sep;25(6):704-12.

263. Schwartz DM, Fingler J, Kim DY, Zawadzki RJ, Morse LS, Park SS, et al. Phasevariance optical coherence tomography: A technique for noninvasive angiography. Ophthalmology. 2014 Jan;121(1):180-7.

264. Scott IU, Ip MS, VanVeldhuisen PC, Oden NL, Blodi BA, Fisher M, et al. A randomized trial comparing the efficacy and safety of intravitreal triamcinolone with standard care to treat vision loss associated with macular edema secondary to branch retinal vein occlusion: The standard care vs corticosteroid for retinal vein occlusion (SCORE) study report 6. Arch Ophthalmol. 2009 Sep;127(9):1115-28.

265. Sekiryu T. Fundus autofluorescence in retinal vein occlusion. In: Lois N, Forrester JV, editors. Fundus Autofluorescence. 2nd ed. Philadelphia: Wolters Kluwer; 2016. p. 242-5.

266. Sekiryu T, Iida T, Sakai E, Maruko I, Ojima A, Sugano Y. Fundus autofluorescence and optical coherence tomography findings in branch retinal vein occlusion. J Ophthalmol. 2012;2012:e1-8.

267. Servais GE, Thompson HS, Hayreh SS. Relative afferent pupillary defect in central retinal vein occlusion. Ophthalmology. 1986 Mar;93(3):301-3. 
268. Shin H, Chung H, Kim H. Association between integrity of foveal photoreceptor layer and visual outcome in retinal vein occlusion. Acta Ophthalmol. 2011 Feb;89(1):e35-40.

269. Shin HJ, Kim HC, Moon JW. Aqueous levels of erythropoietin in acute retinal vein occlusion with macular edema. Int J Ophthalmol. 2014 Jun;7(3):501-6.

270. Shirakata Y, Fukuda K, Fujita T, Nakano Y, Nomoto H, Yamaji H, et al. Pars plana vitrectomy combined with internal limiting membrane peeling for recurrent macular edema due to branch retinal vein occlusion after antivascular endothelial growth factor treatments. Clin Ophthalmol. 2016 Feb;10:277-83.

271. Shrestha RK, Shrestha JK, Koirala S, Shah DN. Association of systemic diseases with retinal vein occlusive disease. Journal of the Nepal Medical Association. 2006 AprJun;45(162):244-8.

272. Shroff D, Mehta DK, Arora R, Narula R, Chauhan D. Natural history of macular status in recent-onset branch retinal vein occlusion: An optical coherence tomography study. Int Ophthalmol. 2008 Aug;28(4):261-8.

273. Silva R, Faria de Abreu J, CunhaVaz J. Blood-retina barrier in acute retinal branch vein occlusion. Graefes Arch Clin Exp Ophthalmol. 1995 Nov;233(11):721-6.

274. Singer M, Tan CS, Bell D, Sadda SR. Area of peripheral retinal nonperfusion and treatment response in branch and central retinal vein occlusion. Retina. 2014 Sep;34(9):173642.

275. Singh R, Lee T, Yau L, Rubio R. Collateral vessel presence in branch and central retinal vein occlusions and their impact on visual acuity and anatomical gains: A retrospective analysis. Retina. 2014 Nov;34(11):2242-9.

276. Siqueira RC, Messias A, Gurgel VP, Simoes BP, Scott IU, Jorge R. Improvement of ischemic macular oedema after intravitreal injection of autologous bone marrow-derived haematopoietic stem cells. Acta Opthalmologica. 2015 Mar;93(2):e174-6.

277. Sodi A, Giambene B, Falaschi G, Caputo R, Innocenti B, Corvi A, et al. Ocular surface temperature in central retinal vein occlusion: Preliminary data. Eur J Ophthalmol. 2007 SepOct;17(5):755-9.

278. Sodi A, Giambene B, Marcucci R, Sofi F, Fedi S, Abbate R, et al. Atherosclerotic and thrombophilic risk factors in patients with ischemic central retinal vein occlusion. Retina. 2011 Apr;31(4):724-9.

279. Spaide RF, Klancnik JM, Cooney MJ. Retinal vascular layers imaged by fluorescein angiography and optical coherence tomography angiography. JAMA ophthalmology. 2015;133(1):45-50.

280. Sperduto R, Yannuzzi L, Sorenson J, Sobel R, Daly J, DeRosa J, et al. Risk factors for branch retinal vein occlusion. Am J Ophthalmol. 1993 Sep;116(3):286-96. 
281. Sperduto RD, Hiller R, Chew E, Seigel D, Blair N, Burton TC, et al. Risk factors for hemiretinal vein occlusion: Comparison with risk factors for central and branch retinal vein occlusion: The eye disease case-control study. Ophthalmology. 1998 May;105(5):765-71.

282. Squirrell D, Watts A, Evans D, Mody C, Talbot J. A prospective evaluation of the heidelberg retina flowmeter in diagnosing ischemia following branch retinal vein occlusion: A masked, controlled comparison with fluorescein angiography. Eye. 2001;15(3):261-6.

283. Stefansson E, Novack RL, Hatchell DL. Vitrectomy prevents retinal hypoxia in branch retinal vein occlusion. Invest Ophthalmol Vis Sci. 1990 Feb;31(2):284-9.

284. Stem MS, Talwar N, Comer GM, Stein JD. A longitudinal analysis of risk factors associated with central retinal vein occlusion. Ophthalmology. 2013 Feb;120(2):362-70.

285. Stitt AW, O'Neill CL, O'Doherty MT, Archer DB, Gardiner TA, Medina RJ. Vascular stem cells and ischemic retinopathies. Progress in Retinal \& Eye Research. 2011 May;30(3):149-66.

286. Sun C, Li X, He X, Zhang Q, Tao Y. Neuroprotective effect of minocycline in a rat model of branch retinal vein occlusion. Exp Eye Res. 2013 Aug;113:105-16.

287. Suzuki N, Hirano Y, Yoshida M, Tomiyasu T, Uemura A, Yasukawa T, et al. Microvascular abnormalities on optical coherence tomography angiography in macular edema associated with branch retinal vein occlusion. Am J Ophthalmol. 2016 Jan;161:12632.

288. Tadayoni R, Waldstein SM, Boscia F, Gerding H, Pearce I, Priglinger S, et al. Individualized stabilization criteria-driven ranibizumab versus laser in branch retinal vein occlusion. Ophthalmology. 2016 Jun;123(6):1332-44.

289. Takahashi K, Muraoka K, Kishi S, Shimizu K. Formation of retinochoroidal collaterals in central retinal vein occlusion. Am J Ophthalmol. 1998 Jul;126(1):91-9.

290. Tan CS, Chew MC, van Hemert J, Singer MA, Bell D, Sadda SR. Measuring the precise area of peripheral retinal non-perfusion using ultra-widefield imaging and its correlation with the ischemic index. Br J Ophthalmol. 2016 Feb;100(2):235-9.

291. Tanaka M, Ninomiya H, Kobayashi Y, Qiu H. Studies on vitrectomy cases associated with complicated branch retinal vein occlusion. Jpn J Ophthalmol. 2001 Jul-Aug;45(4):397402.

292. Teoh SL, Amarjeet K. A comparative study of branch retinal vein occlusion and central vein occlusion amongst malaysian patients. Med J Malaysia. 1993 Dec;48(4):410-5.

293. Thapa R, Paudyal G, Bernstein PS. Demographic characteristics, patterns and risk factors for retinal vein occlusion in nepal: A hospital-based case-control study. Clin Experiment Ophthalmol. 2010 Aug;38(6):583-90.

294. Thompson HS, Corbett JJ, Cox TA. How to measure the relative afferent pupillary defect. Surv Ophthalmol. 1981;26(1):39-42. 
295. Tomomatsu Y, Tomomatsu T, Takamura Y, Gozawa M, Arimura S, Takihara Y, et al. Comparative study of combined bevacizumab/targeted photocoagulation vs bevacizumab alone for macular oedema in ischemic branch retinal vein occlusions. Acta Ophthalmol. 2016 May;94(3):e225-30.

296. Tranquart F., Arsene S., Giraudeau B., Piquemal R., Eder V., Le Lez M.L., et al. Initial color doppler findings in retinal vein occlusion. Journal of Clinical Ultrasound. 2000 Jan;28(1):28-33.

297. Tranquart F, Arsene S, Aubert-Urena AS, Desbois I, Audrerie C, Rossazza C, et al. Doppler assessment of hemodynamic changes after hemodilution in retinal vein occlusion. Journal of Clinical Ultrasound. 1998 Mar-Apr;26(3):119-24.

298. Traustason S, la Cour M, Larsen M. Retinal vascular oximetry during ranibizumab treatment of central retinal vein occlusion. Br J Ophthalmol. 2014 Sep;98(9):1208-11.

299. Tsui I, Franco-Cardenas V, Hubschman J, Yu F, Schwartz SD. Ultra wide field fluorescein angiography can detect macular pathology in central retinal vein occlusion. Ophthalmic Surgery, Lasers \& Imaging. 2012 May-Jun;43(3):257-62.

300. Tsui I, Kaines A, Havunjian MA, Hubschman S, Heilweil G, Prasad PS, et al. Ischemic index and neovascularization in central retinal vein occlusion. Retina. 2011 Jan;31(1):105-10.

301. Tsujikawa A, Sakamoto A, Ota M, Kotera Y, Oh H, Miyamoto K, et al. Serous retinal detachment associated with retinal vein occlusion. Am J Ophthalmol. 2010 Feb;149(2):291301.

302. Tuuminen R, Loukovaara S. High intravitreal TGF-beta1 and MMP-9 levels in eyes with retinal vein occlusion. Eye. 2014 Sep;28(9):1095-9.

303. Van Heuven W, Hayreh M, Hayreh S. Experimental central retinal vascular occlusion. blood-retinal barrier alterations and retinal lesions. Br J Ophthalmol. 1977;97(4):588-618.

304. Vine A. Hyperhomocysteinemia: A new risk factor for central retinal vein occlusion. Trans Am Ophthalmol Soc. 2000;98:493-503.

305. Virchow R. Gesammelte abhandlungen zur wissenschaftlichen medicin. 1st ed. Frankfurt: Meidinger Sohn \& Co.; 1856.

306. Wallow I, Danis R, Bindley C, Neider M. Cystoid macular degeneration in experimental branch retinal vein occlusion. Ophthalmology. 1988 Oct;95(10):1371-9.

307. Wang Y, Fawzi AA, Varma R, Sadun AA, Zhang X, Tan O, et al. Pilot study of optical coherence tomography measurement of retinal blood flow in retinal and optic nerve diseases. Invest Ophthalmol Visual Sci. 2011 Feb;52(2):840-5.

308. Weinberg DV, Wahle AE, Ip MS, Scott IU, VanVeldhuisen PC, Blodi BA, et al. SCORE study report 12: Development of venous collaterals in the score study. Retina. 2013 Feb;33(2):287-95. 
309. Wiek J, Schade M, Wiederholt M, Arntz HR, Hansen LL. Haemorheological changes in patients with retinal vein occlusion after isovolaemic haemodilution. Br J Ophthalmol. 1990 Nov;74(11):665-9.

310. Williamson TH, Baxter GM. Central retinal vein occlusion, an investigation by color doppler imaging. blood velocity characteristics and prediction of iris neovascularization. Ophthalmology. 1994 Aug;101(8):1362-72.

311. Williamson TH, Rumley A, Lowe GD. Blood viscosity, coagulation, and activated protein $\mathrm{C}$ resistance in central retinal vein occlusion: A population controlled study. $\mathrm{Br} \mathrm{J}$ Ophthalmol. 1996 Mar;80(3):203-8.

312. Williamson TH, Keating D, Bradnam M. Electroretinography of central retinal vein occlusion under scotopic and photopic conditions: What to measure?. Acta Ophthalmol Scand. 1997 Feb;75(1):48-53.

313. Williamson TH, Poon W, Whitefield L, Strothidis N, Jaycock P, Strothoudis N. A pilot study of pars plana vitrectomy, intraocular gas, and radial neurotomy in ischemic central retinal vein occlusion. Br J Ophthalmol. 2003 Sep;87(9):1126-9.

314. Williamson TH, Grewal J, Gupta B, Mokete B, Lim M, Fry CH. Measurement of PO2 during vitrectomy for central retinal vein occlusion, a pilot study. Graefes Arch Clin Exp Ophthalmol. 2009 Aug;247(8):1019-23.

315. Wittstrom E, Ponjavic V, Lovestam-Adrian M, Larsson J, Andreasson S.

Electrophysiological evaluation and visual outcome in patients with central retinal vein occlusion, primary open-angle glaucoma and neovascular glaucoma. Acta Opthalmologica. 2010 Feb;88(1):86-90.

316. Wolf S, Arend O, Bertram B, Remky A, Schulte K, Wald KJ, et al. Hemodilution therapy in central retinal vein occlusion. one-year results of a prospective randomized study. Graefes Arch Clin Exp Ophthalmol. 1994 Jan;232(1):33-9.

317. Wykoff C, Brown D, Croft DE, Major JC, Wong TP. Progressive retinal nonperfusion in ischemic central retinal vein occlusion. Retina. 2015 Jan;35(1):43-7.

318. Yasuda S, Kachi S, Ueno S, Piao C, Terasaki H. Flicker electroretinograms before and after intravitreal ranibizumab injection in eyes with central retinal vein occlusion. Acta Opthalmologica. 2015 Sep;93(6):e465-8.

319. Yeshaya A, Treister G. Pars plana vitrectomy for vitreous hemorrhage and retinal vein occlusion. Ann Ophthalmol. 1983 Jul;15(7):615-7.

320. Yoneya S, Saito T, Nishiyama Y, Deguchi T, Takasu M, Gil T, et al. Retinal oxygen saturation levels in patients with central retinal vein occlusion. Ophthalmology. 2002 Aug;109(8):1521-6.

321. Zhang H., Sonoda K.H., Qiao H., Oshima T., Hisatomi T., Ishibashi T. Development of a new mouse model of branch retinal vein occlusion and retinal neovascularization. Jpn J Ophthalmol. 2007 July 2007;51(4):251-7. 
322. Zhang Y, Fortune B, Atchaneeyasakul L, McFarland T, Mose K, Wallace P, et al. Natural history and histology in a rat model of laser-induced photothrombotic retinal vein occlusion. Curr Eye Res. 2008 Apr;33(4):365-76.

323. Zhou J, Xu L, Wang S, Wang Y, You Q, Tu Y, et al. The 10-year incidence and risk factors of retinal vein occlusion: The beijing eye study. Ophthalmology. 2013 Apr;120(4):803-8.

\section{Other Cited Materials:}

A. American Academy of Ophthalmology. Retinal Vein Occlusions Preferred Practice Pattern ${ }^{\circledR}$ Guidelines. http://www.aaojournal.org/article/S01616420(15)01267-1/pdf (accessed 5 April 2017).

B. Edwards SJ, Barton S, Trevor N, Lois N, Nherera L, Hamilton, V. Ranibizumab for the treatment of macular oedema caused by retinal vein occlusion (RVO): A Single Technology Appraisal. BMJ-TAG, London, 2011

C. National Institute for Health and Care Centre. Ranibizumab for treating visual impairment caused by macular oedema secondary to retinal vein occlusion. https://www.nice.org.uk/guidance/ta283 (accessed 5 April 2017).

D. National Institute for Health and Care Centre. Aflibercept for treating visual impairment caused by macular oedema after branch retinal vein occlusion. https://www.nice.org.uk/guidance/ta409 (accessed 5 April 2017).

E. National Institute for Health and Care Centre. Aflibercept for treating visual impairment caused by macular oedema secondary to central retinal vein occlusion. https://www.nice.org.uk/guidance/ta305 (accessed 5 April 2017).

F.National Institute for Health and Care Centre. Dexamethasone intravitreal implant for the treatment of macular oedema secondary to retinal vein occlusion. https://www.nice.org.uk/guidance/ta229 (accessed 5 April 2017).

G. Shyangdan D, Cummins E, Lois N, Royle P, Waugh N. Dexamethasone implants in the treatment of macular oedema due to retinal vein occlusion: a single technology appraisal. Aberdeen HTA group 2010

H. The Royal Collage of Ophthalmologists. Retinal Vein Occlusion (RVO) Guidelines. https://www.rcophth.ac.uk/wp-content/uploads/2015/07/Retinal-VeinOcclusion-RVO-Guidelines-July-2015.pdf (accessed 5 April 2017). 


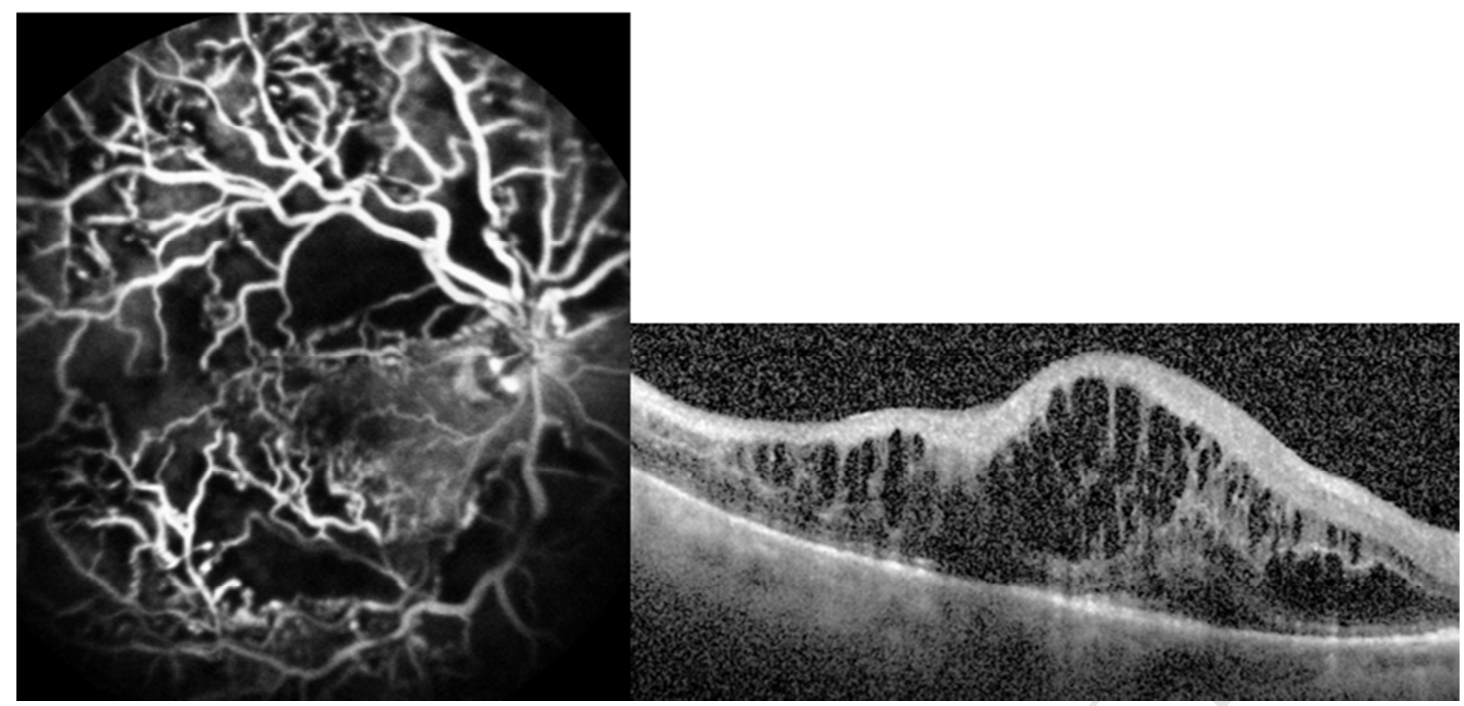




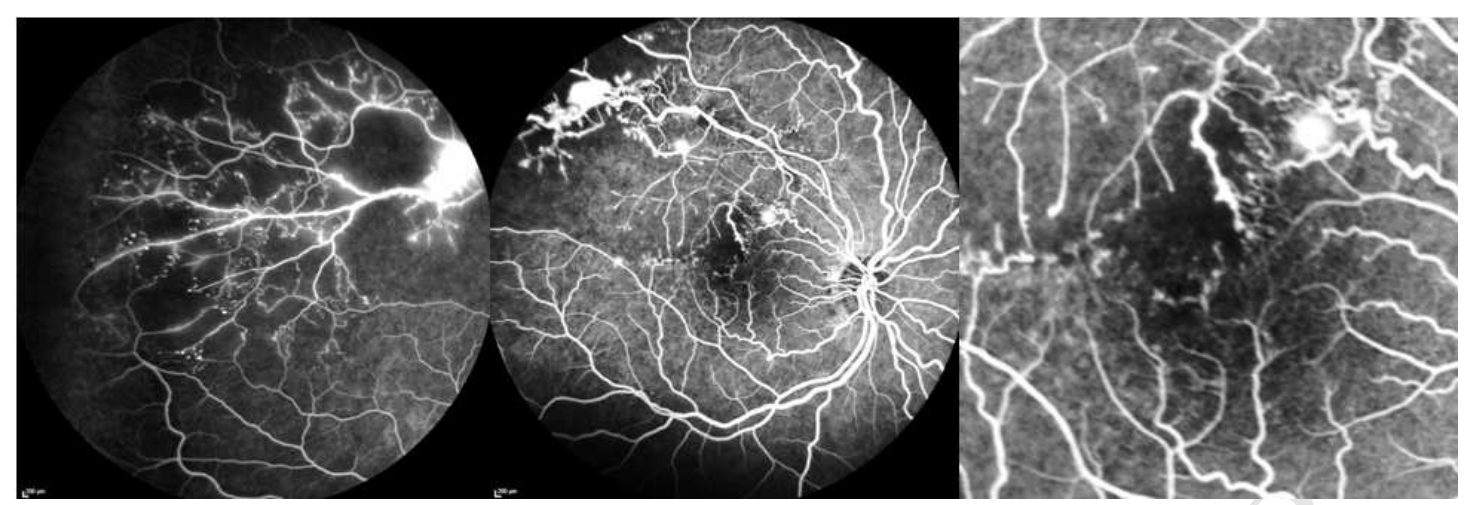



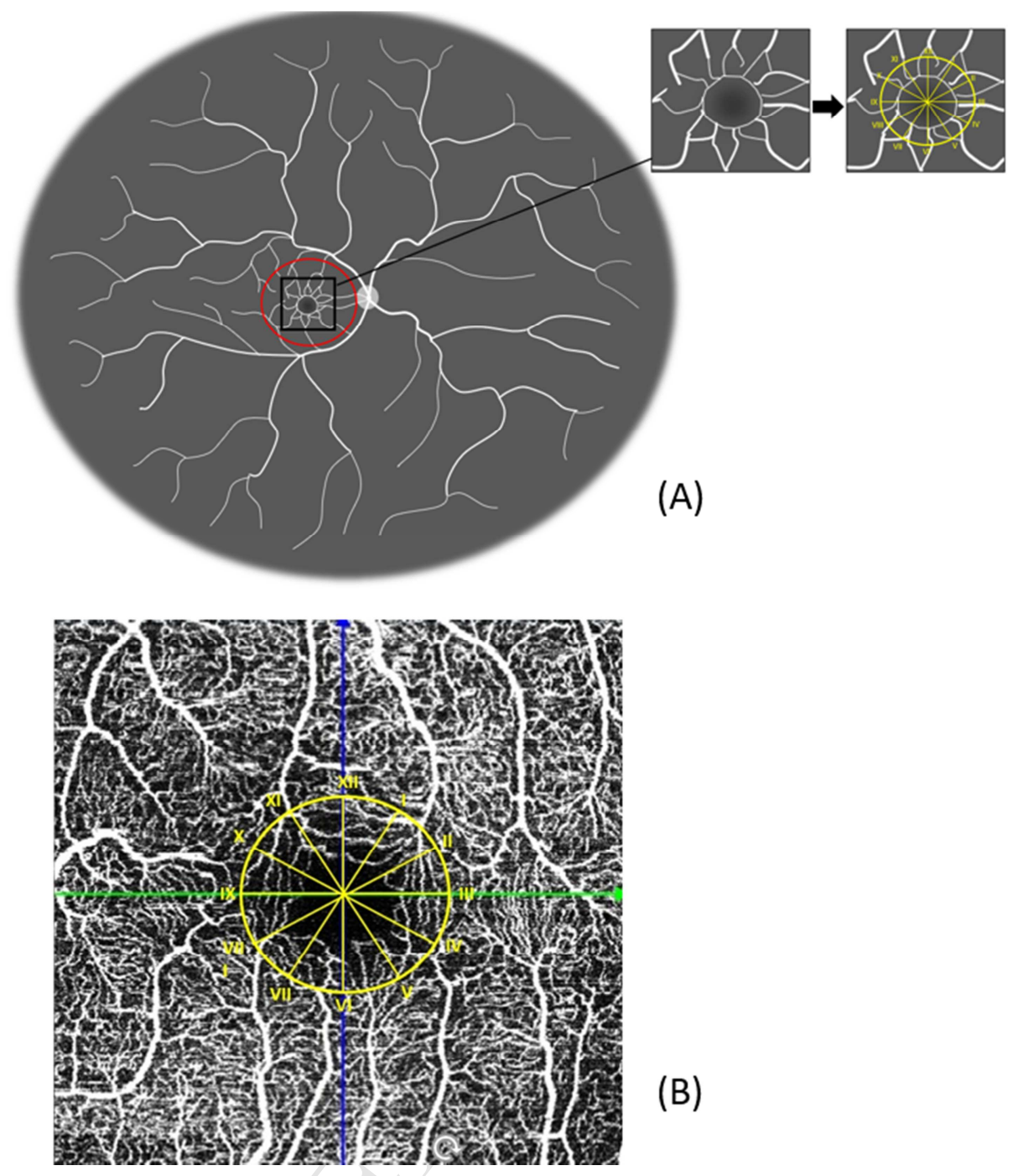

(B) 